\title{
Habitat Stability in Appalachian Headwater Systems and Potential Impacts on Brook Trout Populations
}

\author{
Zac F.W Zacavish \\ zzacavis@mix.wvu.edu
}

Follow this and additional works at: https://researchrepository.wvu.edu/etd

Part of the Natural Resources and Conservation Commons, and the Population Biology Commons

\section{Recommended Citation}

Zacavish, Zac F.W, "Habitat Stability in Appalachian Headwater Systems and Potential Impacts on Brook Trout Populations" (2020). Graduate Theses, Dissertations, and Problem Reports. 7743.

https://researchrepository.wvu.edu/etd/7743

This Thesis is protected by copyright and/or related rights. It has been brought to you by the The Research Repository @ WVU with permission from the rights-holder(s). You are free to use this Thesis in any way that is permitted by the copyright and related rights legislation that applies to your use. For other uses you must obtain permission from the rights-holder(s) directly, unless additional rights are indicated by a Creative Commons license in the record and/ or on the work itself. This Thesis has been accepted for inclusion in WVU Graduate Theses, Dissertations, and Problem Reports collection by an authorized administrator of The Research Repository @ WVU. For more information, please contact researchrepository@mail.wvu.edu. 
Habitat Stability in Appalachian Headwater Systems and Potential Impacts on Brook Trout Populations

Zac F.W Zacavish

Follow this and additional works at: https://researchrepository.wvu.edu/etd

Part of the Natural Resources and Conservation Commons, and the Population Biology Commons 
Habitat Stability in Appalachian Headwater Systems and Potential Impacts on Brook Trout Populations

\author{
Zac Zacavish
}

\begin{abstract}
Thesis submitted to the Davis College of Agriculture, Natural Resources, and Design
at West Virginia University

in partial fulfillment of the requirements for the degree of

Masters in
\end{abstract}

Wildlife and Fisheries Resources

\author{
Kyle Hartman, $\mathrm{PhD}$, Chair \\ Charlene Kelly, PhD \\ Ross Andrew, $\mathrm{PhD}$ \\ Department of Fisheries and Wildlife Management \\ Morgantown, West Virginia
}

2020

Keywords: Brook Trout, Climate Change, Critical Habitat, Habitat Stability, Maxent, Population Dynamics, Monongahela National Forest

Copyright:2020 Zac Zacavish 


\begin{abstract}
Habitat Stability in Appalachian Headwater Systems and Potential Impacts on Brook Trout Populations
\end{abstract}

Zac Zacavish

The impact climate change will have on the habitat for Brook Trout (Salvelinus fontinalis) could directly impact key demographic characteristics. Traditionally, broad-scale studies of climate change effects on the family Salmonidae focus on the thermal shifts predicted over the next century. While some studies shed light onto other variables such as biotic interactions, flow regime, and disturbance, the significance of the climate-trout interaction is not always observed. With the high degree of influence climate cycles can have on habitat and channel morphology, this study aimed to highlight temporal habitat shifts to begin addressing climate-habitat interaction. By studying habitat distribution and trends in 25 headwater systems over 14 years, Chapter 1 documented a significant decreasing trend in critical pool habitat $(\mathrm{S}=-$ 73.0, $\mathrm{p}=0.0004)$ and significant increase in distance between these pools $(\mathrm{r}=0.86, \mathrm{p}=0.003)$ since 2003.

Chapter 2 used presence only data to build a maximum entropy model to assess probability of occurrence of pool habitat throughout the study region. According to the highest scoring AUC models (AUC $=0.89$ ),

pool habitat decreased by 23 percent across the national forest between the two periods; and only demonstrated "stability" in 13 percent of its model presence probability. Finally, we were able to show the impact pool stability had on spawning age Brook Trout. Particularly, the directional change associated with each pool unit deviation from stable pools ( 0.31 individuals per 100 meters) accounting for variations of the random effects' year, site and reach. These results highlight the need to further understand the potential impacts of acute disturbances like floods, debris flows, and other formidable events could have on temporal habitat availability and overall persistence of Brook Trout populations due to a changing climate. 


\section{Acknowledgements}

Many thanks to my advisor, Dr. Kyle Hartman, whom read many confusing writing samples. He helped give foundation for writing organization and overall guidance in Brook Trout research. Additionally, this project would not have been possible without the Hartman Lab who collected the long-term data necessary to put this thesis together. Dr. Ross Andrew was a core member of this lab whom helped not only in structuring my statistical design but also was valuable help to flesh out ideas. Dr. Charlene Kelly for invaluable help in critiques in thesis writing. Many thanks to the West Virginia Watershed Institute, whom provided the funding for me to pursue this project, even though it was not in the scope of the Institute's mission. Dr. James McGraw was an undergraduate mentor that showed me a career path I could be motived within. I am grateful for each piece that helped me along the way and the patience provided in my long absences from campus 
$\underline{\text { Table of Contents }}$

Trends in Brook Trout Habitat in Appalachian Headwater Streams...............................................1

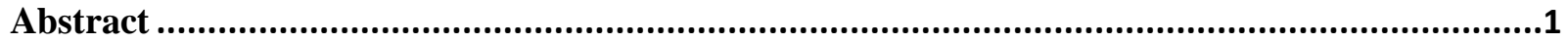

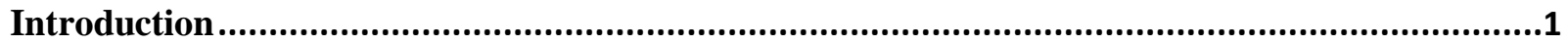

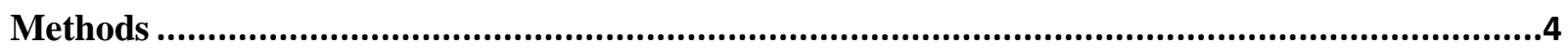

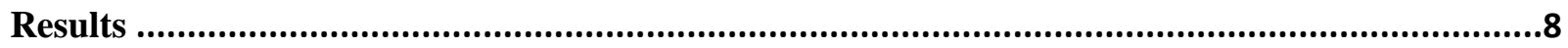

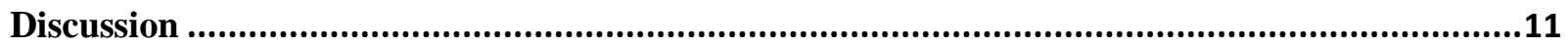

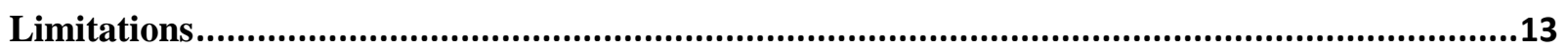

Modeling Changes in Critical Habitat for Brook Trout in the Central Appalachians.........................15

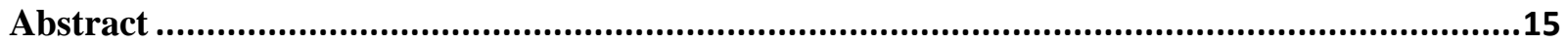

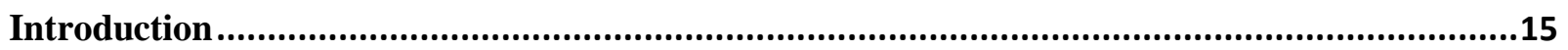

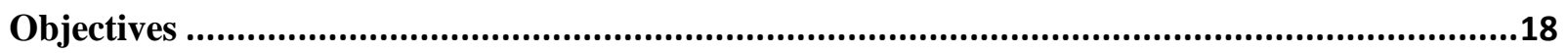

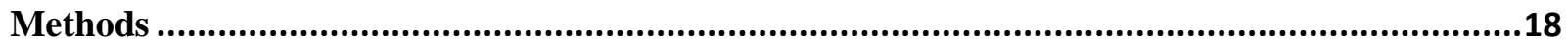

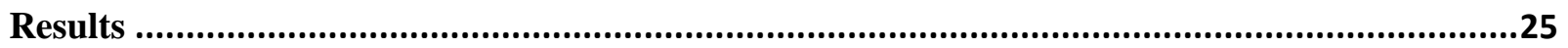

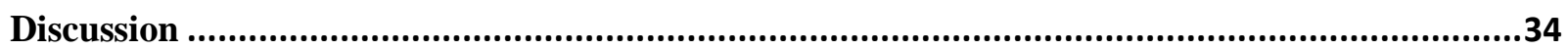

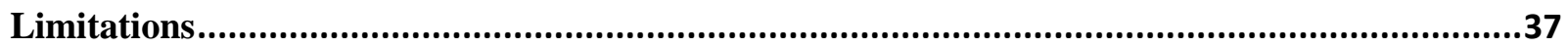

Potential Relationship Between Habitat Stability and Brook Trout Abundances.................................38

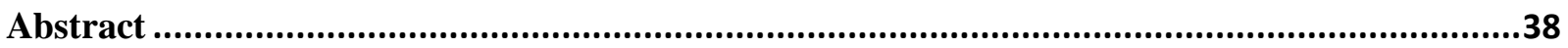

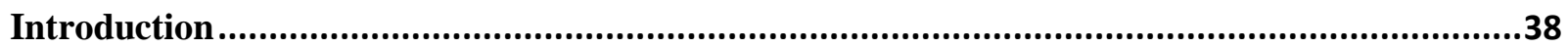

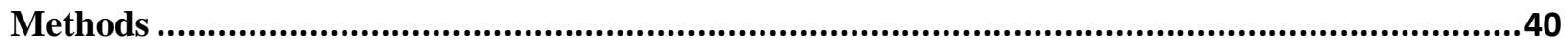

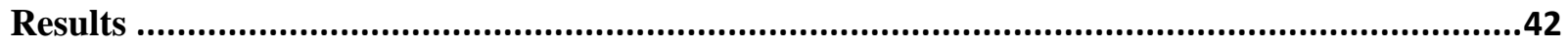

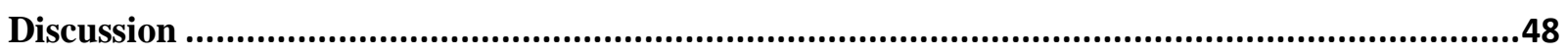

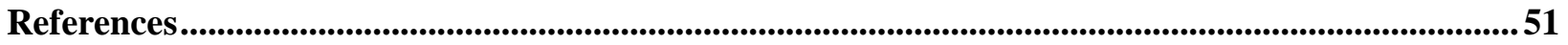

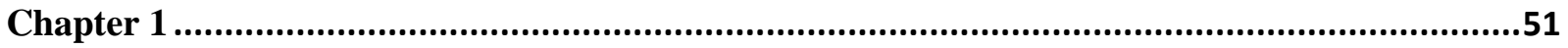

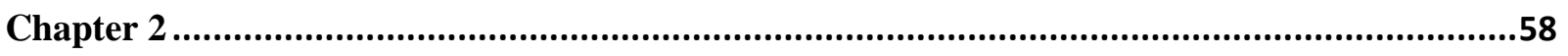

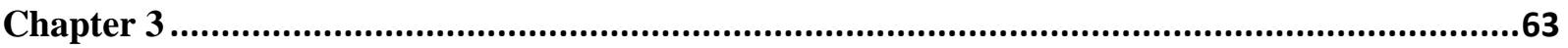




\title{
Chapter 1
}

\section{Trends in Brook Trout Habitat in Appalachian Headwater Streams}

\begin{abstract}
The impact climate change will have on the habitat for Brook Trout (Salvelinus fontinalis) could directly impact key demographic characteristics. Traditionally, broad-scale studies of climate change effects on the family Salmonidae focus on the thermal shifts predicted over the next century. While some studies shed light onto other variables such as biotic interactions, flow regime, and disturbance, the significance of the climate-trout interaction is not always observed. With the high degree of influence climate cycles can have on habitat and channel morphology, this study aimed to highlight temporal habitat shifts to begin addressing climate-habitat interaction. Pro-active management in fluvial networks is often done by pool-monitoring. By studying habitat distribution and trends in 25 headwater systems over 14 years, this analysis documented a significant decreasing trend in critical pool habitat $(S=-73.0, p=0.0004)$ and significant increase in distance between these pools $(r=0.86, p=0.003)$ since 2003. These results highlight the need to further understand the potential impacts of acute disturbances like floods, debris flows, and other formidable events could have on temporal habitat availability. While salmonid populations can be highly resilient, disturbances can create unstable habitat conditions. These conditions could become more probable with projected changes in flow regime due to climate change.
\end{abstract}

\section{Introduction}

A changing climate could have profound effects on the distribution, abundance and persistence of many organisms into the future. The thermal change associated with regional climate has been suggested to have already impacted many species (Parmesan and Yohe 2003, Rosenzweig et al. 2008, Comte et al. 2013). Future predictions suggest a higher rate of change (2-6 degrees Celsius) by 2100 , with variations in precipitation and temperature varying geographically and temporally (IPCC 2007, IPCC 2014). These predictions suggest significant changes in frequency, magnitude, and timing of precipitation, which could drastically alter riverine ecosystems over the course of the next century (Milly et al. 2005, Ficke et al. 2007, Santiago et al. 2017).

Historically, changes in air and water temperatures have been a research focus because they are strongly associated with species native ranges and geographic barriers (Rahel et al. 1996, Davis et al. 2013). Due to their cool temperature requirements salmonids have been thought to serve as an excellent candidate for climate impacted species (Schrank et al. 2003, Hartman and Cox 2008, Petty et al. 2012). Modeling temperature alone, salmonids have been predicted to lose much of their southern, lower elevation, and 
main stem habitats (Rahel et al. 1996, Clark et al. 2001, Flebbe et al. 2006, Williams et al. 2009, Wenger et al. 2011).

Variation in flow regime is a critical variable in aquatic systems, and controls many fundamental ecological processes (Wolman and Miller 1960, Poff et al. 1997, Buffington et al. 2002, Lytle and Poff 2004, Webb 2007, Wenger et al. 2011). Flow regime has been shown to have an equally high impact on fish survivorship with recruitment rates impacted by the timing and frequency of winter floods (LobonCervia 2009, Warren and Baldigo 2009, Kanno et al. 2012, Kanno et al. 2016) and movement and population responses to summer droughts (Roghair et al. 2002, Hakala and Hartman 2004). The projected changes in flow regime due to increases in frequency, magnitude, and timing of precipitation events will likely impact both populations and channel morphology (Jager et al 1999, Frumhoff et al. 2006, Hayhoe et al. 2008, Young et al 2010, Wenger et al 2011, Meyers et al 2013). Merriam et al. (2017) suggests that no decrease in available Brook Trout habitat will occur through 2100 in central Appalachia due to increases in stream discharge. However, the variability of each catchment and confounding environmental variables would make any climate-population interaction hard to observe or project (Comte et al. 2013, Davis et al. 2013).

Of the many requirements Brook Trout need (adequate flow, low-velocity deep-water refuge, foraging locations, cover and spawn habitat) to achieve the highest individual fitness (i.e. survival, growth, and reproductive success); pool habitat can be classified as the most critical (Fausch et al. 1988, Fausch et al. 2002). Pool habitat provides the location for not only growth and cover; but is solely responsible for spawning habitat for Brook Trout in Appalachia. The protections and restoration of this pool habitat constitutes the most common fisheries management tool for Brook Trout moving forward (Petty et al. 2014, Williams et al. 2015). Pool formation processes are caused by locations that mobilizes bed material away from that location faster than it is coming in. In high gradient, forested systems with small drainage areas (less than $100 \mathrm{~km}^{2}$ ), these bed scour areas are mostly found at flow obstructions and bedrockreinforced knickpoints (Buffington et al. 2002). Bedrock irregularities and geological influence are relatively unsusceptible to disturbances over small time intervals, while flow obstructions caused by woody debris or sediment are temporally prone to change (Lisle 1986a, Bisson et al. 1987, Murphy and Koski 1989, Bilby and Ward 1991, Beechie et al. 2000).

The size and stability of pools caused by woody debris or sediment is largely dependent on size of material, channel size, and overall riparian characteristics (Hartman et al. 1994, Flebbe and Dolloff 1995, Hedman et al. 1996, Abbe 2000, Braudrick and Grant 2000, Ralph et al. 2011). Woody debris has been shown to significantly impact Brook Trout biomass (Kratzer and Warren 2013). However, Brook Trout inhabit highly variable systems and while they are evolutionary adapted to these variabilities; a changing 
climate is suggested to increase both the frequency and the magnitude of this variability (Jager et al 1999, Frumhoff et al. 2006, Hayhoe et al. 2008, Young et al 2010, Wenger et al. 2011, Meyers et al. 2013). These changes across a highly diverse landscape could yield varying degrees of change in habitat alteration between watersheds (Roghair et al. 2002, Andrew and Hartman 2014).

In many systems, effective discharge is often thought to be the mechanism responsible for most material movement within a fluvial system, with storm recurrence interval around 2 years (Wolman and Miller 1960, Pickup and Warner 1976, Andrews 1980, Carling 1988, Emmett and Wolman 2001). However, it has been shown that rarer catastrophic events may yield the highest long-term impacts in steeper systems (Kirchner et al. 2001, Vogel et al. 2003, Vogel et al. 2005, Moa and Lenzi 2006). These formidable events (i.e. floods) have been shown to increase woody debris within catchments (Dolloff et al. 1994, Andrew and Hartman 2014). The increase of such events could reduce variability in available pool habitat through time, especially when coupled with increases in flow rate. This could potentially offset future thermal implications on Brook Trout populations brought about by a changing climate. With projected changes in frequency and magnitude of flood events, temporal channel condition assessments could be used to develop proactive management strategies to help mitigate challenges for already restricted riverine species, especially when considering the highly heterogeneous and variable environment Brook Trout must utilize in order to maximize fitness across all life stages (Petty et al. 2005, Kanno et al. 2012, Koizumi et al. 2013, Petty et al. 2014).

The spatial arrangement/structure of this heterogenous environment has a high correlative effect on a species that has been shown to move long distances to find refuge, forage, and reproduce (Lonzarich et al. 2000, Petty et al. 2012, Letcher et al. 2015). However, few studies have been able to correlate habitat change with pre/post event data (Lamberti et al. 1991, Propst and Stefferund 1997, Swanson et al. 1998, Roghair et al. 2002, Andrew and Hartman 2014). While salmonid populations are evolutionarily adapted to be resilient to variable conditions, catchments do not always have resilience or resistance to disturbance, creating unstable habitat conditions (Elwood and Waters 1969, Roghair et al. 2002, Caroline et al. 2003). With an increase in frequency and magnitude of precipitation events, it is probable that unstable habitat condition will be common in high gradient streams; which would cause differential declines in probability of Brook Trout survivorship through the next century in Appalachia.

Habitat diversity assessments are widely used in channel condition assessments (USDA and USDI 1994, USDA 1995, NMFS 1996). This is because of the direct linkage associated with vertebrates (Bisson et al.1982, Sullivan 1986, Lonzarich and Quinn 1995, Montgomery et al. 1999) and invertebrates (Huryn and Wallace 1987, Wallace et al.1995) to channel morphology. The research presented below will focus specifically on the temporal shifts of pool habitat observed in Appalachian streams since 2003. Due to the 
outlined changes above and the lack of research done on temporal habitat shifts in cold-water systems, the primary objective was to address long-term habitat quantity trends in Appalachian streams. We tested the hypothesis that the overall trend in Appalachia habitat quantity experienced a non-monotonic trend throughout the study period, especially considering Superstorm Sandy's 2012 established differential impact on watersheds in the study area (Andrew and Hartman 2014). Deviation from a monotonic trend would suggest environmental factors inhibiting long-term resistance or resilience, which could be attributed to historic land use (i.e. logging) or accelerated variation in the water cycle. The second objective was to address spatial arrangement of habitat through time. Spatial arrangement along a stream gradient would logically follow a random distribution, with the variety of environmental factors dictating pool formation. Considering the accelerated frequency of bank full events and catastrophes, these systems are likely not experiencing random distribution. Channel characteristics that are not conducive to pool formation will probabilistically be lost through time. Testing the hypotheses from this study will yield valuable insight into overall resistance and resilience of Appalachian systems and begin to address if Brook Trout are topographically protected in Appalachian to future thermal and flow regime predictions based solely on thermal refuge changes.

\section{Methods}

\section{Study Area}

The study area is composed of 25 stream segments with a high degree of variability in characteristics representative of Central Appalachian headwater systems with self-sustaining Brook Trout populations. The 25 segments are located throughout the Monongahela National Forest with a few on privately owned land, and distributed among six HUC-10 watersheds (Cranberry River, Deer Creek of Greenbrier River, Dry Fork, Middle Fork, North Fork of South Branch of the Potomac River, and the Elk River). These sites were defined as small headwater tributaries (mean drainage area $=7.39 \mathrm{~km}^{2}$ ) located in the mountainous eastern part of West Virginia. These systems all have naturally reproducing Brook Trout and consistent of typical fish assemblages of water generally less than $19{ }^{\circ} \mathrm{C}$.

\section{Long Term Data Collection}

Stream habitat was sampled following a modified basin-wide visual estimation technique (BVET, Hankin and Reeves 1988). From 2003 to 2009, 12 or 13 of these streams were surveyed for habitat on alternating years (i.e. Seneca Creek was sampled 2003 but not 2004, and sampled again in 2005). From 2010 through present, all 25 streams were sampled annually. Habitat sampling was typically conducted in low-flow conditions (which historically occurs between June and October). This low-flow sampling ensures that the most habitat complexity was observed within the survey locations, and accuracy of estimates is increased 
in determining cover and spawning areas. The starting point of each survey occurred in the same locations among years, and was typically marked with orange spray paint, orange ribbon, and GPS points. Using a hip chain, surveyors recorded the beginning and end distance of each habitat unit (riffle, run, pool, dry, or cascade) relative to starting location. Three transects widths/depths are recorded for every habitat unit progressing upstream. Additional variables collected included; random large woody debris (LWD) counts and size categories (Andrew and Hartman 2014), wetted widths, and bank full widths per individual habitat units. Post-2009, every pool was measured for maximum depths, pool out depth (depth of the thalweg at outflow of pool), cover area, pool formation type, and spawn area. Pool area was calculated using pool length and widths. These habitat reaches ranged in length from approximately 900 to 3000 meters, depending on drainage area.

The focus of this study was on the distance between pools and total number of pool habitat units. Pool quality was not considered as it would have reduced temporal scale. Surveyors defined pools as any low velocity, unbroken deep water with area greater than one square $\mathrm{m}$ and depth greater than $30 \mathrm{~cm}$ in that square meter area. Since surveyors did not directly record distance between or among pools, digitization in ArcGIS was utilized to geotag each pool location within the survey area using recorded hip chain distances traveled from starting locations to each habitat unit. Since calculation of pool area used these length measurements, it was assumed these distances represented most accurate data for pool locations.

\section{Digitization}

One of the objectives of this study was to address temporal distances between pools. In order to analyze habitat data beyond simple counts per year, digitization was performed using ArcGIS 10.5.1 (ESRI, Inc. Redlands, California). Data was collected with the beginning and end distances of each habitat unit in each study segment measured, making it easy to digitize individual pool units over a corrected stream water grid using the measure tool. To achieve the highest degree of spatial accuracy, the points were overlain on corrected water grid generated off 1/9 arc second ( 3 -meter cell size) digital elevation model (DEMs). While this approach can carry uncertainties in flow projections because grids cannot account for the scale that rugged areas demonstrate (Wise 2007), corrected flow grids were primarily used as a method to most accurately predict stream channel path. With intrinsic errors associated with digitizing historical data and stream channel changes; any pools found within 10 meters between years were considered as the same pool. The location was picked as overall average location between the years in that 10-meter range based from first pool occurrence year. Each pool was also filtered to exclude any pools that did not achieve the defined pool parameters (greater than $30 \mathrm{~cm}$ depth). 
By using a hydro-corrected DEM among all the study sites (Mathuis and Wang 2006, Zhang 2013), digitization of the pool features was able to follow a 3 meter grid stream channel that represented the most accurate depiction of average stream channel over the course of the study period because it followed elevation and flow accumulation at the lowest grid points. In addition, a basin area flow model was able to be generated to account for daily flow rate encountered by surveyor the day habitat was sampled. This model utilized elevation and basin area ratios to best determine flow rates upstream of a USGS gage location. Since surveys did not record flow rates, this helped account for serial correlation that pool variables were a result from flow variations.

Corrected basin area flow model was established for each study segment to generate best approximation of flow rates for the date surveys were completed. This approach incorporates 30-year normal precipitation values to spatially correct for variability in precipitation and basin areas that contribute to each USGS gauging station (Zegre 2016). This spatially corrected for variability in precipitation over each drainage, yielding the most accurate flow estimations encountered during the habitat sampling dates. While this method has intrinsic errors because it cannot account for many hydrological variables (springs, upwellings, karst, exc.), it allows for the environmental variable flow rate to be accounted for at the location of each stream segment based upon basin accumulation and 30 year normal-averages. With flow playing such an important determination on habitat complexity and determination (Hilderbrand 1999, Hakala and Hartman 2004), the mean daily discharge (CFS) at each stream on the day of habitat surveys gave an understanding of whether variability in relative discharge levels between years was responsible for pool quantity changes, or if stream morphology changed through time. While USGS sites were beyond the recommended modeling distance from many of the study sites, the flow estimations were assumed to be appropriate representations of habitat surveys during that day. This is largely due to habitat surveys being done during lowest flows to accurately assess highest degree of channel morphology diversity and the average flow rate taken amongst all study site estimations.

\section{$\underline{\text { Spatial Analysis }}$}

Beyond the temporal change in pool numbers and area, the digitization process allowed statistics to be gathered using spatial patterns and distances. Nearest Neighbor (NN) test was used as a tool to assess the spatial pattern in habitat point data. More simply, it is the relation of each pool to one another in a given area. This tool measured the distance between each point feature (pool habitat) and its corresponding $\mathrm{n}^{\text {th }}$ neighbor location. In order to calculate the spatial statistic, the analysis divided the observed average distance amongst pools by the expected average distance (hypothetical random distribution of the points covering same area). If the average was greater than the hypothetical average of random distribution, the features were considered dispersed (Bayard and Elpick 2010). Null hypothesis and basic assumption were 
that pool features had equal or random probability of occurring through each study area. Study sites were individually tested per year within basin area to understand distribution change across broader spatial scales.

Nearest neighbor was chosen for this analysis, because the features before 2010 did not contain relatable continuous variables (i.e. spawn area and/or cover area). This test is most often associated with an exploratory approach to understanding spatial patterns in habitat selection not necessarily habitat itself (Bayard and Elphick 2010). However, the use of NN has been proven useful in confidently uncovering trends in habitat changes (Wing et al. 1999). Ideally, pool quality attributes such as cover and spawn area would have been included in this analysis. However, the presented data were not collected in a manner to incorporate additional spatial analyst assessments. Understanding the change in average distances and significant patterns could provide insights into potential channel morphology changes.

\section{Statistical Analysis}

Trend and change detection in environmental variables are statistically challenging since it is hard to define change, assumptions are not always fulfilled, and application of the many different methodologies to the same data may yield different results (Kundzewicz and Radziejewski 2006). To detect potential changes or trends in habitat along Appalachian streams, several tests were chosen. The first test was the Mann-Kendall test to analyze any overall series trend in the average pool number, nearest neighbor and area. This test was selected because it is a non-parametric test that shows monotonic trends in a variable over time and is widely recommended by the World Meteorological Organization for public application (Radziejewski and Kundzewicz 2004). The habitat data were not serially correlated, allowing us to test for potential trends of the independent data. This tested the null hypothesis that habitat variables (number, area, and nearest neighbor) followed no significant trend throughout the study period (alpha=0.05). While Mann-Kendall is widely used in hydrological analysis, it has been shown to have increased probabilities of committing type I errors (Yue et al. 2002). After significant trends were assessed, the degree of magnitude of the linear/monotonic trend was tested using the Spearman's Partial Correlation Trend Test using flow as covariate (alpha=0.05). This method was used with the covariate flow, to partial out the environmental variance that flow on habitat sampling dates could have had on both habitat quantity, size and distance. Since flow rates impact habitat complexity and designations (Hakala and Hartman 2004), this tested whether pool number, area, and $\mathrm{NN}$ between years was correlated more with changes in flow rate change versus the actual trend through time.

Pettitt's test is a change-point detection test that was applied to assess if there was a point in which the distributions of the habitat data did not have the same location parameters (trend changed). This is a 
commonly used method for non-parametric test and used when the exact time of change is unknown. However, this dataset encompasses Superstorm Sandy in 2012 which was shown to impact habitat differentially (Andrew and Hartman 2014). Thus, this test was used to see if mean pool area and quantity changes throughout the study area occurred due to this event. With the lack of temporal habitat studies occurring with major hydrological events during the study period, detecting changes in pool distribution from these events was considered valuable. If any outlying parameters altered the distribution of habitat data significantly then a change point exists (Pettit 1979). The null hypothesis would be that no significant change in variable distribution was present in the study period.

\section{Results}

An overall trend of declining mean number of pools per stream from 2003-2017 was evident (Figure 1). According to the Mann-Kendall test, there was a highly significant negative trend $(S=-73.0, p=0.01)$ in pool habitat number. However, covariate test results of the environmental variable (flow) followed a monotonic trend during the same time frame $(S=21.00, \mathrm{p}=0.32)$; indicating that trend changes in the number of pools over time was not correlated to positive trend associate with mean flow rate differences in discharge during habitat surveys. When flow was accounted for, the Spearman's correlation test (to indicate magnitude of the linear/monotonic trend with time), observed a highly significant decreasing trend in pool number $\left(\mathrm{r}_{\mathrm{s}}=-0.839, \mathrm{p}=0.01\right)$. With the magnitude and significant change in pool number through time, the final step was to indicate if a significant change took place using the Pettitt-test. This test resulted in significant change-point of the habitat data after $2011(\mathrm{Kt}=52$ and $\mathrm{p}=0.02)$. Before 2011, the overall rate of change was roughly -2.7 pools lost per stream per year. Post-Superstorm Sandy in 2012 , this rate of change was 0.10 pools gained per year.

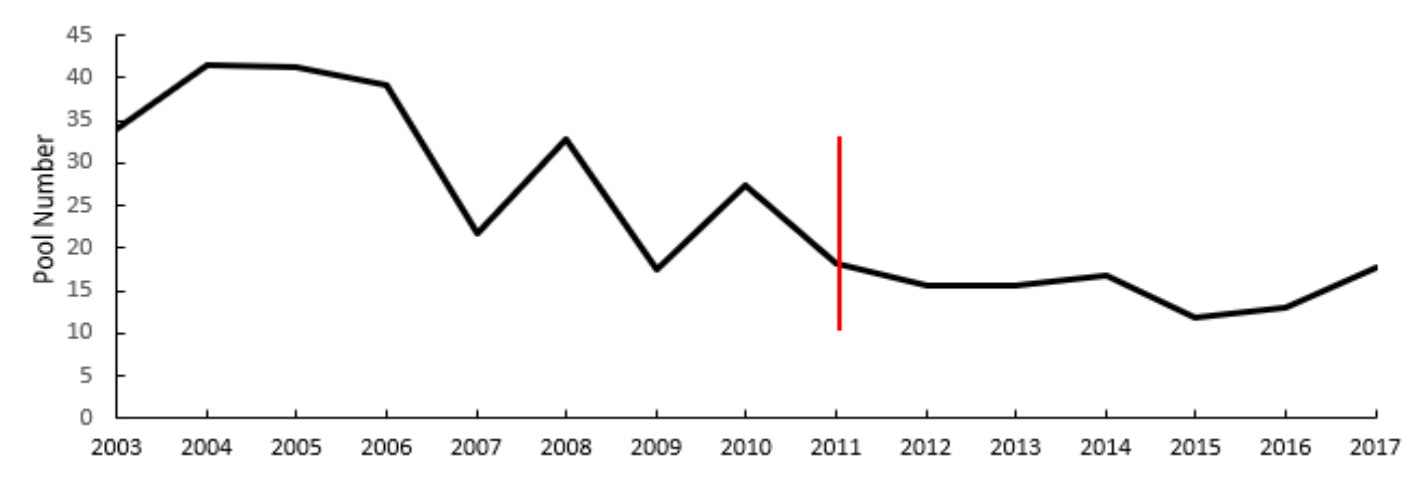

Figure 1- Mean number of pools per stream from 2003-2017. Prior to 2009 streams were sampled every other year and annually thereafter. The vertical red line represents the significant point change in 2011 from the Pettitt-test. 
There was no temporal trend associated with pool area across the study sites $(S=-37, p=0.08)$. Likewise, neither covariate (pool number $(\mathrm{p}=0.87)$ or flow $(\mathrm{p}=0.20)$ ) were correlated with the pool area. MannKendal tests are prone to type I errors, thus the null hypothesis that pool area did not follow a trend probabilistically would need to be accepted at such a $\mathrm{p}$-value $(\mathrm{p}=0.08)$. There was no significant point change in the pool area test $(\mathrm{p}=0.65)$. Overall pool numbers are decreasing through time, but the area did not follow the same trend; this would suggest that some pools have environmental attributes that make them temporally more stable. The average rate of change in pool area across streams did not show the same significant shift as average pool number. However, prior to Super Storm Sandy pool area was declining by $76 \mathrm{~m}^{2} / \mathrm{yr}$ per stream; and then shifted to negative $46 \mathrm{~m}^{2} / \mathrm{yr}$ per stream. This significant point change post Super Storm Sandy somewhat stabilized pool area loss.

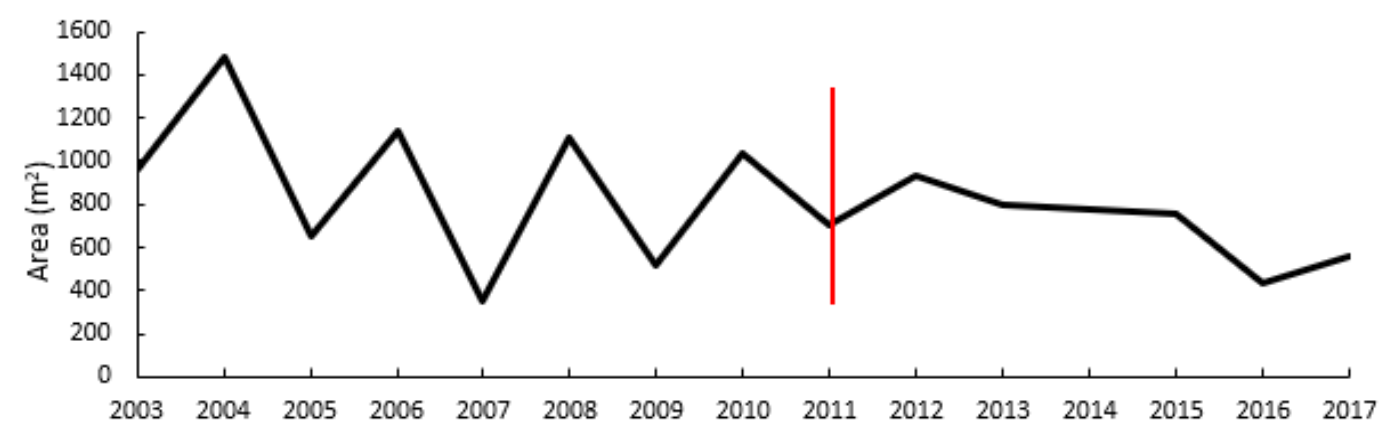

Figure 2- Average Pool Area (meters squared) across 25 streams from 2003-2017.

\section{$\underline{\text { Spatial }}$}

The average nearest neighbor distance (stream thalweg distance between pools) increased by 256 percent during the study period, with a mean distance of $27.9 \mathrm{~m}$ from 2003-2010 to $71.4 \mathrm{~m}$ from 2011-2017

(Figure 3). This nearest neighbor distance trend showed a highly positive significance $(r=0.86, p=0.01$.

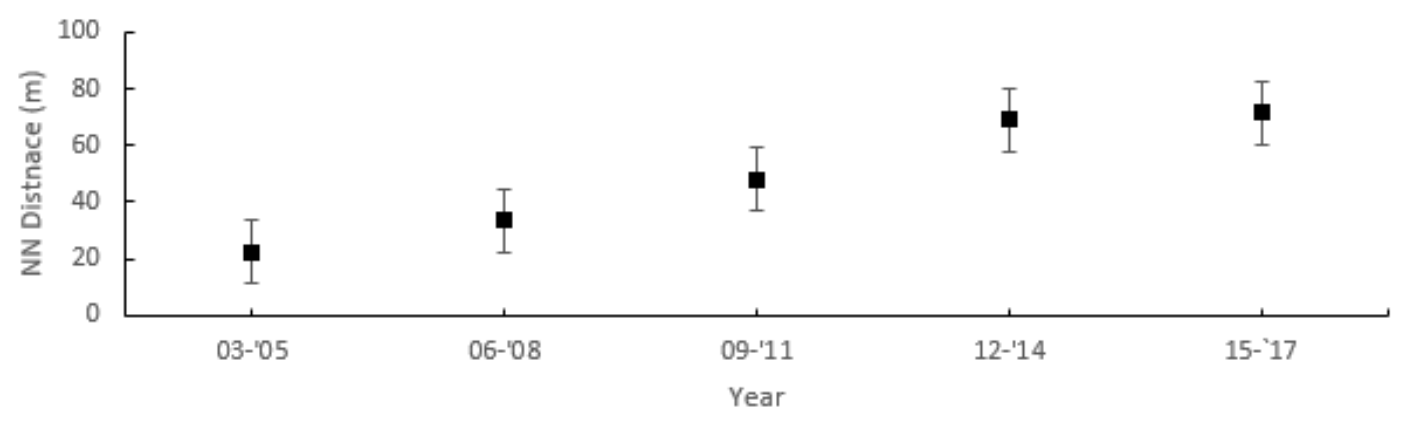


Figure 3-Average Nearest Neighbor distance (meters) found between pools from 2003-2017. Graphical representation in three year intervals to demonstrate the overall pool distance from its neighbors over study streams. Averaging over three year intervals also allows for the better graphical representation in variation of flow rates between years and the alternating years for habitat collection prior to 2010 .

This NN result also showed a drastic change in the probability of significantly dispersed habitat among the study sites. The probability that a site would display significant dispersal of pool habitat increased from 12 percent from 2003-2010 to a probability of 51 percent from 2011-2017 (Figure 3). This result is negatively correlated with the significant reduction in pool number occurring during these same time frames (Figure 4). However, the rate of change shifted in 2012. Prior to 2012, distance between pools was increasing by $3.9 \mathrm{~m} / \mathrm{yr}$. Post-Superstorm Sandy the slope leveled off near $-1.0 \mathrm{~m} / \mathrm{yr}$.
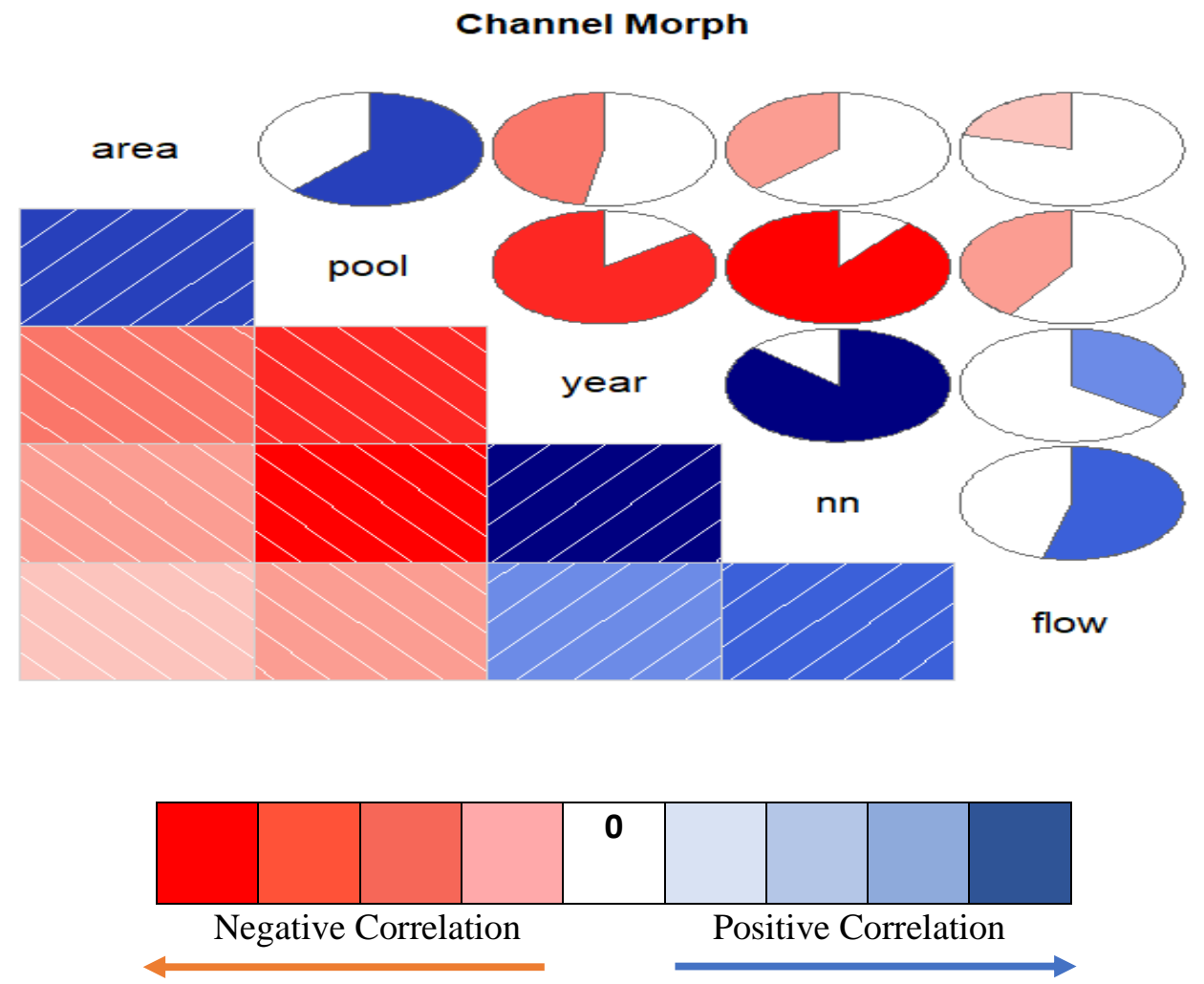

Figure 4- Correlogram showing relationship between the variables ((Pool area $\left(\mathrm{m}^{2}\right)$, Pool Number, Year, Nearest Neighbor, and Flow (cfs)). The shade and color represent the degree of correlation among the variables; with red representing negative correlation and blue representing positive correlation. The shade and fill represent the magnitude of correlation. 


\section{Discussion}

Our study of 25 headwater streams found that pools were becoming fewer and farther between, yet pool area was being maintained over a 15-year period. There was a lack of correlation and trend in pool area related to overall pool number or flow rates. This is likely due to the difference in point change found in pool number and not across pool area. While mean flow increased from 4.0 cfs across study areas in 2003-2010 to nearly 6.0 cfs from 2011-2017, pool area did not significantly increase. However, the expected pool quantity declines associated with increases in velocity and volume were observed. This could suggest that trends in pool quantity and distance were due to channel morphology change and not temporal variability in discharge. This conclusion is substantiated by the significant point-change and variability change post 2011 observed in pool quantity (Figure 1). This analysis carries many limitations, however given we counted pools within $10 \mathrm{~m}$ of a previous location as the same pool from year-to-year, our estimate of pool stability is likely conservative and given that this is a systematic bias our trends and results are reasonable.

Ross and Hartman (2014) suggested that events such as Superstorm Sandy could act as stabilizing forces on broad spatial scales, considering the high percent change in large woody loadings in wood-poor streams. Our study of the same streams demonstrates stability in NN, quantity, and pool area post-Sandy. This potentially highlights the importance of such "formidable events" creating stability across broad spatial scales. Pool scouring mechanisms are largely impacted by effective sediment transport, thus the presence rate of 'less-effective pools' is dependent on effective discharge intervals. Formidable events potentially remove the 2-year variability of "less-effective" or less stable pools from a catchment; resulting in a post-event stability. This is brought about by channel retaining or gaining characteristics of stable bed-scouring features (larger material, or bedrock knickpoints). This directly means that smaller features and temporally susceptible pools will be more frequently outpaced by increase sediment loads brought about by an increase in magnitude and frequency of extreme weather events.

Regardless, the observed decreasing trend in pool number and the increases in distance between pools should be alarming. While it can be argued that these systems lost poor, unstable pools; these pools could provide refuge and aide movement along the stream gradient. Declines in pool quantity and quality have been shown to drastically impact Brook Trout and other salmonid species (Lonzarich et al. 2000, Elliot 2006, Wenger et al. 2011, Petty et al. 2012, Kanno et al. 2014). While most studies focus on population responses to these variables, this study addressed the overall trend in critical (pool) habitat of an already restricted species. Although relatively short in temporal scaling, it should not be surprising that these 
trends exist. These systems experienced extensive logging, and likely have historically experienced a dramatic change in channel morphology (Hartman et al. 1995, Hudy et al. 2008, Ralph et al. 2011). These impacts likely persist because most forest stands within the study sites are considered secondary growth stands. The small average riparian timber size likely can account for long term decline and year-year variability of pool habitat (Murphey et al. 1989, Flebbe and Dolloff 1995, Ralph et al. 2011)

Even without considering this historic land use, the same decreasing trend in pool numbers could likely manifest itself due to a changing climate (IPCC 2014). Increases in fall precipitation make it more likely that sampling over time would take place during higher fall base flows, which would increase overall stream volume and area. The opposite is true for decreases in precipitation which has been shown to decrease overall depth and quality of pool habitat within a system (Hakala and Hartman 2004). This change in precipitation timing and magnitudes has been suggested to have already occurred over the last 50 years in Appalachia with similar trends projected to continue (Parmesan and Yohe 2003, Hayhoe et al. 2008, Rosenzweig et al. 2008, IPCC 2012, Combe et al. 2013). These projected changes in timing, magnitude and intensity of precipitation events highlight the importance to understand specific systems resistance and resistance to these climatic alterations. The changes we observed in slope of linear models for pool number and nearest neighbor post Superstorm Sandy (2012) indicate that disturbances can lead to habitat stabilization through time or shift to favorable conditions via wood loading (Andrew and Hartman 2014). However, disturbance scale events do not necessarily form long-term pool habitat and can even remove long-term potential woody debris from an area (Roghair et al. 2002, Jones and Daniels 2008). Increased frequency of storms could cause small diameter woody debris to be primary habitat forming material in riparian area. This smaller diameter is less suitable for stable habitat formations; whereas the secondary growth that would have been otherwise would from more stable habitat (Roghair et al. 2002, Jones and Daniels 2008). Little research has been done to analyze temporal pool stability, especially considering the variability demonstrated across watersheds and stream networks. Identifying these areas and the long-term shifts in habitat could help not only conserve cold-water fisheries, but determine which systems are habitat favorable in an uncertain future.

Trout populations occupying these high gradients systems already undergo drastic fluctuations in abundance and survival (Wenger et al. 2011, Bassar et al. 2016, Kanno et al. 2016). These temporal variations are largely due to temperature, disturbances, competition, and natural variations in environmental factors (Hakala and Hartman 2004, Petty et al. 2014, Wenger et al. 2011, Bassar et al. 2016, Santiago et al. 2017). Our finding of a decade of pool habitat loss is alarming alone. When coupled with increases in distance amongst pool; the compounding yearly variability raises concerns on resistance and resilience of Brook Trout populations moving forward. 
A strong relationship between the proximity of pools and movement of stream fishes has already been suggested (Lonzarich et al. 1998, Lonzarich et al. 2000, Letcher et al. 2007, Petty et al. 2012). With this increasing distance between spawning habitat and refuge, not only could these distances be effective, temporary impasses; but potentially they could drastically increase predation, competition and density dependence. In such a complex, heterogenous environment with high degrees of annual fluctuations in prey densities, temperature, and stream flow; the ability of an individual fish to move between/among pool habitat is crucial to maximize fitness (Petty and Grossman 2004, 2010; Young et al. 2010, Petty et al. 2012). Additionally, this does not consider annual movements associated with growth and spawning, nor does it accurately assess a changing flow regime or climates compounding impact on a trend in the critical habitat (Papadinki et al. 2016, Merriam et al. 2017, Santiago et al. 2017)

While this study does not directly address impacts of legacy timber harvest, the lingering effects could still be impacting Appalachian streams. Combined with the compounding effects of climate change, the lasting effects of timber activities could further exacerbate the trend in habitat loss across Appalachia via reduced natural wood recruitment to streams. Climate change, in conjunction with the increases in distance between and among pools in a system, could intensify population impacts during episodic events like droughts by reducing the carrying capacity for Brook Trout in a system. However, disturbance events could be favorable to a population if the system is favorable to stable habitat formation via large woody debris or boulders. Salmonids have been predicted to lose much of their southern, lower elevation, and main stem habitats with climate change (Rahel 1996, Flebbe et al. 2006, Wenger et al. 2011), with some regions expected to lose up to 60 percent of available trout habitat if air temperature alone rises $5{ }^{\circ} \mathrm{C}$ (Rahel 1996), while many other populations will not exceed 90 percent modeled persistence within the next 100 years (Roberts et al. 2013, Kovach et al. 2016, Santiago et al. 2017). Facing this grim outlook for Brook Trout, it will be important to further understand what makes pool habitat more temporally available and stable through time in order to protect the genetic diversity and overall range of this valuable species (Haak et al. 2011). In addition, it will be important to identify and remedy the streams that do not exhibit a strong habitat stability through time or are experiencing a continued trend in habitat loss.

\section{Limitations}

This analysis relied on generation of some variables from data digitization (NN). This process carries some inherent errors from the ArcGIS measure tool accuracy, DEM accuracy of stream channel, and error in study site starting/ending points. Steps to mitigate duplicating pools between years were outlined in the methods. However, errors in spatial scaling (1/9 arc second) are likely missing the detail required to approximate headwater channel complexity. While this associated error is a drawback, the overall 
analysis of pool number trends still indicated a negative trend through time. Logically, this would cause the digitized pools to increase in distance between one another.

Another potential limitation is in the reclassification of pools to standardized 30 centimeter depths over one square meter area. This reclassification is warranted to standardize data across study sites. However, some sites have limited numbers of pools that met our criteria (greater than $30 \mathrm{~cm}$ deep over 1 square meter) and one, (i.e. Lick Run) had no pools by that criteria. Pools just below this threshold, but with large maximum depths are likely still functioning as pool habitat in these systems, providing cover and thermal relief across systems through time. While these sites are present across systems, this aspect could alter overall number and thus trends across time.

Another limitation lies within the data before 2010, where sampling of sites was split between years. The overall average of pools could have a skewed average and with increases in sample size after 2010 could naturally drop the mean around the true habitat quantity. This data also did not contain information of pool quality (spawn area or cover area) which would have given this analysis stronger insight of pool quality along with the quantity. If high quality pools are getting better with respect to habitat quality over time, changes in the total number of pools over time may be inconsequential if those pools that fluctuate are of lower quality.

Even with the limitations of this study, there are few studies that specifically investigate the temporal nature of salmonid habitat (especially between and among flooding events in small, heterogeneous catchments across large spatial extent). Even fewer studies are able to correlate temporal habitat availability to population vital rates as we did in Chapter 3. Future studies should collect and address specific attributes of temporal pool quality, availability and arrangement, especially when studying longterm impacts of any environmental variable on a riverine species, due to direct linkage associated of organisms to channel morphology. This will help management of a valuable resource moving forward into a changing world. 


\title{
Chapter 2
}

\section{Modeling Changes in Critical Habitat for Brook Trout in the Central Appalachians}

\begin{abstract}
A changing climate in Appalachia is expected to have significant impacts on species in aquatic systems near the edge of their distributions. While these changes could be topographically mitigated, the impacts will likely affect distribution and temporal availability of critical habitat. The main objective of this study was to model changes in stream habitat across the Monongahela National Forest from 2003-2017. Stream habitat data was broken into two periods, pre- and post-2011, based upon a significant point change detected in 2011. By using presence only data, a maximum entropy model was created to assess probability of occurrence of pool habitat throughout the study region. According to the highest scoring AUC models ( $\mathrm{AUC}=0.89$ ), pool habitat decreased by 23 percent across the national forest between the two periods; and only demonstrated "stability" in 13 percent of its model presence probability.

Temporally stable habitat is a fundamental contributor to population dynamics and overall system health. Flow regime and severe weather events alter the temporal availability of critical habitat availability which impact Brook Trout resistance and resilience. Predicted increases in severe weather events and climate anomalies highlight the importance of understanding needed to adequately manage streams least resistant or resilient to changes in habitat.
\end{abstract}

\section{Introduction}

Thermal changes in salmonid habitat is a primary topic in fisheries biology, and incorporation of secondary data is very problematic when dealing with persistence estimations of populations (Mccullough et al. 2009, Hudy et al. 2010, Kovach et al. 2016). However, most research into thermal predictions unanimously agree that sizable reductions in habitat will occur as a result of climate change (Comte et al. 2013, Kovach et al. 2016). With much of the southern, low elevation, and main stem habitats becoming uninhabitable for Salmonidae (Rahel 1996, Clark et al. 2001, Flebbe et al. 2006, Williams et al. 2009, Wenger et al. 2011). Projected habitat loss varies spatially and temporally, with some regions expected to lose 30-100 percent of trout habitat if air temperature rises $3{ }^{\circ} \mathrm{C}$ (Rahel 1996, Clark et al. 2001, Flebbe et al. 2006) and modeled population persistence of some salmonid populations will not exceed $90 \%$ in the next 100 years (Lawler 2009, McCullough et al. 2009, Wenger et al. 2011, Comte et al. 2013). However, 
it is suggested that a large degree of thermal refuge will be protected by high flow, topography and cover relief (Clark et al. 2001, Fink et al. 2008, Trumbo et al. 2010, Merriam et al. 2017)

Thermal refugia is mostly attributed to headwater reaches and small, high elevation tributaries with many ground-water inputs. These areas are subject to high variability in flow regime, which is predicted to undergo drastic changes due to increasing magnitude, frequency, and timing of precipitation (Webb et al. 2007, Meyers et al. 2013, Merriam et al.2017). Hitt et al. (2020) documented complete fish assemblage shifts due to increased flow stochasticity. Outside of the predicted thermal shifts, changes in flow regime could have a confounding impact on the trout-climate relationship into the future (Santiago et al. 2017, Merriam et al. 2017). There is evidence that long-term projected streamflow could be equally impactful to trout demography as projected temperature increases (Jager 1999, Arismendi et al. 2013, Ehrlen 2015, Letcher et al. 2016, Kovach et al. 2016). The confounding impact of climatic variables and the heterogeneity observed among salmonid populations (especially populations at the 'edges') make these climate-population relationships difficult to quantify (Hilborn et al. 2003, Penaluna et al. 2015).

Most climate predictions on habitat loss seemingly make all habitat units equivalent in supporting a healthy population. Studies generally focus on length of stream below modeled thresholds versus quality of habitat along entire stream gradient (Clark et al. 2003, Flebbe et al. 2006). Fundamentally, habitat within these systems are not continuous and consist of riffles, runs, pools, and glides. Pool habitat can be classified as the most critical for individual fitness and refuge in salmonids (Fausch et al. 1988). The integral heterogeneity in these high gradient systems has been shown to directly impact population vital rates (Lonzarich et al. 2000, Hakala and Hartman 2004, Letcher et al. 2007, Ohlund et al. 2008). Brook Trout (Salvelinus fontinalis) are suggested to move long distances to maximize fitness or escape stressors. These movements are linked to the spatial and temporal variability in habitat at a watershed scale (Petty et al. 2012). Although a population does not necessarily need rifles, runs or pools for persistence, quality pool habitat typically allows for successful foraging and spawning opportunities while also providing refuge from predation, temperature and formidable events. The associative increase in fitness generally results in high population abundance, conditions, and persistence rates (Elliot 2006, Caroline 2003, Hakala and Hartman 2004, Petty et al. 2014, Papadiki 2016). The connectivity along the riverscape and potential impacts on meta-population dynamics could also see drastic changes if pool habitat changes (Ohlund et al. 2008, Reinman et al. 2011, Petty et al. 2014). All these factors make research into the temporal shifts of specific, critical habitat features vital for understand temporal projections of organisms directly associated with these features.

There has been very little long-term research done on temporal pool availability, and even fewer studies have attempted to model this critical habitat over a large spatial and temporal extent. By using pool 
location data, this study hopes to determine habitat resistance in the Monongahela National Forest and where the potential topographic relief is found in West Virginia. "Resistance" and "resilience" are often factors taken into account for restoration and conservation issues. Resilience is defined by the ability of a system/feature to recover from a disturbance, while resistance is the ability of a system/feature to remain unchanged post-disturbance event. Considering and quantifying stream resiliance and resistance attempts to account for variabilities of catchments due to land use, effective discharge, disturbance magnitude and frequency; and is suggested by researchers to reduce the impacts of climate change (Lawler 2009, Williams et al. 2015).

There is some emerging evidence that Brook Trout in Appalachia could see a buffer of stream temperature by the modeled increases in stream discharges associated with climate change (Merriam et al. 2017). However, the alterations in flow regime could alter pool habitat distribution and formation rate (Buffington et al. 2002, Roghair et al. 2002, Andrew and Hartman 2014). The temporal stability of pool habitat is largely driven by bedrock knickpoints, and flow obstructions that cause bed scour (Buffington et al. 2002). The differential response manifested across spatial and temporal extents could lead to underlying mechanisms that are controlling long-term pool stability. Thus, individual sub-watersheds response to climate patterns across time and space may further exacerbate differences in existing habitat conditions and formative mechanisms at these scales. Appalachia is assumed to have thermal protections due to catchments characteristics such as topographical relief, ground water upwelling and high gradient. However, projected frequency of droughts and floods coupled with underlying pool habitat trends could cause pool loss to be underestimated in current climate change models projections for species associated with pool habitat. Understanding specific temporal pool location change and resistance could be a valuable metric in uncovering critical habitat loss temporally.

Within a long-term study done in Appalachia, habitat surveys were conducted annually on 25 streams since 2010; with alternating surveys by site from 2003-2009. Overall trend of pool habitat in the study reaches have shown a dramatic decrease in overall number and 150 percent increase in distance between each other since 2003 (Chapter 1). Additionally, this data set encompassed the Super Storm Sandy (2012) - a formidable event that was shown to differentially impact catchment and potentially act as a broad scale stabilizer to large woody debris (Ross and Hartman 2014). If stream segments are losing pool habitat, Brook Trout will have to move further distances, sustain longer periods of stress, and encounter more competition to complete their life cycles (Grossman et al. 2010, Utz and Hartman 2009, Bassar et al. 2016). This change in movement would be based upon habitat stability across spatial and temporal scales, which has been shown to influence Brook Trout movement (Gowan et al. 1994, Petty et al. 2012). Headwater systems are thought to be relatively random in their habitat composition, and have received 
very little research to that end. Applying a spatial and temporal scale to physical habitat presence will give valuable insights into which areas are indeed topographically protected from a changing climate, and which areas are seeing a negative trend in critical pool habitat.

Utilizing the Maximum Entropy (MaxEnt.) method, this study aims to show changes in probability of pool habitat through time and which areas of the Monongahela National Forest are topographically protected (Phillips et al. 2006, Merow et al. 2013, Phillips et al. 2017). Utilizing a series of presence locations as the input, this modeling approach estimates occurrence rates in each grid cell of the user defined landscape from defined environmental variables. While MaxEnt does carry some assumptions and limitations, it allows for a large spatial scale to be applied to presence data (Merow and Silander Jr. 2013). This study not only used stationary point locations (pool habitats), it also applied a temporal scale to each study segment. This bolstered point locations and adds power to the stationary environmental variables (elevation, grade, curvature, riparian slope, dissection) that are not rapidly changing.

\section{Objectives}

The overall objective of this study was to model the changes in pool habitat across the Monongahela National Forest. The Forest is a 687,966 hectare section of the central Appalachians that encompasses the center of the native distribution of Brook Trout. MaxEnt. modeling should give valuable insights on the topographically protected areas located in the Central Appalachian rRange. We expected to see an overall decrease in pool habitat occurrence probability due to increases in flow rate and overall lack of large material associated with natural progression of historic logging activities. Additionally, by using time frames associated with an extreme event we sought to understand areas that any temporal stability and resistance persists within the Appalachian Range. Due to high gradient and capacity for sediment loading, we expected to observe a low overall stability across the range due to many "less-favorable" pools being lost.

\section{Methods}

\section{$\underline{\text { Study Area }}$}

The study area was composed of 25 stream segments with a high-degree of variability in characteristics that is representative of Central Appalachian headwater systems with self-sustaining Brook Trout populations. The 25 segments are located throughout the Monongahela National Forest with a few on privately owned land, and distributed among six HUC-10 watersheds (Cranberry River, Deer Creek of Greenbrier River, Dry Fork, Middle Fork, North Fork of South Branch of the Potomac River, and the Elk 
River). All sites were defined as small, cold, headwater tributaries that consist of typical fish assemblages of this stream type in Appalachia.

Stream habitat was sampled following a modified basin-wide visual estimation technique (BVET, Hankin and Reeves 1988). From 2003 to 2009, 12 or 13 of these streams were surveyed for habitat on alternating years (i.e. Seneca Creek was sampled 2003 but not 2004, and sampled again in 2005). From 2010 through present, all 25 streams were sampled annually. This habitat sampling was typically conducted in low-flow conditions (which historically occurs between June and October). This low-flow sampling ensures that the most habitat complexity was observed within the survey locations, and accuracy of estimates is increased in determining cover, spawn and pool areas. The starting point of each survey occurred in the same locations among years, and was typically marked with orange spray paint, orange ribbon and GPS points. Using a hip chain, surveyors recorded the beginning and end distance of each habitat unit (riffle, run, pool, dry, or cascade) relative to survey starting location. Three transects width/depths were recorded for every habitat unit progressing upstream in order to calculate habitat area. Additional variables collected included large woody debris counts (Andrew and Hartman 2014), wetted widths, bank full widths per individual habitat units were also collected. Every pool was measured for maximum depths, pool out depth, cover area, pool formation type, and spawn area.

The extent and distribution of the study area within the Monongahela National Forest allowed for broad scale modeling process to be an effective (Figure 5). The study sites encompass a high degree of variability of Appalachian Brook Trout streams, from high gradient to lower gradient meandering systems; with many different geology types and river morphology characteristics (Table 1). Being one of the largest National Forests in the East, the Monongahela has nearly $1600 \mathrm{~km}$ of naturally occurring Brook Trout streams within its boundary. The historical restriction of Brook Trout into these river miles have left populations isolated and at risk of extirpation into the future, and make pool habitat even more vital. 
Table 1: Study stream site summary of mean watershed variables.

Stream Legnth Drain_Area Max_Elevation Sinuosity Gradient Flow NN LWD_M Tree Geology

\begin{tabular}{|c|c|c|c|c|c|c|c|c|c|c|}
\hline & $(m)$ & $\left(k m^{\wedge} 2\right)$ & $(m)$ & 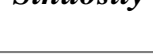 & & $(C F S)$ & $(m)$ & & & \\
\hline Big & 1532.5 & 3.8 & 1199.00 & 1.13 & 1.22 & 2.60 & 34 & 0.01 & hemlock & hampshire \\
\hline Birch & 1818.8 & 5.1 & 910.00 & 1.09 & 2.12 & 8.40 & 61.6 & 0.14 & birch & pottsville \\
\hline Block & 1591.2 & 7.3 & 1065.00 & 1.07 & 2.24 & 5.02 & 39.64 & 0.00 & na & chemung \\
\hline Brushy & 2225.7 & 18.7 & 810.00 & 1.06 & 2.60 & 1.23 & 42.69 & 0.08 & mixed & limestone \\
\hline Clubhouse & 1741.2 & 8.1 & 991.00 & 1.13 & 1.72 & 3.63 & 84.56 & 0.16 & mixed & chemung \\
\hline Crooked & 1723.7 & 8.4 & 1053.00 & 1.08 & 2.09 & 3.32 & 67.02 & 0.16 & mixed & mauchchunk \\
\hline Elklick & 3311.2 & 13.7 & 674.00 & 1.07 & 1.39 & 3.23 & 75.31 & 0.82 & oak & hampshire \\
\hline Elleber & 1888.3 & 5.6 & 1206.00 & 1.05 & 2.31 & 4.67 & 69.97 & 0.00 & na & chemung \\
\hline Lick & 1311.1 & 2.6 & 1025.00 & 1.06 & 2.21 & 2.07 & 59.13 & 0.04 & hemlock & chemung \\
\hline Light & 1451.8 & 6.1 & 785.00 & 1.09 & 1.69 & 9.39 & 73.42 & 0.13 & hemlock & pottsville \\
\hline Little & 1263.3 & 2.0 & 1119.00 & 1.06 & 4.28 & 1.04 & 45.35 & 0.23 & hemlock & mauchchunk \\
\hline Little Low & 1686.7 & 5.5 & 1029.00 & 1.05 & 3.03 & 3.09 & 52.06 & 0.02 & na & hampshire \\
\hline Long (Sen) & 1662.3 & 13.8 & 725.00 & 1.11 & 3.03 & 1.76 & 38.88 & 0.03 & oak & mauchchunk \\
\hline $\operatorname{Long}(W E R F)$ & 1748.7 & 7.7 & 804.00 & 1.08 & 1.84 & 2.50 & 49.02 & 0.18 & birch & pottsville \\
\hline NF Panther & 1389.6 & 3.6 & 805.00 & 1.19 & 2.92 & 4.99 & 57.26 & 0.28 & birch & pottsville \\
\hline NF Red & 2239.2 & 13.9 & 1015.00 & 1.09 & 2.05 & 2.82 & 62.30 & 0.06 & hemlock & mauchchunk \\
\hline Panther & 1557.8 & 0.5 & 812.00 & 1.09 & 2.41 & 5.06 & 57.23 & 0.15 & mixed & pottsville \\
\hline Poca & 1022.2 & 2.5 & 1108.00 & 1.07 & 3.77 & 1.09 & 55.95 & 0.17 & mixed & hampshire \\
\hline Roaring & 1347.7 & 6.3 & 829.00 & 1.08 & 4.15 & 0.43 & 30.61 & 0.09 & hemlock & mauchchunk \\
\hline Rocky & 1833.2 & 8.4 & 866.00 & 1.10 & 1.92 & 5.25 & 56.93 & 0.11 & birch & pottsville \\
\hline Sand/Red & 1284.1 & 4.6 & 1109.00 & 1.11 & 2.41 & 1.12 & 41.53 & 0.03 & hemlock & mauchchunk \\
\hline Schoolcraft & 1480.5 & 7.9 & 766.00 & 1.10 & 1.40 & 3.54 & 48.29 & 0.21 & mixed & pottsville \\
\hline Seneca & 1407.9 & 5.3 & 1153.00 & 1.12 & 1.16 & 3.09 & 41.95 & 0.05 & hemlock & hampshire \\
\hline Sugar & 1688.8 & 1.7 & 960.00 & 1.09 & 3.84 & 4.36 & 84.77 & 0.20 & birch & pottsville \\
\hline Whites & 2434.0 & 12.8 & 839.00 & 1.06 & 2.01 & 1.32 & 44.31 & 0.30 & mixed & hampshire \\
\hline
\end{tabular}




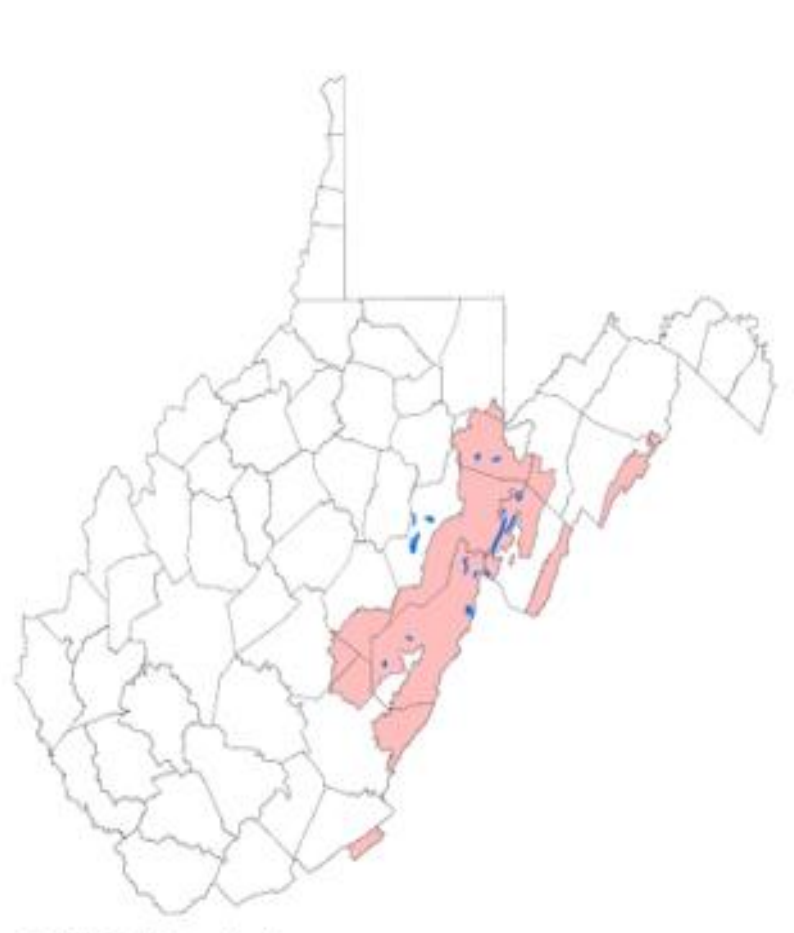

6- HUC 8 Watersheds

12- HUC 10 watersheds

25 Stream Reaches
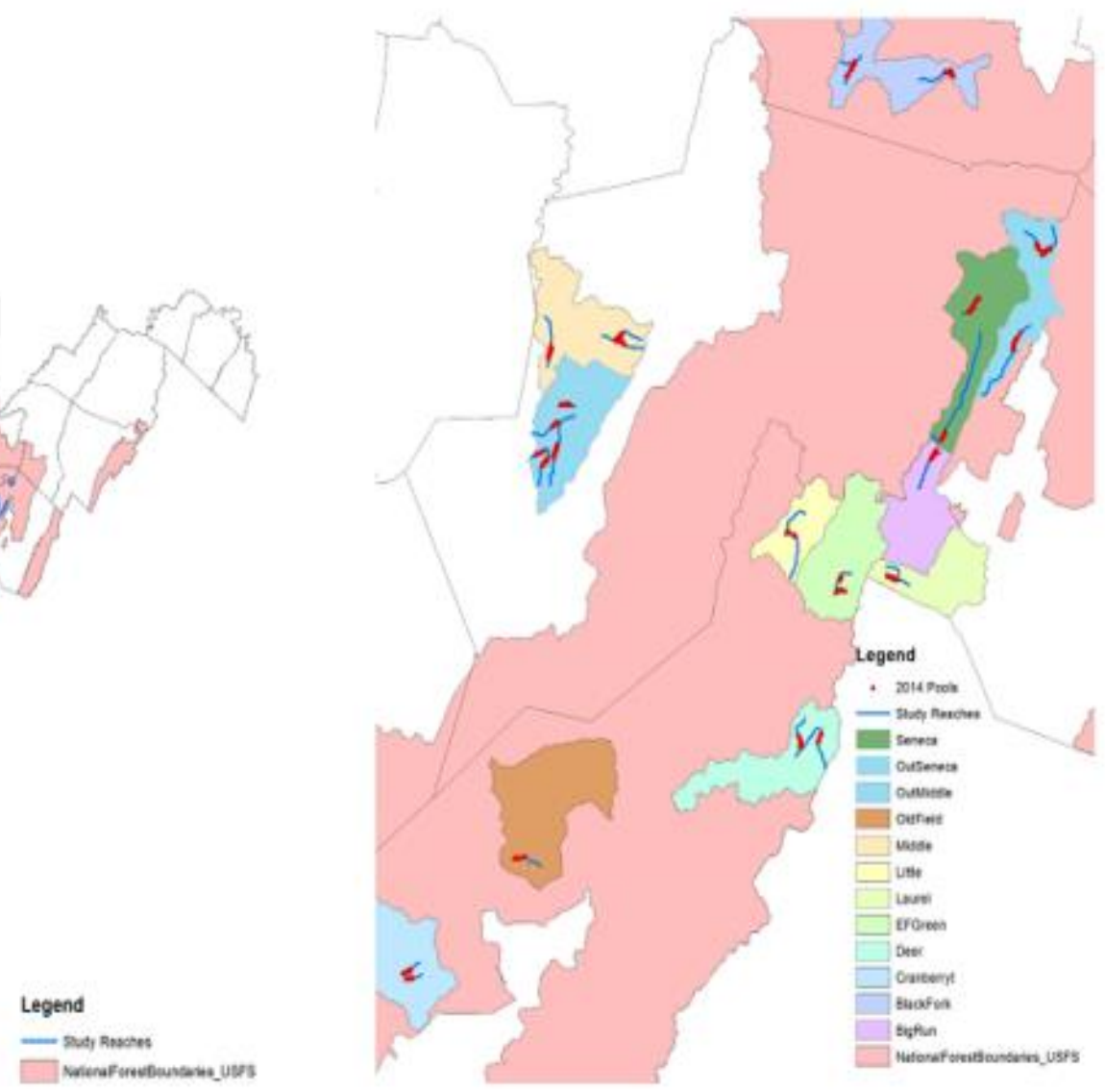

Figure 5 -Overview of study area. Left panel demonstrates spatial extent in which the stream reaches are spread within and outside of the Monongahela National Forest. The right panel is zoomed in extent of these study reaches with one year of digitized pool habitat in the respective HUC 12 watershed

\section{Digitization}

The focus of this study was on pool locations sampled between 2003-2017. Digitization of the habitat was done using ArcGIS 10.5.1. With the beginning and end distances of each habitat unit known; measure tool in ArcGIS was used digitize individual pool units over a hydro-corrected stream water grid (Zegre 2016). To achieve the highest degree of spatial accuracy, the points were overlain on this corrected water grid generated off $1 / 9$ arc second ( $3 \times 3$ meter) digital elevation model (DEMs). While this approach can carry uncertainties in flow projections because grids cannot account for the scale that rugged areas demonstrate (Wise 2007), corrected flow grids were the most efficient and accurate way to predict historic stream channel path. With intrinsic errors associated with digitizing historical data and stream channel changes; any pools found within 10 meters between years were considered as the same pool and 
locations was picked as overall average location between the years in that 10-meter range. Each pool was also filtered to exclude any pools that did not achieve the defined pool parameters (to be considered a pool depth was $\geq 30 \mathrm{~cm}$ ); to more accurately scale long term surveys definition of pool habitat. For habitat done prior to 2010, reclassification was needed in order to meet the defined pool habitat characteristic established after 2009 sampling period (>30 $\mathrm{cm}$ deep and $>1 \mathrm{~m}^{2}$ ). By using a hydrocorrected DEM among all the study sites (Maathuis and Wang 2006), digitization of the pool features was able to follow a $3 \times 3$ meter grid stream channel that represented the most accurate depiction of average stream channel over the course of the study period because it followed elevation and flow accumulation at the lowest grid points.

\section{$\underline{\text { Model }}$}

MaxEnt is predictive model building software that takes predictor variables (climate, topography, biogeographic, exc.) to estimate a probability distribution over a study area from established occurrence data (Phillips et al. 2006, Phillips et al. 2017). This process establishes constraints around each predictor variable in relation to each occurrence data point (pool) with each constraint defined by error association against empirical average of predictor variable to each pool location. MaxEnt, a presence-only model, does not assume any location in a study area lacks a probability of occurrence and avoidance the uncertainty that exists with absence data or incomplete information, and highlights probability. While this model is widely applied to species-distributions, provides robust analysis of relatively small sample sizes (Philips et al. 2006, Phillips et al. 2017), and proven to be more conservative than other predictive models (Elith et al. 2011, Phillips et al. 2017), it is seldom applied to areas outside species-distributions. However, studies have been able to utilize MaxEnt algorithms to successfully model fire and landslide occurrence probabilities related to environmental variables (Parisen and Mortiz 2009, Covertino et al. 2013, Chen et al. 2015). This modeling approach was not designed to specify the conditions that lead to particular pool habitat, but to evaluate relative strength in topographic constraints on long-term pool distributions. Thus, topographic controls that logically control river morphology were applied to simply highlight temporal ratio change, meaning climatic environmental elements exhibiting strong variation would show up as areas of low-probability of temporal pool stability. Limitations of MaxEnt are generally attributed to overfitting and inability of logistic output to be interested in cell-cell occurrence probabilities and extrapolation outside study area (Phillips et al. 2006). MaxEnt 3.4.1 was used to handle model builds using various topographic factors (Phillips et al. 2017).

Since topography is a major driver of river morphology and the presence of pool habitat, static watershed characteristics were generated from high resolution digital elevation models (DEMS) for the extent of the Monongahela National Forest downloaded from U.S. Geological Survey (USGS). A variety of variables 
were tested to build the strongest Maxent model based upon a priori assumptions that dictate habitat characteristics (sinuosity, curvature, channel grade, flow and riparian slope). Table 2 lists all the variables generated and considered in building the MaxEnt models. All environmental rasters were managed and handled within ARCGIS 10.5.1. Corrected flow accumulation and hydro-processing allowed for associated hydro-network variables to be extracted at highest available extent associated with DEMS (Mathuis and Wang 2006, Zegre 2016). The establishment of a categorical water grid ensured all modeled pool probability corresponded within the channel network. All predictor variables were based upon 3x3 meter cell sizes, except for PRISM raster (Precipitation-elevation Regression on Independent Slopes Model) which was integrated into study extent at $3 \times 3 \mathrm{~m}$ spatial resolution overlain on specific catchment (PRISM Climate Group). Additionally, correlation between the two intervals needed the most accurate models to be generated from similar environmental layers.

The objective of this analysis was to address temporal aspects of pool habitat. In order to account for this temporal stability while retaining the static environmental variables associated with topography, time frames were selected in the occurrence data. This would suggest the model is evaluating underlying condition changes between the time periods (i.e. stability change from floods, effective flow frequency variability). Presence locations of pool habitat were broken down in intervals of 2003-2010 and 20112017. This interval was chosen from exploratory trend analysis of pool data and observed impact of large woody debris loadings caused by Superstorm Sandy (Andrew and Hartman 2014). Additionally, a significant point change was detected after 2011 using the Pettitt-test $\left(\mathrm{K}_{\mathrm{t}}=52, \mathrm{p}=0.02\right)$. Significant point change present in the pool data could pro-actively address pool-monitoring to a larger spatial and temporal scale; potentially addressing flooding impacts and variability of climate factors.

Prior to generated pixel probabilities, appropriate Maxent model selection and tuning techniques were needed. Initial variable evaluation was done by running comprehensive model; evaluating response curve plots (fluctuations from 0 to 1 addressing predictor variability to average value with points), jackknife test (each variable is excluded and model created with remaining variables related to training data), and overall variable contributions. In order to evaluate model predictive power; random partitioning of datasets ( 80 percent training and 20 percent test) and area under the curve (AUC) were done. The default threshold of a completely random model is denoted by an AUC of 0.5, while values approaching 1.0 achieved better discrimination power in minimizing false-positive predictions (Fielding and Bell 1997). In presence only data, this is achieved by applying randomly sampled background data as the absence data (Philips et al. 2006). 
Table 2: List of all tested variables used to create MaxEnt model. The source refers to toolbox used to generate the variables and includes appropriates toolbox creator. A brief description is associated with each variable. + denotes variables used in final model

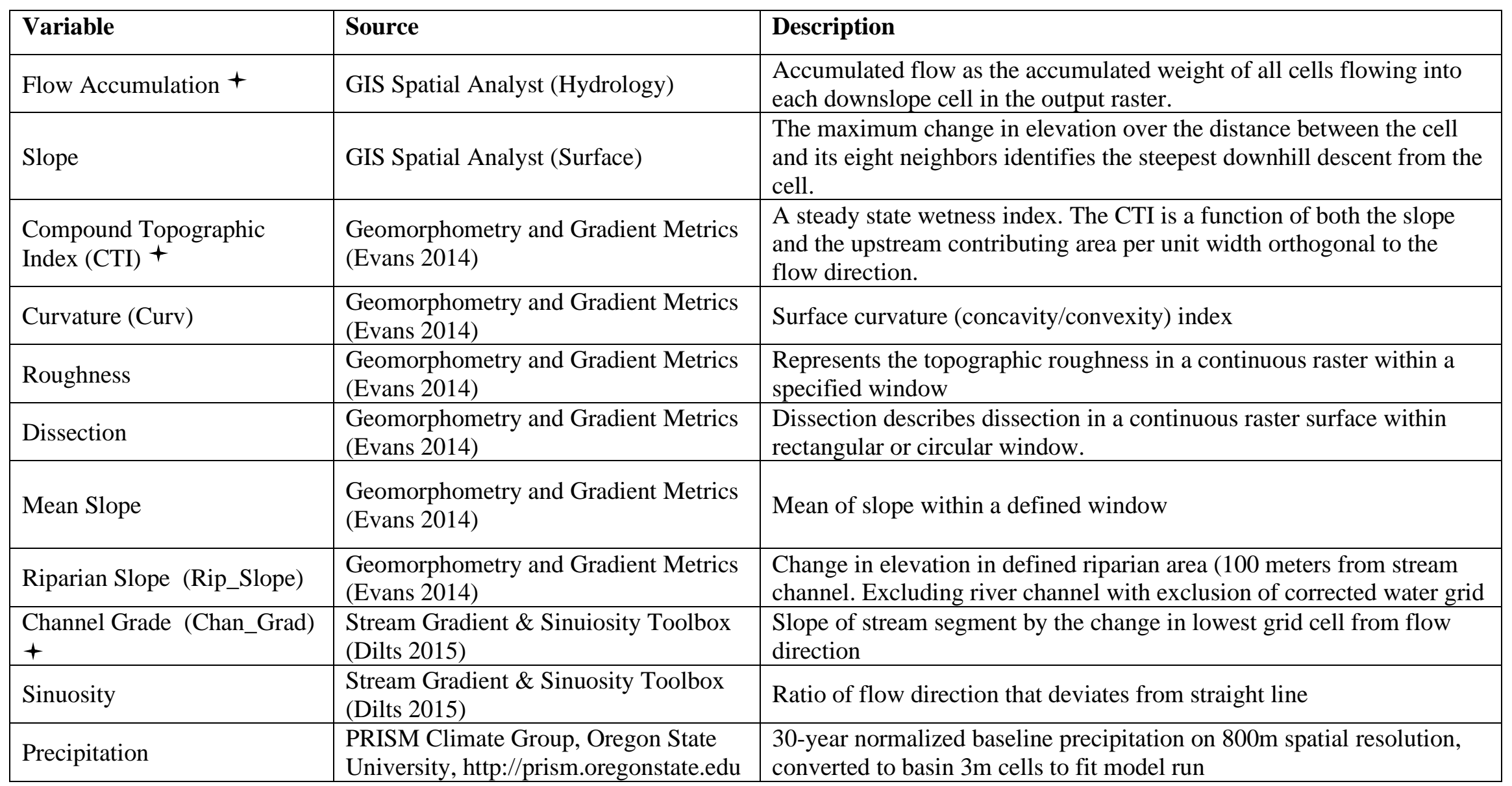


For each of the representative study periods (2003-2010, 2011-2017), the model generated a raster grid surface of occurrence probabilities. The temporal objective of this study was in the comparison of these probability distribution outputs; so further raster handling and analysis were done. The raster grids were projected into ArcGIS, which allowed for swatch of raster handling tools. Incorporation of presence points outside of the Monongahela National Forest ( 7 streams in the model data occurring on private land). The probability rasters were filtered to only include presence probabilities of greater than $95 \%$, resulting in a categorical raster of presence (1) or absence (0). This allowed for calculations to be made among the two models. The combination of both grids by multiplication resulted in raster output we referred to as "stable." This is due to the probability of pool presence between the two intervals being probabilistically similar; resulting in topographically driven pool-monitoring on large spatial extent. Additionally, modeled area outside of known-trout streams were assumed to be potential habitat.

\section{Results}

MaxEnt models were able to accurately predict the location of pools across the study sites using several landscape variables. MaxEnt models for each time period achieved AUC scores of $>0.86$ for their respective best fits. The associated p-value for balance training omission (Figure 6), predicted area and threshold value were significant across models $(2010, \mathrm{p}<0.01)(2017, \mathrm{p}<0.001)$. Using 3489 point locations, the 2003-2010 period best fit model achieved an AUC of 0.88; derived from sinuosity, flow accumulation, channel gradient, CTI and precipitation (Figure 7). The 2011-2017 period model used 4930 points and the best AUC score was 0.90; derived from channel gradient, accumulation, CTI, and precipitation (Figure 7). Water grid was used as a categorical variable across all models. Standardization of the model was built so each time frame used the same variables nominally decreasing the AUC of both time periods, 2010 achieved AUC of 0.86 and 2017 performance at 0.88 . These models incorporated environmental layers of channel gradient, accumulation, precipitation, sinuosity, and categorical water grid. Omission error indicates overall percentage that the observed pool locations (20 percent test dataset) were located in areas predicted to be unsuitable (false negatives). Both models performed at an omission error percent of 1 percent (2017) and 3 percent (2010). The conclusion from both AUC and omission errors can be interpreted as a high likelihood of model maximizing true-positives and minimizing falsenegativesThe overall regularized test gain by the jackknife test is presented below (Figure 8.) 

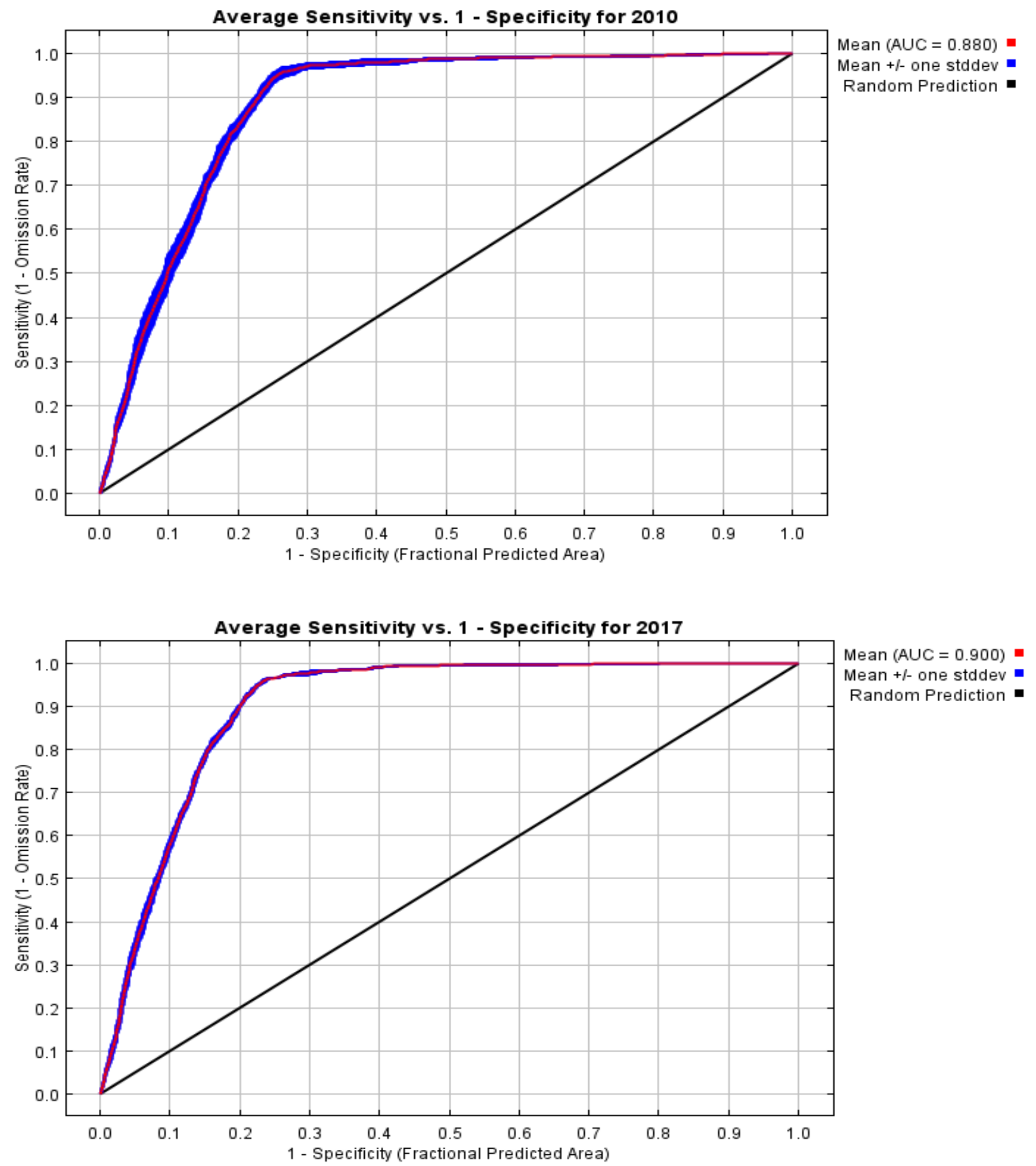

Figure 6 - The area under the ROC curve (AUC) graphic of MaxEnt model for both 2010(top) and 2017(bottom). The red line illustrates the mean AUC of 10 separate models, with the blue area representing the standard deviation of these models. The black line represents a random prediction of the data. 


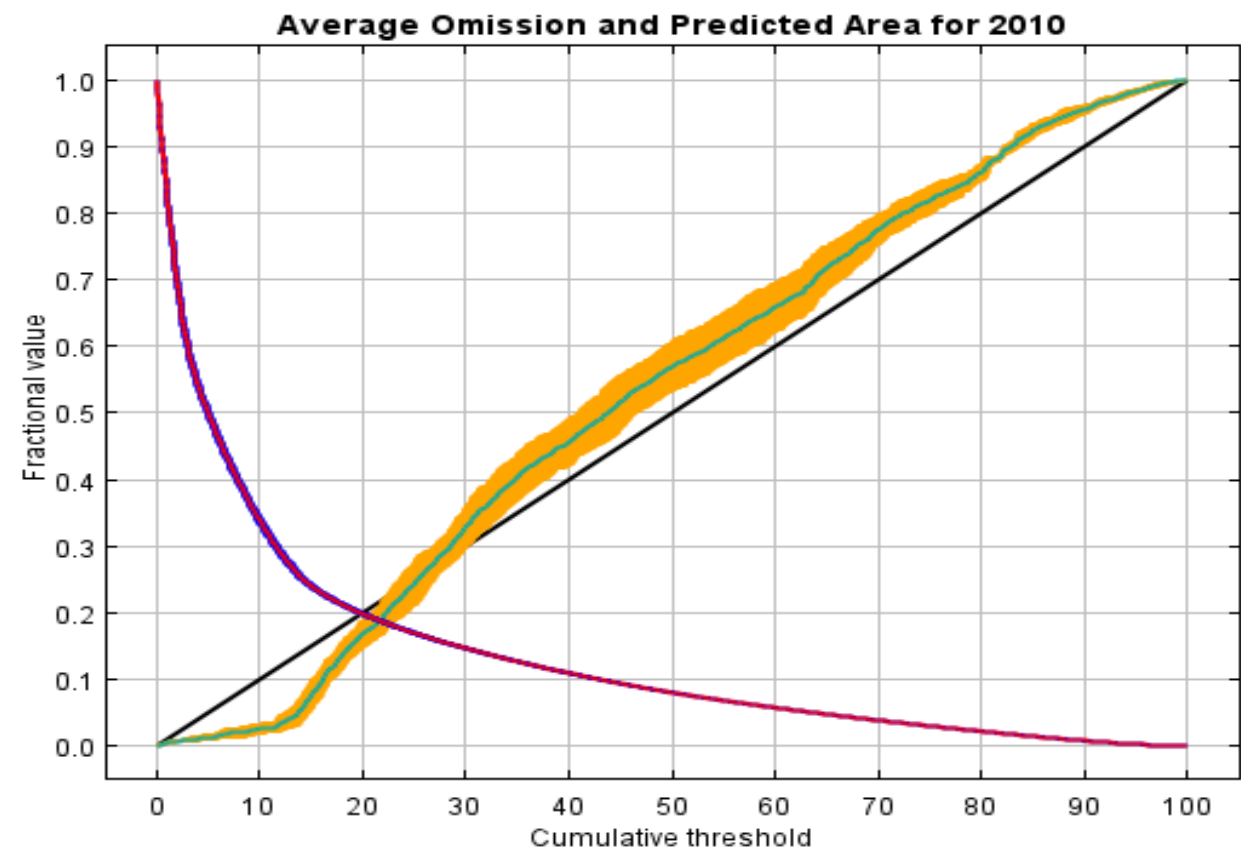

Mean area $+/$ - one stddev Mean omission on test data Mean omission +- one stddev Predicted omission

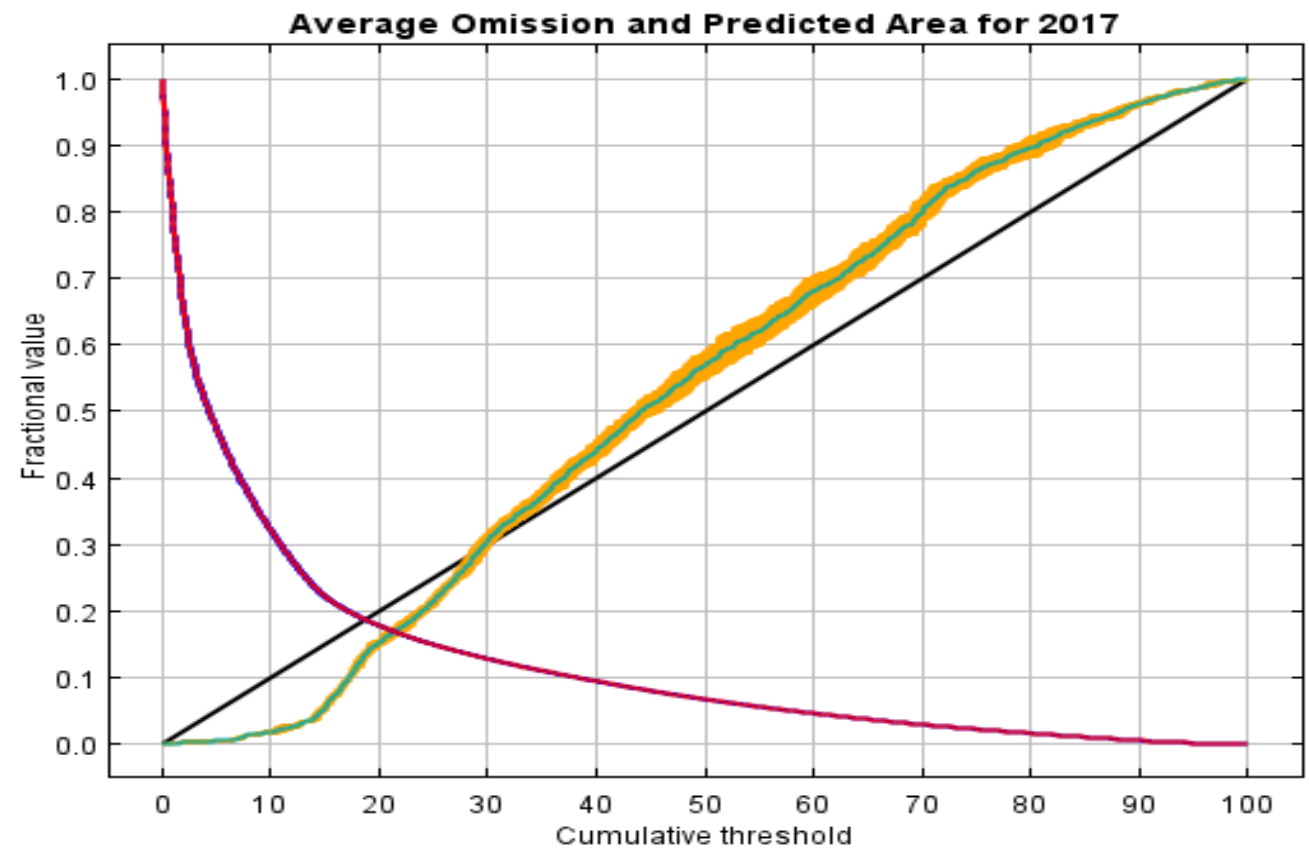

Mean area Mean area +/- one stddev Mean omission on test data Mean omission +- one stddev Predicted omission

Figure 7 - Test and training data omission on predicted area by choice of cumulative threshold. Here we see that the omission on test data (green) is a good match to the predicted omission (black line).

Channel gradient contributed 50 and 51.3 percent to the respective models (2010 and 2017) and was the most important singular variable in terms of training gain (Figure 8). The next highest variable of importance could be attributed to precipitation at 14.9 and 14 respectively. Sinuosity and flow 
accumulation were the other variables incorporated in the correlative model build and attributed 25 and 10 percent contribution respectively. Water grid importance was not derived as major percent contributor (7.3 and 6.3 percent) but analysis of response curve, the output of model was able to accurately correlate the assumption that water accumulation and pool presence were identically correlated. Response curves of single variable responses show that increasing gradient directly shapes pool occurrence probability, with increasing gradient yielding higher pool probability predictions. Precipitation response curve is far less intuitive, with a high degree of predictive power across range. The variability could be attributed to the underlying sediment loading variability across all watersheds due to flow rates from precipitation, with DEM generated precipitation variability potentially capturing this energy movement capacity across range. Riparian slope showed a negative trend toward probability of suitable conditions, so that higher riparian slopes lead to less stable pools (Figure 9).

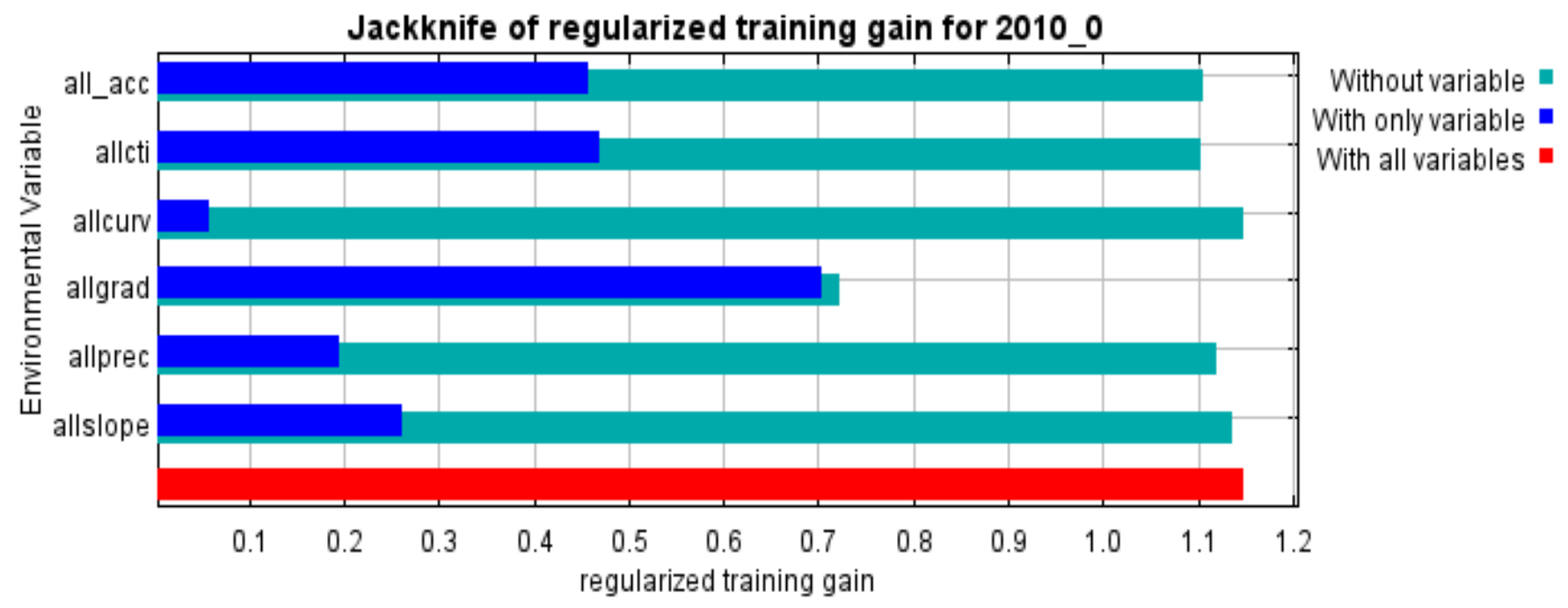

Figure 8 -Jackknife test for average variable contribution of input variables to models aimed at explaining pool habitat change and stable pool locations in headwater streams in the Monongahela National Forest. Here, allacc is channel accumulation, allcurv is sinuosity, allgrad is channel gradient, allslope is riparian slope, allcti is compound topographic index and allprec is normalize precipitation (PRISM). 
allgrad

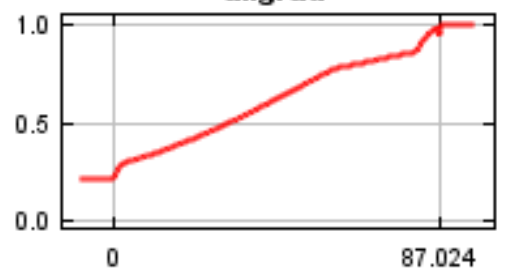

allcti

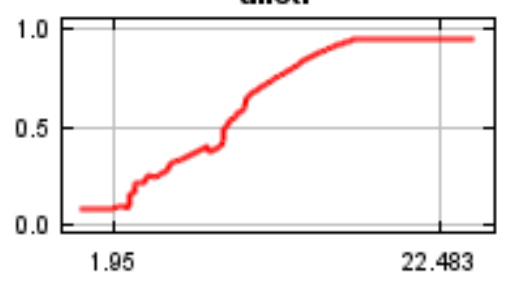

allslope

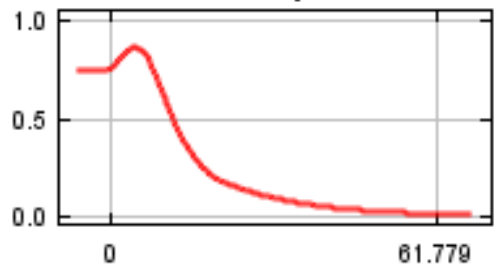

allprec

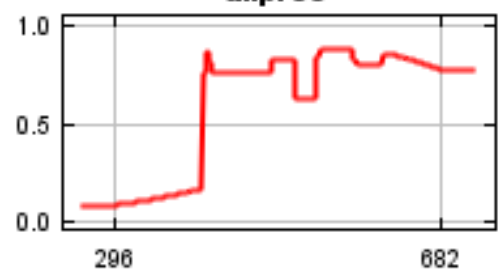

Figure 9 - Response curves of highest-ranking variables across model runs. Value shown on the y-axis is predicted probability of suitable conditions, with all other variables set to average over the presence localities. The $\mathrm{x}$-axis represents the values associated along the range of the variable of interest. Here, allgrad is channel gradient, allslope is riparian slope, allcti is compound topographic index and allprec is normalize precipitation (PRISM).

The temporal scale applied to this study was in the separation of data into two time frames, potentially accounting for underlying factors driving pool stability. The preliminary analysis of trend in pool quantity highlighted a near 50 percent decrease in pool number and observed a point occurred post-2011. Deviations from percent decrease observed in the dataset would suggest underlying control of stability, and the combined models observed a $23.9 \%$ decrease in modeled pool probability area. There appears to be a dispersal pattern emerging in the modeled probability of pool presence with locations less probable at lower stream reaches and dispersed across the upper reaches (Figure 10). The overall area modeled in 2003-2010 appears to be randomly dispersed across the national forest (Figure 11), while the modeled pool habitat in 2011-2017 appears to be concentrated further in the headwater regions (Figure 12). These results really are not surprising, but an interesting concept of our analysis is highlighted in Figure 13. This stable habitat model used the overlapping probability of presence between the two periods to create stream segments that likely have undergone the least amount of change. The stable habitat model indicates that approximately $13.3 \%$ of habitat in the Monongahela National Forest is temporally stable and resistant to extreme events such as Super Storm Sandy over the period of study. 


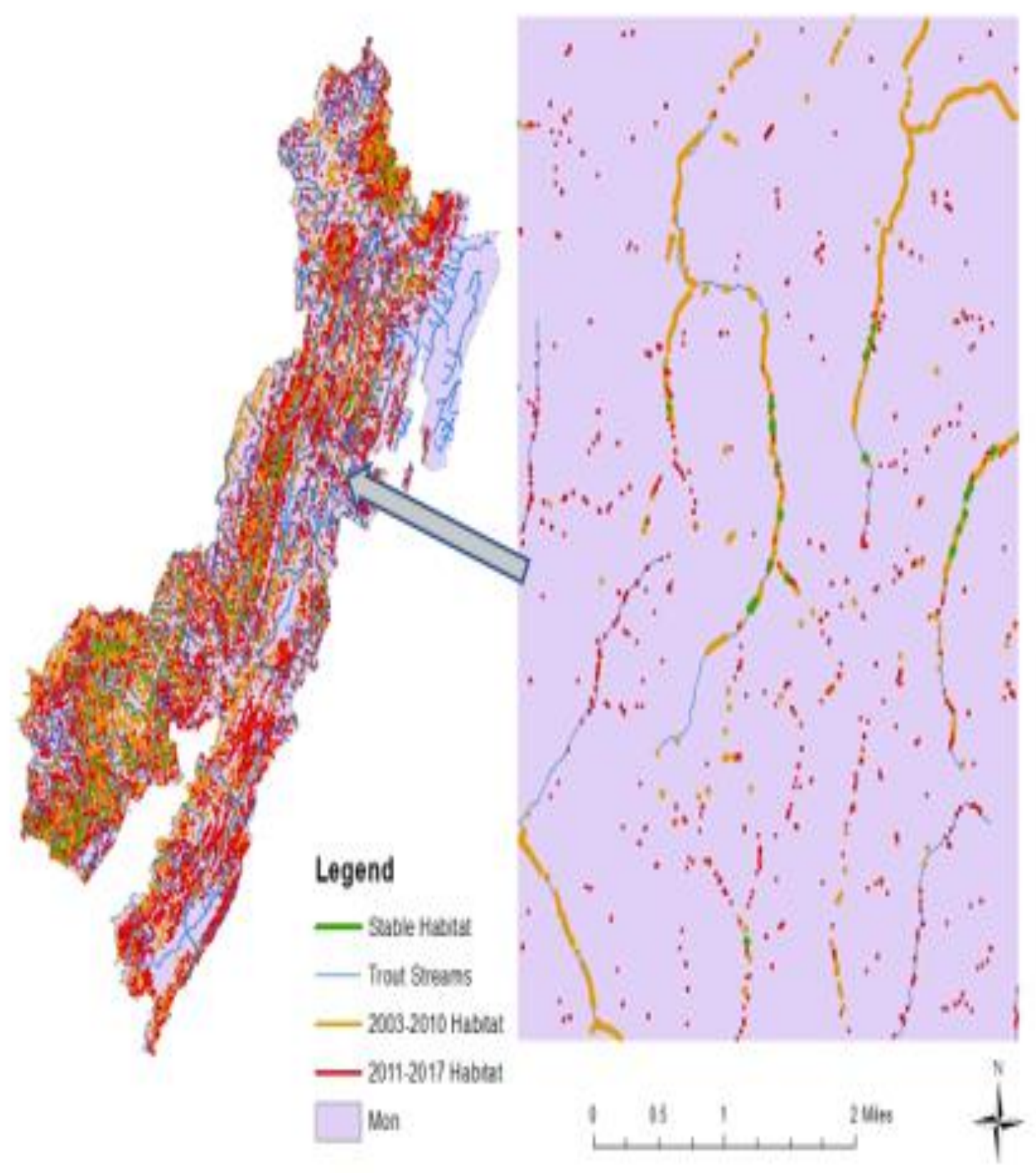

Figure 10- Pool habitat across the Monongahela National Forest in West Virginia. The zoomed in extent of all modeled habitat generated with blue segment being known trout streams from DEP/EPA updated 2016 map. The stable habitat (green) were the areas that were modeled in the same location between the 2 periods. 


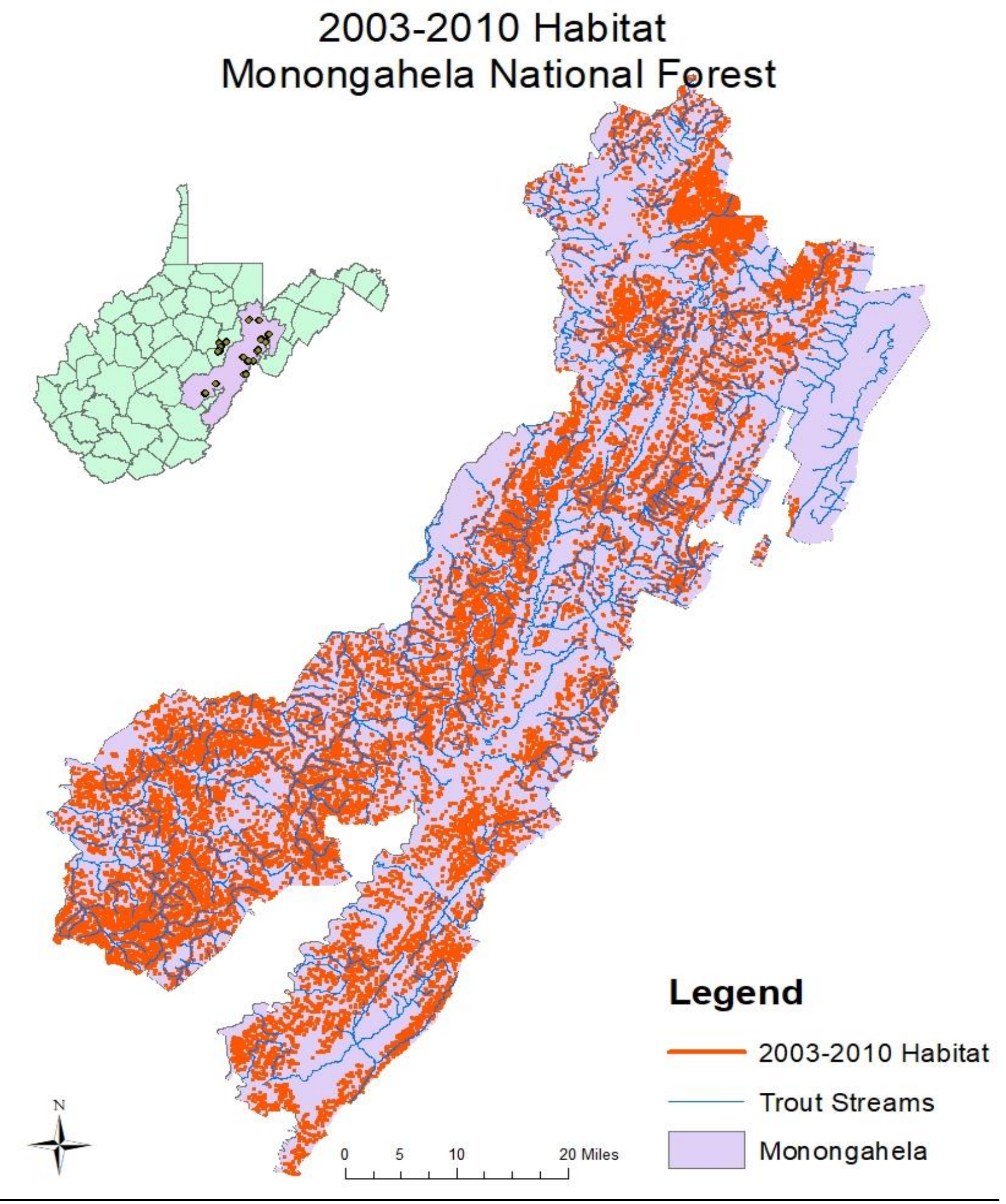

Figure 11. Full extent of modeled 2003-2010 pool habitat with blue lines being known trout streams. The orange represents the modeled pool habitat locations based upon known pool locations during period 2003-2010 (AIC=0.869). 


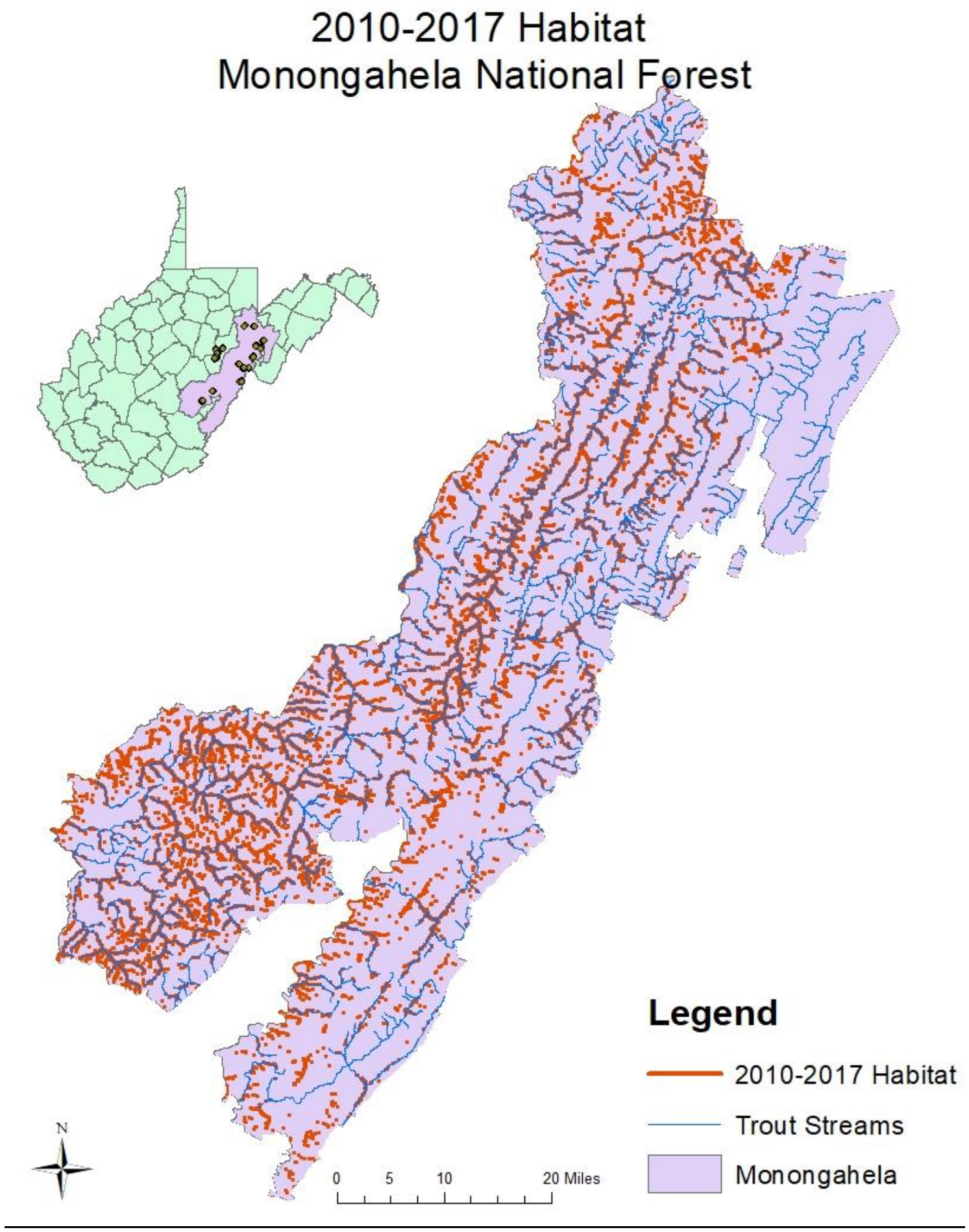

Figure 12- Full extent of modeled 2010-2017 pool habitat with blue lines being known trout streams. The highlighted orange represents the modeled pool habitat locations based upon known pool locations during period 2011-2017 (AIC=0.884). 


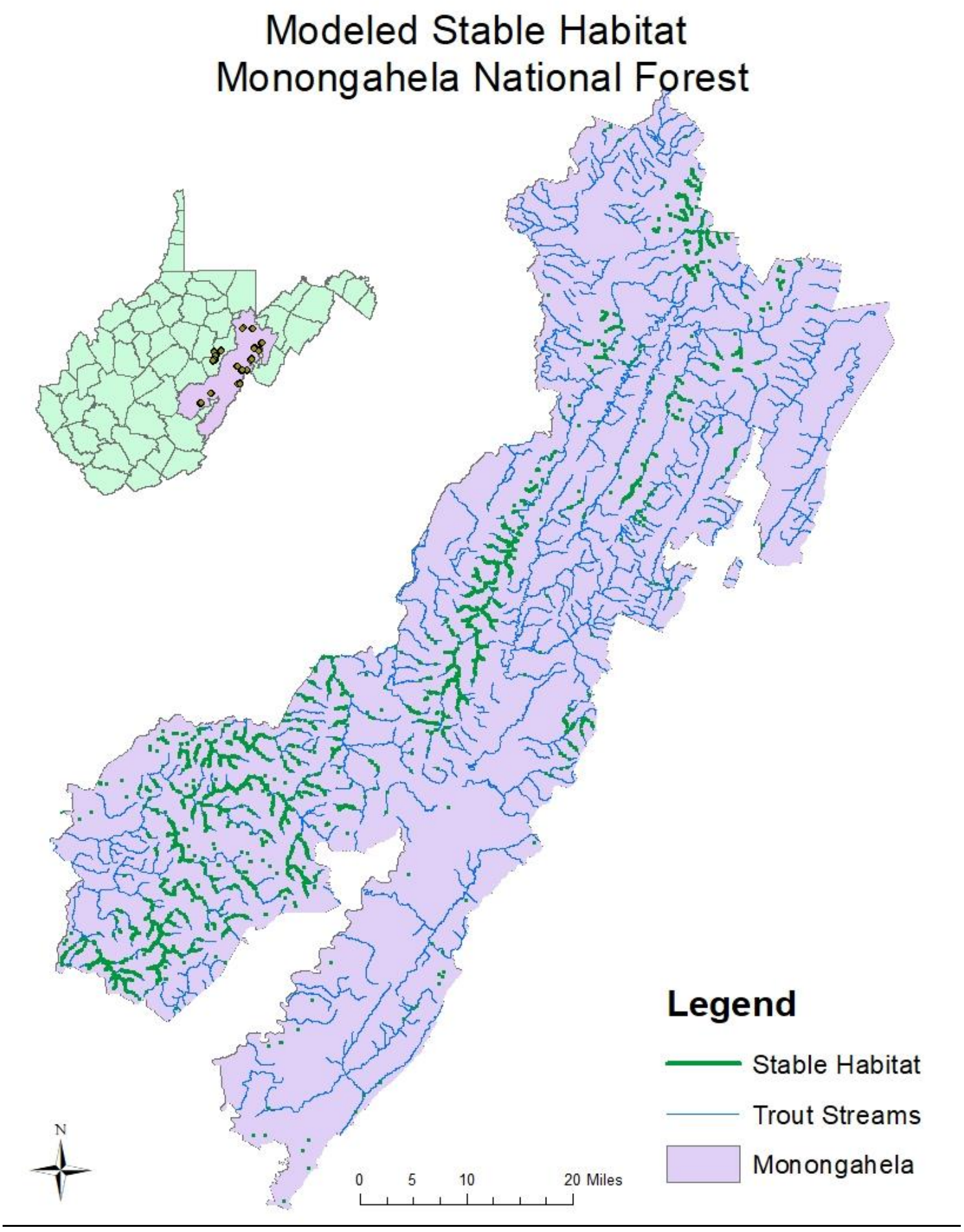

Figure 13- Modeled stable habitat generated from like locations modeled between the time frames. The green area represents the cells that were modeled to exist in both time periods 2003-2010 and 2011-2017. 


\section{Discussion}

With many models predicting extensive habitat loss for cold water species into the future, it is important to understand which areas are sensitive or resistant to change (Clark et al. 2001, Williams et al. 2009, Wenger et al. 2013, Kovach et al. 2016, Papadiki et al. 2016). This study highlights the areas across 687,966 ha of the Central Appalachians that have likely experienced the highest level of stability during the last decade, and likely will continue to experience similar stability into the future. The stability was modeled using watershed characteristics that are more static through time than environmental or temporal patterns such as stream flow or temperature. While it is believed that a relatively large portion of centralized Brook Trout habitat is topographically protected, this study is the first to model which of these areas likely fall into this designation and highlights the relative ratio of this protection (Figure 13). Most models simply use stream length to assess habitat alterations, however habitat units within a given stream are a more precise measure of habitat quality and space. These habitat units are likely more closely related to overall population dynamics, and the temporal change would be an important factor in determining fluctuations in relative abundance and condition.

While this prediction of stable habitat is not necessarily correlated with Brook Trout abundances or growth, it is a useful approximation of spatial distribution and stability in Appalachian systems. This can give helpful insights into available space for a population to occupy and relative connectivity of stream networks in which meta-population dynamics operate. Populations along the Appalachian gradient of streams experience varying and complex interactions of climate, flow regime, biota, and catchment characteristics (Clark et al. 2001, Petty et al. 2012, Kanno et al. 2016, Kovach et al. 2016). However, it can be deduced that fish populations that persist in these high-gradient streams are shaped by the habitat available through time. This habitat and the fish themselves are rapidly shaped by flow events on a relatively miniscule time scale (Roghair et al. 2002) but sometimes these events can alter habitats and populations in the long term (Caroline et al. 2003, Webb et al. 2007). While these conditions have persisted through time and the species located within each population can be evolutionary adapted to combat such events, the effects of projected chronic disturbance and increased frequency of effective discharge could be highly deleterious to stream habitat and population persistence through time (Kovach et al. 2016, Santiago et al. 2017)

This model did not directly incorporate any thermal conditions; pool habitat is the primary refuge from environmental flow and temperature extremes (Caroline et al. 2003, Hakala and Hartman 2004, Elliot et al. 2006, Petty et al. 2012, Santiago et al. 2017). Stable locations could still see dramatic declines in 
available space due to increases in summer water temperatures that exceed critical thresholds for cold water species. This impact could also enhance meta-population dynamics even if there is adequate pool habitat throughout a given watershed (Petty et al. 2014). The differences shown in Figure 4 and Figure 5 address the concern that not only is temperature driving critical pool habitat further into the headwaters, but topography controls the temporally stability of these pools. With increased probability of catastrophic flood events unevenly distributing pool habitat, coupled with increasing temperatures pushing thermal refuge further into headwaters; predictive models could be drastically misrepresenting habitat loss due to a changing climate.

The highly mobile nature of Brook Trout and complex spatial structure needed for them to thrive/survive makes our analysis very powerful. Not only because of the spatial extent, but the temporal scale applied to such a crucial habitat unit that dictates vital rates at not only an individual level but at the population scale. Pool habitat provides forage, thermal refuge and spawning habitat (Hakala and Hartman 2004, Warren et al. 2009, Warren et al. 2010, Petty et al. 2012, Petty et al. 2014) and the distance between habitat units is suggested to influence movement of fishes (Longzarich et al. 2000, Petty et al. 2012, Kanno et al. 2014). While this is mostly attributed to riffle depth, the overall trend in pool number decline could lead to more severe effects of pool isolation. The density-dependent response and stress involved from drought conditions could be confounded in these cases if the riparian area is scoured of large woody debris inputs (Roghair et al. 2002, Hakala and Hartman 2004, Bassar et al. 2016). By showing areas that are likely stable; managers could not only target unstable areas but target areas that will connect populations (Letcher 2007, Polar-Jeffers et al. 2009, Kovach et al. 2015).

Streamflow and seasonal temperatures drastically impact population dynamics; and the interaction will have complex impacts on varying spatial and temporal scales (Clark et al. 2001, Waren et al. 2009, Warren et al. 2010, Wenger et al. 2011, Kanno et al. 2016, Merriam et al. 2017). Each year a different element may impact any given population, however it is the cumulative and chronic changes that will push a population to the brink of extinction. Directly impacting annual streamflow in a free-flowing river is impractical, and the only management practices to mitigate temperature is stream shading with riparian cover, increasing deep pools and undercut banks (Lawler 2009). The most practical models for stream dwelling creatures are ones that include variables that can be directly affected by management practices. This temporal examination of stream pools highlights one of the single most important variables for individuals and populations of Brook Trout, and can be directly managed. This direct management can take an immediate or long-term approach. The immediate approach is to directly add large woody/cobble material or simply increase size and number of pools. A long-term approach is to protect riparian areas for 
adequate tree size to be achieved and increasing channel meander (Lawler 2009). Both strategies help protect populations from variations in extreme temperature and discharges.

In the raw data, pool number decreased across study period approximately 65 percent. While the degree of pool habitat decline did not manifest itself in the model, it is reassuring that the model was able to extrapolate the data from stable pool habitat conditions across the study extent. This would indicate there are locations within Appalachia that could see topographically-mediated thermal relief and watershed characteristics conducive for temporally stable pool habitat. When coupled with ground water inputs, and increases in projected streamflow (IPCC 2014, Merriam et al. 2017), the annual variation among Brook Trout population health in certain areas simply might become more variable annually but see no significant long-term trends (Roghair et al. 2002). These complex and confounding variables are what makes population modeling hard in any species, especially when looking at long term factors that go into population dynamics. The next step is to ground truth these locations across the modeled extent. While we cannot determine pool age in non-sampled segments, it can be used to calculate pool prediction accuracy and potential areas to study further.

Pool habitat was shown to be dispersing and decreasing in number across the long-term study segments (Chapter 1), this study highlights the potential areas where pool habitat is protected topographically. Overall, the analysis of pool habitat could yield logical connections to Brook Trout dynamics and areas where management needs to focus. Fewer pools along the same stream reaches could reduce population persistence via density dependency, reductions in recruitment distance between refuge and overall individual condition (Lonzarich et al. 2000, Clark et al. 2001, Hakala and Hartman 2004, Petty et al. 2004, Elliot 2006, Bassar et al. 2016, Kanno et al. 2016, Papadaki et al. 2016, Santiago et al. 2017). While the number of habitat units does not always significantly decrease uniformly in all stream reaches (Swanson et al. 1998, Roghair et al. 2002, Andrew and Hartman 2014), the increase in pool distance could isolate populations, which would be especially deleterious during extreme conditions (Hakala and Hartman 2004, Wenger et al. 2011, Petty et al. 2014, Papadaki et al. 2016). Meta-population dynamics could then severely impact overall population persistence due to high variability in habitat accessibility and movement between/among habitat patches.

Appalachian streams have been left wider, shallower, and straighter following the large-scale timber operations of the 1800s (Hartman et al. 1994, Webb 2007, Hudy et al. 2008, Ralph et al. 2011). Inherently causing long-term impacts on a systems resilience. Some streams likely have not been able to achieve adequate habitat and periodic floods leave systems unable to accumulate appropriately sized debris to form stable pools. The overall predicted low ratio of stable pool habitat could be related to the lack of large trees in riparian areas. High discharge events remove these temporally susceptible pool areas over a 
larger extent; stabilizing pool area around underlying geological controls, large material deposition, and areas of a catchment that bed material scour remains relatively uniform through time. Examination on such a spatial and temporal extent in vital habitat allows for targeted management. This means that watershed managers can specifically add pools to areas exhibiting low temporal stability or specifically target characteristics adept to protect features to formidable events. Validation of this model would further strengthen the ability of managers to confidently apply pool additions, and continuation of longterm pool study would allow further understanding of population dynamics, formidable events, and critical habitat availability. The precision in which management can take place is directly related to these understandings.

\section{Limitations}

While the interest and importance of this study's topic/scaling are clear, it does come with limitations.

The overall accuracy of pool habitat locations is dependent on hand measurements based only on starting locations of all previous habitat surveys. Ground-truth pool habitat is the only correction to this limitation, but the temporal scale of this analysis would be lost. In addition, all environmental variables were derivatives from a $3 \mathrm{~m}$ DEM which does not account for the fine scale of which pools are found. Incorporation of other variables such as temperatures, flows, riparian cover, etc. would help to complete the representation of how temporal environmental variables will impact vital habitats through time. In addition, there is no standardization for the number of pools a trout stream segment should contain. Restoration efforts generally construct pools with only a goal to provide thermal refuge. However, the complex riffle/run dynamic in a Brook Trout system allows for foraging, juvenile habitat, and overall ecosystem health. There is likely an ideal number of pools a system can support. This study could allow for a spatially explicit justification on restoration efforts toward a standardized habitat composition. This study also does not account for pool quality variables (pool depth, spawn, cover area, or area). The longterm dataset used to generate the model indicated the net change in pool area was slightly decreasing, which means while pool number is decreasing, these pools could simply be transient habitat units. Pool area could not be used since the digitization and scale of DEM would not account for this fine of a scale. While the overall objective of this project was met, improving the model toward a focused, spatially explicit, and longer temporal frame has great power in cold-water fisheries management. 


\title{
Chapter 3
}

\section{Potential Relationship Between Habitat Stability and Brook Trout Abundances}

\author{
Abstract \\ Understanding the temporal habitat stability and its influence on population dynamics is important for \\ fisheries management into the future. The variability in projected environmental factors and their direct \\ impact on populations and indirect impacts on habitat is vital for mitigating dire projections. The primary \\ goal of this study was to examine how pool and spawning habitat changes influence both Brook Trout \\ Salvelinus fontinalis spawner and recruit abundances. From 7 years of data collected across 25 headwater \\ streams, we were able to show the impact pool stability had on spawning age Brook Trout. Particularly, \\ the directional change associated with each pool unit deviation from stable pools ( 0.31 individuals per \\ 100 meters) accounting for variations of the random effects' year, site and reach. The stability of pools \\ did not impact recruit abundances, but previous year spawner abundances and spawn area did $(\chi 2$ \\ $(1)=8.26, p=0.04$. Thus, stable pool habitat could be associated with higher adult abundances and \\ recruitment. Regardless, future research and management should address habitat stability.

\section{Introduction}

The variability in fish populations occupying headwater streams and the streams themselves are largely shaped by significant flow events (flood and drought). A population's persistence is closely related to the characteristics of the system, allowing it to be resilient or resistant to these formidable events (Roghair et al. 2002, Lawler 2009, Williams et al. 2009). Brook Trout Salvelinus fontinalis occupying high-gradient, head-water systems experience wide variations in physical (flow and temperature) and biological conditions (prey densities and habitat availability) on varying temporal scales (Gowan and Fausch 2002, Petty \&Grossman 2010, Koizumi et al. 2013, Kanno et al. 2014, Merriam et al. 2017). The ability of Brook Trout to respond to these variations can be often correlated with pool habitat and movement (Roghair et al. 2002, Petty et al. 2012, Kovach et al. 2016).

Pool habitat can be classified as the most critical habitat for salmonids and specifically for lotic residing Brook Trout. The characteristics of pool habitat include adequate streamflow at low-velocity and with deep-water refuge; pool habitat can also contain foraging sites, overhead cover, and spawning gravel (Fausch et al. 1988). Due to these characteristics, it has been shown that salmonids spend most of their time within or nearby these pool habitats (Kristensen and Closs 2008, Grossman et al. 2010, Hartman and Logan 2010, Petty et al. 2012). The tail section of pools is where most spawning/redd construction effort occurs due to depth, temperature and gravel deposition in lotic systems (Letcher et al. 2007, Theriault et 
al. 2007, Kanno et al. 2012). These spawning efforts are suggested to be directly correlated with recruitment the following year; thus, pool habitat may be a critical-limiting factor for salmonids (Hakala and Hartman 2004, Warren 2009, Warren et al. 2012, Kanno 2016). Recruitment efforts can be limited by many physical characteristics across temporal scales; summer temperatures, fall stream flow, winter spates, competition, and overall water quality (Hakala and Hartman 2004, Warren et al. 2009, Warren et al. 2012, Bassar et al. 2016, Davis and Wagner 2016, Kanno et al. 2016, Kovach et al. 2016).

Climatic alterations are projected to have detrimental effects on salmonids. The projected loss of habitat and subsequent population persistence's of cold-water fishes is particularly concerning with projected temperature increases alone (Rahel et al. 1996, Clark et al. 2001, Wenger et al. 2011, Kovach et al. 2016, Munoz-Mas et al. 2016). It is well documented that stream temperatures have increased over the last few decades and probability of persistence in many populations doesn't exceed 90\% (Clark et al 2001, Wenger et al. 2011, Comte et al. 2013). Incorporation of other climatic variations (flow regime and increased frequency of spates/drought) complicate these projections spatially and temporally. However, these models still suggest habitat loss ranging for 30-100 percent (DeWeber and Wagner 2015, Merriam et al. 2017, Santiago et al. 2017). Increases in formidable hydrological events (extreme storms, larger floods, longer droughts) will be detrimental to salmonid movement, spawning, survival, and overall population dynamics (Roghair et al. 2002, Caroline and McCullough 2003, Webb et al. 2007, Wenger et al. 2011, Petty et al. 2012, Davis et al. 2013, Kovach et al. 2013, Bassar et al. 2016, Munoz-Maz et al 2016). During these events (flooding/droughts) it has been shown that pool area, pool proximity, and refuge are positively correlated with adult/recruit abundances and fitness (Schlosser et al. 1995, Lonzarich et al. 1998, Lonzarich et al. 2000, Caroline and McCullough 2003, Hakaka and Hartman 2004, Letcher et al. 2007, Meyers et al. 2013, Kanno et al. 2016, Papadiki et al. 2016). Given the projected increases in frequency and duration of these hydrological events, it is important to understand the resistance and resilience of Brook Trout critical habitat-- pools.

Variability in watershed characteristics will show differential impacts on habitat change and Brook Trout populations. Large woody debris (LWD) additions have been shown to greatly increase habitat quality, fish/invertebrate biomass, and overall biotic processes of lotic systems (Schlosser et al. 1987, Reice et al 1990, Roghair et al. 2002, Andrew and Hartman 2015). Extreme events have been shown to increase both LWD additions and substrate size immediately following disturbance events, however the results are not always consistent (Roghair et al. 2002, Caroline and McCullough 2003, Andrew and Hartman 2015). The few long-term studies on temporal stream morphology and population dynamics are within single systems, and generally show habitat/populations returning back to previous levels (Smith and Atkinson 
1999, Roghair et al. 2002, Carline et al. 2003). While there is variability, it is often attributed to watershed characteristics (forest-stand age, flooding severity, substrate sizes, land-use, and gradient).

Habitat stability positively affects fish populations. Fish biomass and individual size respond positively to stability of physical habitat parameters (Kushlan 1976). Movement rates of lotic Smallmouth Bass Micropterus dolomieu, increase when pools are unstable (Fajen 1962). For salmonids, spatial stability of home range is linked to availability of pool habitat (Heggenes et al. 1991). Over long time periods, stable habitat structures such as logs increase pool volume and adult trout abundance in small headwater streams (Jones and Daniels 2008, White et al. 2011). Conversely, unstable habitat conditions may lead to reduced genetic structure and increased migration rates (Østergaard et al. 2008). Therefore, in suitable habitats with the absence of rare catastrophic events, it stands to reason that adult Brook Trout populations would be maximized under spatiotemporal stability of key habitat features such as pools.

In 2003, West Virginia University began a long-term study of Brook Trout populations and habitat on 25 headwater streams in central Appalachia. Annual fish and habitat surveys on these streams form the basis for evaluating the role of pool habitat and its stability upon Brook Trout populations. This period captured Superstorm Sandy, and other formidable hydrological events. The objective of this paper is to explore relationships between pool habitat stability and Brook Trout populations. By using a linear mixed model approach, we expected to find that pool stability impacted spawning aged fish abundances; and recruit abundances impacted by previous year spawning effort.

\section{Methods}

\section{$\underline{\text { Data Collection }}$}

The long-term dataset comes from an ongoing study using 25 West Virginia headwater (mean drainage area $=7.9 \mathrm{~km}^{2}$ ) streams. Study area is composed of 25 stream segments with a high-degree of variability in characteristics that is representative of Central Appalachian headwater systems with self-sustaining Brook Trout populations. The 25 segments are located throughout the Monongahela National Forest with a few on privately owned land, and distributed among six HUC-10 watersheds (Cranberry River, Deer Creek of Greenbrier River, Dry Fork, Middle Fork, North Fork of South Branch of the Potomac River, and the Elk River). All sites are defined as small, cold, headwater tributaries that consist of typical fish assemblages of this stream type in Appalachia.

Surveys on these locations included habitat properties (spawn gravel and area) and Brook Trout population parameters (age 0 and spawner abundances) continuously from 2010 through 2017. Habitat was assessed using a modified basin-wide visual estimation technique (BVET, Hankin and Reeves 1988). 
Habitat surveys were done during low flow conditions (June-October), and did not include GPS coordinates of specific coordinates of pool habitat. However, these survey points did include distance traveled along the thalweg from benchmarked starting locations between years. This allowed for digitization of each year's pool habitat location using distance traveled from starting point to each habitat unit. Digitized points were doubled checked with distance traveled from the previous pool habitat and assumed a pool within $10 \mathrm{~m}$ of any previous year pool was the same pool. This allowed for both segmentand basin-wide analysis influence on Brook Trout abundances. In order to achieve this number of stable pools found throughout the study, each pool had to be present throughout the study period. These collected events were then subtracted from current year pool number [Collected Events- year(N)]. This value gave each year's habitat additions or losses relative to overall stable habitat. Additionally, pool change [year(N)-year(N-1)] and spawn gravel change [SpawnGravel(Year+1)-SpawnGravel(Year)] were used as an underlying lagged variable effect on population dynamics.

Fish population surveys were conducted October through November each year, in all study reaches. These fish were collected using backpack electro-shocker and a standard three pass removal techniques. All Brook Trout captured were measured in total length $( \pm 1 \mathrm{~mm})$ and weighed $( \pm 0.1 \mathrm{~g})$, then differentiated between recruits (age 0 ), age 1 , and age 2 and older (spawners) based on length-frequency histograms. These categorizations were validated using scale-aging techniques (Devries and Frie 1996, Stolarski 2007, Hakala and Hartman 2004). Age 1 Brook Trout have inadequate levels of hormones to reach maturity during the prime spawning window (Schafhauser and Benfey 2001). While some age 1 Brook Trout demonstrate sexual maturity, they were not considered in the scope of spawning adults due to timing of sexual 'ripeness', inconsistency along population gradient, and size-specific competition with older Brook Trout (Hutchings 1994).

\section{$\underline{\text { Analytical }}$}

Analysis of the influence of pool habitat on adults and recruitment were done at two different spatial scales. A fine-scale analysis restricted habitat stability and quantity only within the same $100 \mathrm{~m}$ reaches where fish population surveys were done (three $100 \mathrm{~m}$ reaches per stream). Thus, in the first analysis fish numbers were exact measures instead of stream wide estimations to capture potential spawning selection and movement (Reach). The second spatial scale used basin-wide habitat data in comparison with Brook Trout population and recruitment estimates for analysis (Site). Here, stream-wide estimates were done using pool deviation from mean stable habitat [Collected Events- Year(N)]. Both analyses also looked at yearly changes in spawning gravel to determine impact on current and future recruitment. 
Using the pool stability and spawning gravel change this study sought to understand whether spawner abundances and juvenile recruitment were influenced by key habitat units like pool numbers or pool quality. In order to achieve this, linear mixed effect models (LME) and analysis of variation models were used in both reach and stream wide estimations. Linear mixed effects allow for analysis of the nonindependence in the repeated random effects (year, site and reach) to be teased apart from the various fixed effects (pool stability, spawn gravel change, nearest neighbor, lagged spawner abundance, recruit abundance). Since pool variables and population responses were taken yearly and in the same location, we needed to assign random error produced by the random effects of year/site/reach. These baseline models gave an intercept for a particular response variable [i.e. Spawners $=(1 \mid$ Year $)+(1 \mid$ Site $)+$ Residual Error]. For the second spatial scale, we added the nested random value of Reach ([.e Spawners $=(1$ | Year)+(1| Site/Reach)+Residual Error], to account for potential of movement restrictions or site selection in the study. Nearest Neighbor and pool stability were not used in the nested reach analysis due

to inability to conduct spatial analysis with the few pools located within each reach. Pool change was used here to highlight year to year fluctuations in pool number at the reach level.

The interest of the study was on the habitat variables (fixed effects) impact on both spawner and recruit abundances. These additional models were generated by stepwise addition of the fixed effects [i.e. Spawners $=$ PoolChange $+(1 \mid$ Year $)+(1 \mid$ Site $)+$ Residual Error $]$. The intercept generated from the addition of a fixed effect could then be compared to the intercepts of the random effects influence of the response variables. Fixed effects then became predictors of abundances by testing changes in the likelihood of the models with or without the factor of interest. The comparison of the fixed effects and random effects additive or non-additive effects on model fit, we employed likelihood ratio tests using analysis of variance (ANOVA). Restricted maximum likelihood (REML) was used as default parameter as it is less biased than maximum likelihood fitted models. A significant $(\mathrm{p}<0.05)$ divergence between the models would indicate a non-additive impact the fixed effect (i.e. pool change) had on intercept of response variables (i.e. spawners).

\section{Results}

\section{Stream level}

Stream wide analysis indicated pool stability and quality through time impacted spawner abundances. At the stream wide level pool stability and spawning area impacted adult abundances, but did not directly impact recruit abundance. The variety of analysis and difference in significant results can be found in Table 3. Deviation from stable habitat impacted spawning aged fish abundances $(\chi 2=0.294, \mathrm{p}<2.2 \mathrm{e}-16)$, directionally affecting spawner abundances by $0.114( \pm 0.069)$ per each pool deviation from stable pool 
mean (ie., an increase in 10 pool units yields 1.14 additional adult Brook Trout). Spawning gravel area between years impacted spawner abundances at the stream wide level $(\chi 2=7.761, p=0.005)$ increasing spawner abundances by $0.054( \pm 0.0234)$ individuals per square meter of spawning gravel change.

Therefore, an increase in spawning area of 18.52 square meters results in addition of 1 adult spawner. Distance between pools is suggested to have a weak impact on spawner abundances $(\chi 2=2.746, p=0.097$. Nearest neighbor interaction with spawning area $(\chi 2=3.186, \mathrm{p}<0.203)$ and pool stability $(\chi 2=2.89 \mathrm{p}<$ 0.235 ) did not impact spawner abundances. Previous year spawners significantly impacted spawner abundance when accounting for pool stability as random effect $(\chi 2=3.725, p=0.031)$, increasing spawners by 1.7 individuals $( \pm 0.15)$ per $\mathrm{km}$ of stream. When pool stability was not considered in the model, previous year spawners did not significantly impact spawner abundances $(\chi 2=2.23, \mathrm{p}=0.135)$.

Recruit abundances were driven more by number of spawners than by pool habitat features. Recruit abundances were not impacted by pool stability $(\chi 2=1.45, \mathrm{p}=0.222)$, nearest neighbor $(\chi 2=0, \mathrm{p}=1.0)$ or spawning gravel change $(\chi 2=0, p=1.0)$. However, recruit abundances were impacted by previous year spawner abundances $(\chi 2=8.260, \mathrm{p}=0.041)$, increasing recruitment by $3.24( \pm 1.40)$ individuals per $\mathrm{km}$.

Table 3: Significance test of each fixed effect model compared against null models (random effects) at basin wide scale for abundance of spawner or recruit Brook Trout. Significance levels of likelihood ratio test: green $(p<0.05)$, yellow $(p<0.10)$, and unfilled $(p>0.10)$.

\begin{tabular}{|c|l|l|}
\hline Fixed Effects & Spawner & Recruit \\
\hline Pool Stability & & \\
\hline Spawning Area & & \\
\hline Nearest Neighbor & & \\
\hline Pool Area & & \\
\hline Lagged Spawner & & \\
\hline Pool Stability*Lagged Spawner & & \\
\hline Lagged Spawning Area*Lagged Spawner & & \\
\hline Pool Stability*NN*Spawn Area & & \\
\hline Nearest Neighbor *Spawning Area & & \\
\hline Nearest Neighbor * Pool Stability & & \\
\hline
\end{tabular}



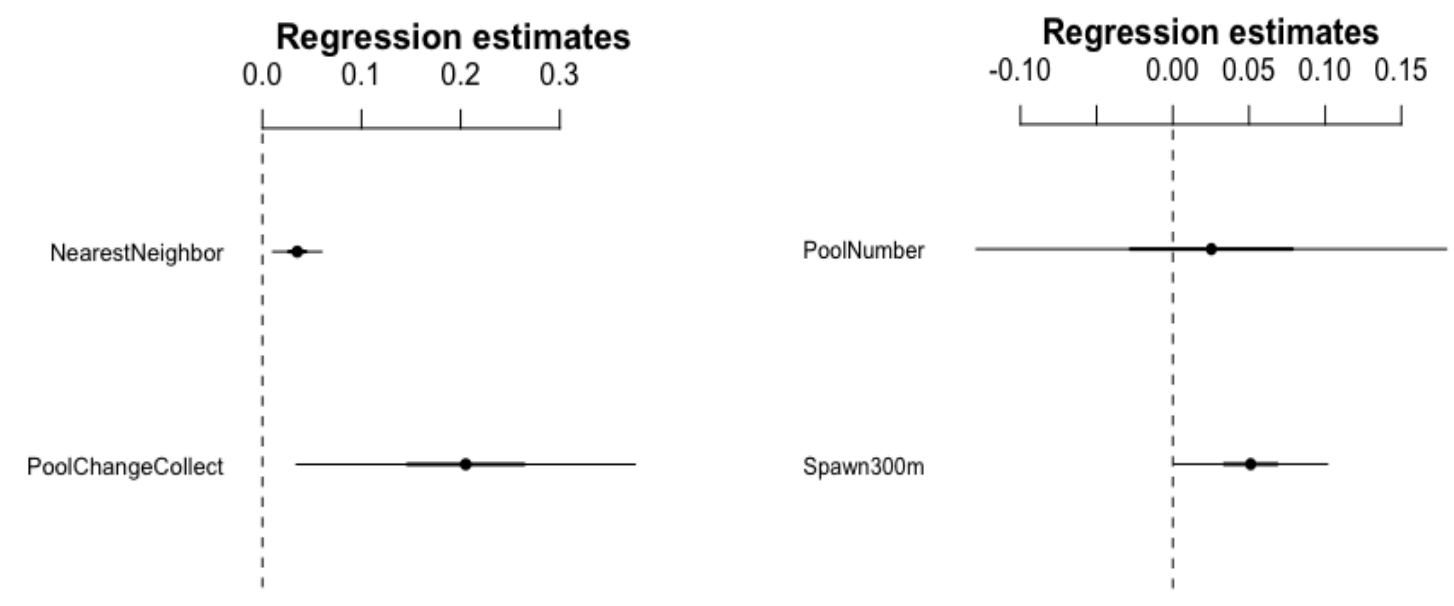

Figure 14- Coefficient plots showing variables importance on response variable. Left shows importance of Nearest Neighbor (distance between pools) and Pool Change Collect (deviation from stable pools through study) impact on Spawner abundances. Right shows simple pool number and Spawning gravel area per 300 meters impact on Spawner number. The vertical dashed line represents the threshold of significance. 


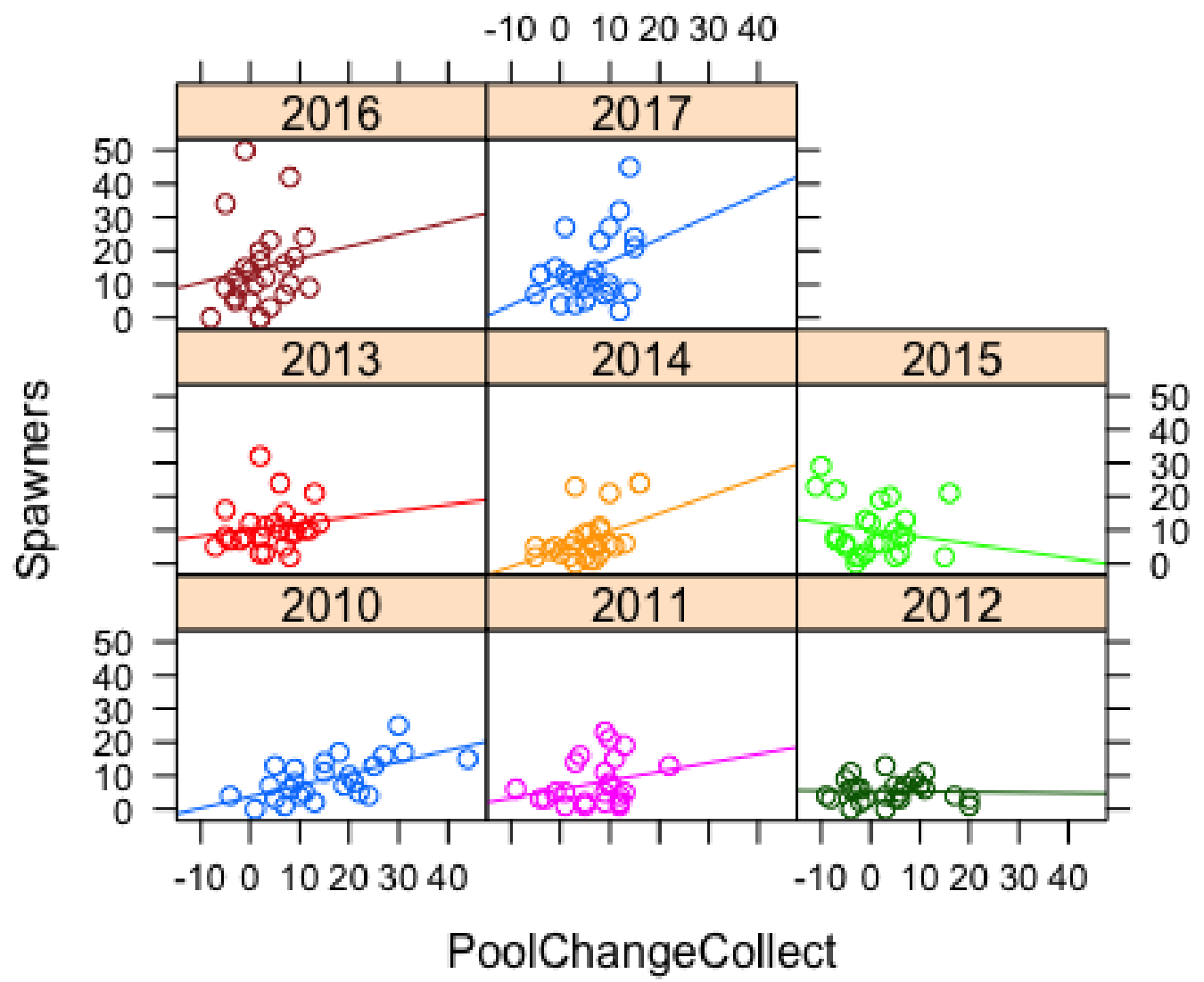

Figure 15- Plots of Spawner abundance response to yearly deviation from stable pool habitat (PoolChangeCollect). Illustrating the unique patterns that persist amongst each random year. 


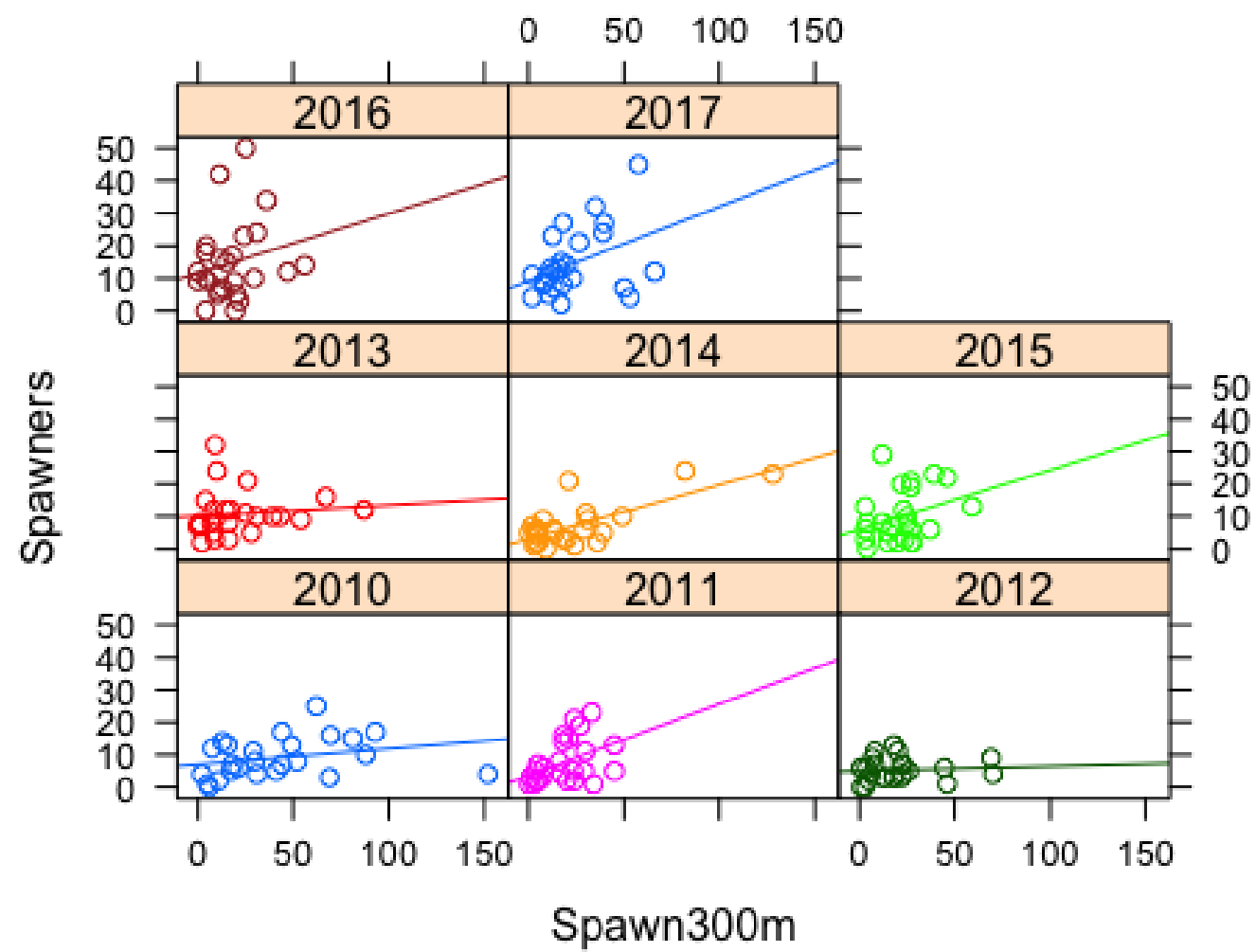

Figure 16- Plots of Spawner abundance response to spawning gravel per 300 meters (Spawn300m). Each box accounts for the random effect that year had on Spawner abundances relating to fixed affect (Spawn Gravel area per $300 \mathrm{~m})$.

\section{Reach level}

At the reach level, similar relationships between pool stability and adult Brook Trout were observed, but new relations between recruits and pools emerged (Table 4). Year-to- year pool habitat change affected Brook trout spawner abundances $(\chi 2=9.041, p=0.029)$, increasing it by 0.161 spawners per 100 meters with no change in pool number $( \pm 0.46$ Brook Trout.), and 0.682 spawners per 100 meters with positive change ( +0.51 Brook Trout). Additionally, overall pool number within reach among years affected spawner abundances $(\chi 2=9.017, \mathrm{p}=0.003)$ by 0.598 Brook Trout per 100 meters $( \pm 0.19$ Brook Trout $)$. Spawning gravel change did impact spawning age Brook trout $(\chi 2=16.181, \mathrm{p}=2.2 \mathrm{e}-16)$, increasing spawning aged fish $0.17( \pm 0.04)$ Brook Trout per 100 meters. Recruit abundances were not impacted by temporal pool change $(\chi 2=3.926, \mathrm{p}=0.140)$; but were impacted by overall pool number $(\chi 2=6.324$, $\mathrm{p}=0.011)$, decreasing recruit abundances by 0.437 recruits $( \pm 0.748)$ per 100 meters. Decreases in 
spawning habitat decreased recruit abundances $( \pm 0.04$ bkt per 100 meters $)$, while a negative change in pool habitat and current year spawner abundances significantly impacted recruit abundances $((\chi 2$ $=64.257, \mathrm{p}=6.118 \mathrm{e}-12)($ Figure 17)

Table 4: List of fixed effect models tested against null models (random effects) at reach scale. Significance levels of likelihood ratio test: green $(p<0.05)$, yellow $(p<0.10)$, and unfilled $(p>0.10)$.

\begin{tabular}{|c|l|l|}
\hline Fixed Effects Include in Mixed Model & Spawner & Recruit \\
\hline Pool Change & & \\
\hline Pool Number & & \\
\hline Spawn Gravel Change & & \\
\hline Pool Change*Spawn Gravel Change & & \\
\hline Lag Spawners*Spawn Gravel Change & & \\
\hline
\end{tabular}

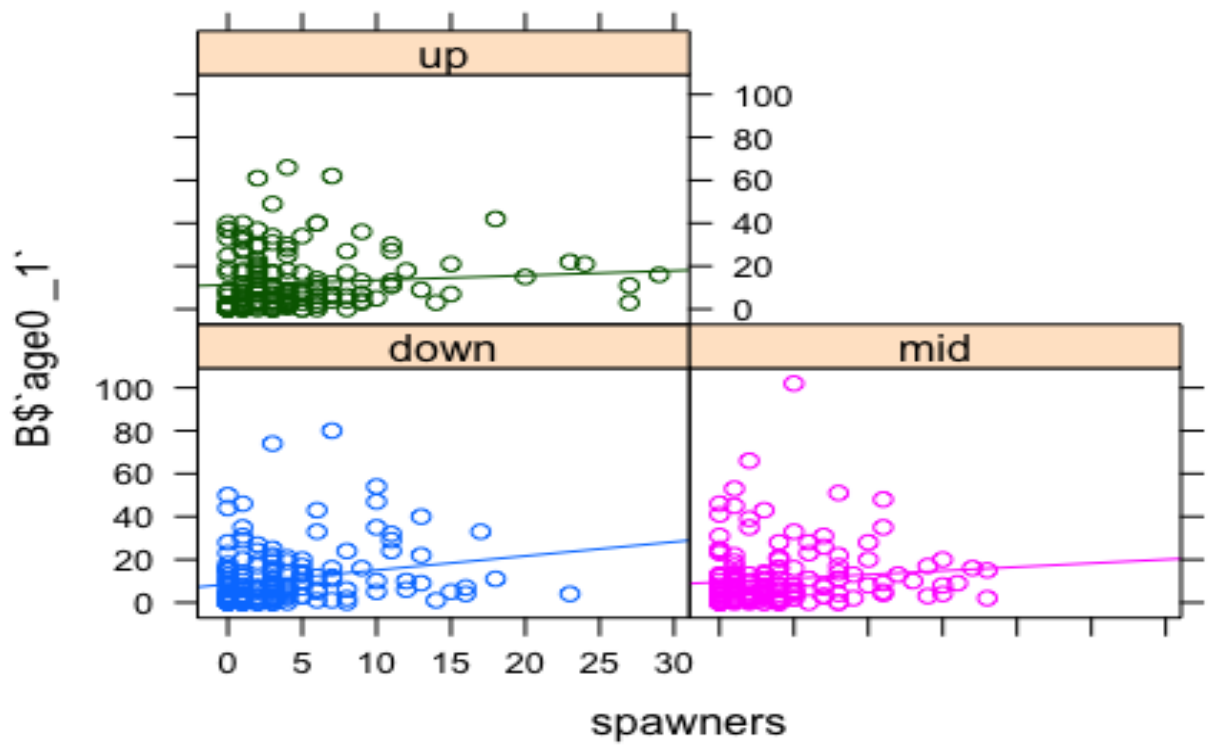

Figure 17- Plot of lagged recruit abundances (next year recruits, B\$'age0_1') response to Spawner abundances by reach. This plot has reach as random effect and Spawner abundances as fixed effect. This analysis was derived at reach level with assumption recruits have negligible movement distances. 


\section{Interaction Plot}

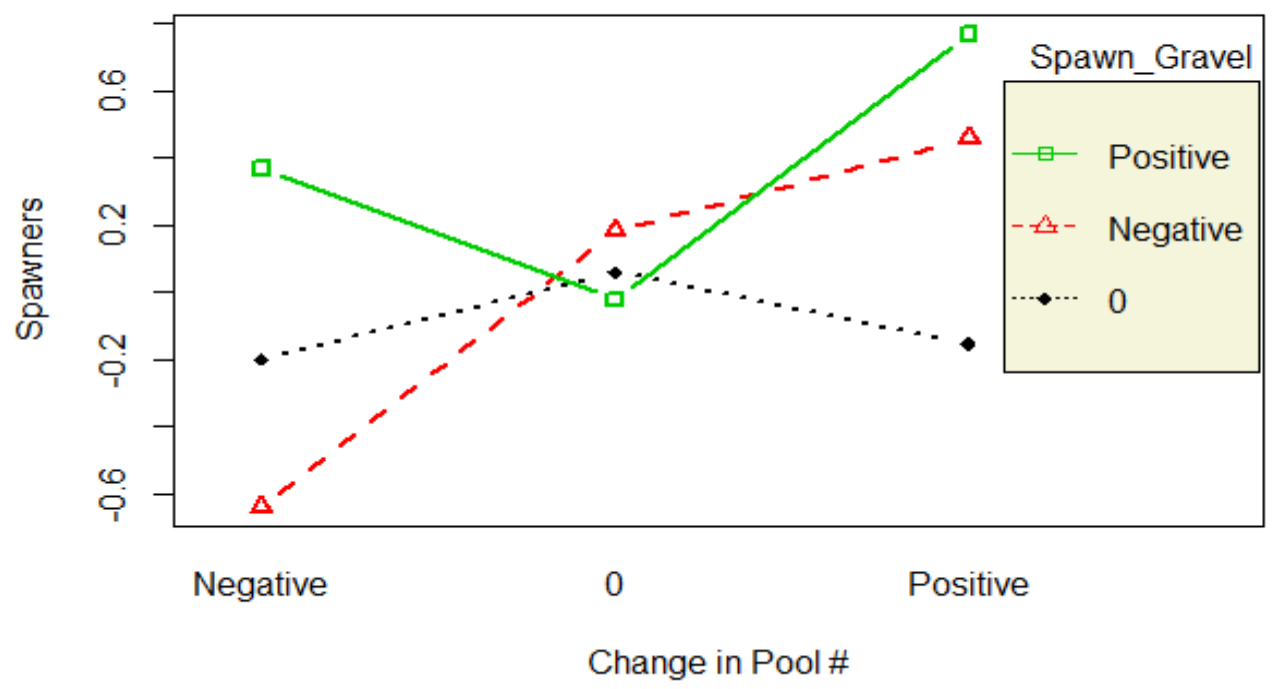

Figure 18- Interaction plot of the 2-way Anova result. Interaction of pool habitat change and spawn gravel change impact on spawning age fish abundances. Green line represents positive changes in spawn gravel, while red line corresponds to negative changes in spawn gravel. Black line is no change in spawn gravel. The $\mathrm{X}$ represents the categorical change in Pool Number per year. The significance shows in the neutrality of the black line, additionally the high degree of change in observed when both variables are experienced negative/positive change.

\section{Discussion}

Pools have been demonstrated to be important to Brook Trout as refugia during floods and droughts (Caroline and McCullough 2003, Hakala and Hartman 2004, Petty et a. 2012), and additionally functioning as spawning and nursery areas (Petty et al. 2005, Kanno et al. 2012, Kanno et al 2016). However, little work has focused on how stability of this critical habitat may influence populations. Given that Hakala and Hartman (2004) found pool area to be critical to the survival of adults during and following drought, it follows that resistance and resilience of these populations is linked to pools and their stability. Therefore, we hypothesized stability of critical pool habitat should lead to increased resistance and resilience, or stability of Brook Trout populations. Our results support this "stable habitat hypothesis."

This study demonstrated the impacts habitat stability had on Brook trout abundances. Increases in spawning aged trout were found when no or positive changes occurred in stable pool habitat (Figure 18). This would suggest that spawning aged fish are either staying in pools that are "stable" between years, or 
are moving into these areas. The opposite is true when these pool units are not available, causing the spawning aged fish to move into other reaches or streams. Additionally, spawning area directs spawner abundances and is potentially the limiting factor in recruitment at a specific adult density (Figure 17). Figure 18 seems to show a level of saturation in spawner abundances (10-15) per $100 \mathrm{~m}$ that directs recruit abundances. The interaction of spawn area and pool stability likely is the most important for healthy population dynamics, however pool stability alone directionally impacts spawner abundances greater than spawn area.

The response of recruits was not directly related to pool stability; however next year recruits were related to spawning aged fish and spawn habitat. These results were found on both reach- and stream-level analysis. This lagged impact may be due to spawning effort, and seems to highlight a carrying capacity related to recruitment at roughly 10-15 spawners per $100 \mathrm{~m}$ (Figure 17). This highlights an indirect impact that pool stability and spawn area has on population dynamics. However, it could be deduced that increases in resident spawning aged fish will decrease recruitment abundances due to density-dependence and predation (Elliot 2000, Hakala and Hartman 2004, Petty 2012, Bassar et al. 2016, Kanno et al. 2016). Our results confirm this density-dependence and predation due to the recruit abundances being negatively impacted by pool number and spawner abundances occurring that year. Additionally, other environmental variables (droughts and floods) are directly driving recruit abundances (Hakala and Hartman 2004,LobonCervia 2009, Warren and Baldigo 2009, Kanno et al. 2012, Kanno et al. 2016)

The effects of climate change are not limited to changes in temperature in streams, but precipitation may be affected which can affect habitat. Overall precipitation is projected to increase in Appalachian systems (Webb et al. 2007, Hayhoe et al. 2008, McCullough et al. 2011, Wenger et al. 2011, Doll and Schmied 2012, IPCC 2014, Kovach et al. 2016), this additional precipitation is suggested to buffer the thermal impacts of a changing climate (Papadiki et al. 2016, Merriam et al. 2017). However, the timing and magnitude of this increase in precipitation could drastically impact recruitment (Lobon-Cervia 2009, Warren and Baldigo 2009, Kanno et al. 2015, Kanno et al. 2016). Additionally, the increase in flood and drought probabilities will impact survivorship (Caroline and McCullough 2003, Meyers et al. 2009). However, high gradient stream fish populations are suggested to rebound quickly due to historic instability of these systems (Reice et al. 1990, Roghair et al. 2002). This evolutionary adaptation to instability could be negligible if these catastrophes continue to diminish and isolate pool habitat, leaving high probability of extirpation.

Particular systems can see higher rates of large woody debris in the system with increases in flooding (Andrew and Hartman 2014), which should increase pool formation and thus pool stability. However, this wood loading is not uniform and extreme events have been suggested to diminish large woody debris 
from riparian area, which could take decades for suitable large woody debris inputs to be generated (Hornbeck and Kochenderfer 2000).

Although we found a relationship between pool stability and age class abundances, our results represent only a snapshot of population and habitat parameters on these streams during separate seasons. Habitat surveys were taken during low flows in summer and most closely represent conditions for resident trout. Fish surveys were completed in the fall when some adult fish may be returning to headwater streams to spawn and therefore inflate adult numbers in those areas with high spawning habitat. Similarly, the relationship between stability in spawner abundances may reflect the reliance of pool tails for spawning and redd construction. The analysis was also limited by the assumption that no barriers exist. Seasonal and permanent barriers are certain to exist in these systems, or highly limit mobility (Lonzarich et al. 2002, Poplar-Jeffers et al. 2009, Petty et al. 2012). To adequately solve the questions associated with spatial and temporal habitat stability, additional habitat and fish measures need to be taken through various seasons and flows during the preceding years. Ideally, on habitat measures taken during each season, and at least one additional fish measure taken during spring. These measures would allow for more predictive habitat versus flow models to be generated, as well as flushing out temporal habitat stability and its impact on brook trout dynamics. This could also give more insight into seasonal habitat loss and overall population stability tracked by changes in seasonal and yearly habitat availability.

Previous studies have highlighted population fluctuations caused by food availability, density dependence, flooding, and movement (Hakala and Hartman 2004, Wenger et al. 20011, Petty et al. 2012, Kanno et al. 2014, Petty et al. 2014, Bassar et al. 2016, Kanno et al. 2016). However, very few studies have looked into critical habitat stability between years as a variable driving population dynamics. Simply having large amounts of woody materials in a stream will not maximize Brook Trout population stability and resilience if the habitat itself is not stable. Previous studies by (Sweka and Hartman 2006, Stolarski 2007, Sweka et al. 2010, Andrew and Hartman 2014, Studinski et al. 2017) have shown that adding large wood to streams haphazardly does little to increase pool habitat or stability. In those studies, adding large wood resulted in new pool formation with low stability, and at the expense of other pools. While the results of our study suggest stable pool habitat is related to stable Brook Trout populations, strengthening the "stable habitat hypothesis" could help managers strategically identify and restore streams that are less prone to generate stable habitat, identify stable source populations, or target reaches within a stream to maximize restoration efficiency. Further research is needed to develop baselines and target stable pool habitat metrics to guide habitat restoration efforts for Brook Trout and potentially other trout species. 


\section{References}

\section{Chapter 1}

Abbe, T.B. 2000. Patterns, mechanics and geomorphic effects of wood debris accumulations in a forest river system. PhD dissertation, University of Washington, Seattle

Andrew, R.G. and K.J. Hartman. 2014. Uneven inputs of woody debris in Appalachian streams from superstorm Sandy. Canadian Journal of Fisheries and Aquatic Sciences 72:1-6.

Andrews, E.D. 1979. Scour and fill in a stream channel, East Fork River, Western Wyoming. US Geological Survey Professional Paper 1117.

Bassar, R.D., Letcher B.J., Nislow K.H., Whiteley A.R. 2016. Changes in seasonal climate outpace compensatory density-dependence in eastern brook trout. Global Change Biology 22: 577-593.

Bayard, T.S. and C.S. Elpick. 2010. Using Spatial point-pattern assessment to understand the social and environmental mechanisms that drive avian habitat selection. The AUK 127:485-494

Beechie. T.J., Pess G, Kennard P, Bilby RE, Bolton S. 2000. Modeling recovery rates and pathways for woody debris recruitment in northwestern Washington streams. North American Journal of Fisheries Management 20: 436-452.

Bilby, R.E., Ward J.W. 1991. Characteristics and function of large woody debris in streams draining oldgrowth, clear-cut, and secondgrowth forests in southwestern Washington. Canadian Journal of Fisheries and Aquatic Sciences 48: 2499-2508.

Bisson, P.A, Nielsen J.L, Palmason R.A, and Grove L.E. 1982. A system of naming habitat types in small streams, with examples of habitat utilization by salmonids during low streamflow. In Proceedings of a Symposium on Acquisition and Utilization of Aquatic Habitat Inventory Information. AFS, Western Division: Portland, OR; 62-73.

Bisson, P.A, Bilby R.E, Bryant M.D, Dolloff A.C, Grette G.B, House R.A, Murphy M.L, Koski K.V, and Sedell J.R. 1987. Large woody debris in forested streams in the Pacific Northwest: Past, present, and future. In Streamside Management: Forestry and Fishery Interactions,University of Washington, Institute of Forest Resources: Seattle, WA; 143-190

Braudrick, CA, Grant GE. 2000. When do logs move in rivers? Water Resources Research 36: 571-584.

Buffington, J.M, Lisle, T.E., Woodsmith, R.D., and Hilton, S. 2002. Controls on the size and occurrence of pool in coarse-grained forest rivers. River Research and Applications 18:507-531

Carline, R.F. \& McCullough B.J. (2003) Effects of floods on brook trout populations in the Monongahela National Forest, West Virginia. Transactions of the American Fisheries Society, 132, 1014-1020.

Carling, P.A. 1988. Channel change and sediment transport in regulated U.K. rivers. Regulated Rivers: Research and Management 2: 369-387

Clark, M.E., Rose K.A., Levine D.A.,Hargrove W.W. 2001. Predicting climate change effects on Appalachian trout: combining GIS and individual based modeling. Ecological Applications, 11: $161-178$.

Comte, L., Buisson L., Daufresne M., Grenouillet G. 2013. Climate-induced changes in distribution of freshwater fish: observed and predicted. Freshwater Biology 58, 625-639. 
Davis, J.M., C.V. Baxter, E.J. Rosi-Marshal, J.L. Pierce, B.T. Crosby. 2013. Anticipating stream ecosystem responses to climate change: toward predications that incorporate effects via landwater linkages. Ecosystems 16, 909-922.

Dolloff, C.A., Flebbe, P.A., and Owen, M.D. 1994. Fish habitat and fish populations in a southern Appalachian watershed before and after Hurricane Hugo. Transactions of the American Society. 123: 668-678.

Elliott, J.M. 2006. Periodic habitat loss alters the competitive coexistence between brown trout and bullheads in small stream over 34 years. Journal of Animal Ecology.75,54-63.

Elwood, J. W., and T. E Waters. 1969. Effects of floods on food consumption and production rates of a stream brook trout population. Transactions of the American Fisheries Society 98:253-262.

Emmett, W.W. and Wolman M.G. 2001. Effective discharge and gravel-bed rivers. Earth Surface Processes and Landforms 26:13 Special Issue:Sediment Transport Dynamics 1369-1380

Fausch, K.D., Hawkes C.L., Parsons M.G. 1988. Models that predict standing crop of stream fish from habitat variables: 1950-1985. USDA Forest Service. General Technical Report PNW-213.

Fausch, K.D., C.E. Torgersen, C.V. Baxter, and H.W. Li. 2002. Landscapes to riverscapes: Bridging the gap between research and conservation of stream fishes. BioScience 52:483-498

Ficke, A.D., Myrick C.A. Hansen L.J. 2007. Potential impacts of global climate change on freshwater fisheries. Reviews Fisheries Biology, 17:581-613.

Flebbe, P.A., L.D. Roghair, J.L. Bruggink. 2006. Spatial modeling to project southern Appalachian trout distributions in a warmer climate. Transactions of the American Fisheries Society $135: 1371-1382$

Frumhoff, P., McCarthy J., Melillo S., Moser S., Wuebbles D. 2006. Climate change in the US Northeast. Union of Concerned Scientists. Foundation for Assessing the Impact of Our Changing Climate. AGU Fall Meeting Abstracts.

Grossman, G.D., Ratajczak R.E., Wagner C.M., Petty J.T. 2010. Dynamics and regulation of the southern brook trout population in an Appalachian stream. Freshwater Biology.55:1494-1508.

Haak, A.L., J.E. Williams, H.M. Neville, D.C. Daulwatler, W.T Colyer. 2011. Conserving peripheral trout populations:The values and risks of life on the edge. Fisheries 35:530-549.

Hakala, J.P., and K.J. Hartman. 2004. Drought effect on stream morphology and Brook trout populations in forested headwater streams. Hydrobiologia 515:203-213.

Hankin, D.G., and Reeves, G.H. 1988. Estimating total fish abundance and total habitat area in small streams based on visual estimation methods. Canadian Journal of Fisheries Science 834-844. doi:10.1139/f88-101.

Hartman, K.J., Cox, K.M. 2008. Refinement and testing of brook trout bioenergetics model. Transactions of the American Fisheries Society. 137: 357-363.

Hartman,G.F., J.C. Scrivener, and M.J. Miles. 1994. Impacts of logging in Carnation Creek, a highenergy coastal stream in British Columbia, and their implications for restoring fish habitat. Canadian Journal of Fisheries and Aquatic Sciences 53:237-251

Hayhoe, K., C. Wake, B. Anderson, X. Liang, E. Maurer, J. Zhu, J. Bradbury, A. DeGaetano, A. Stoner, and D. Wuebbles .2008., Regional climate change projections for the northeast USA, Mitigation Adaptations and Strategies Global Change 13: 425436. 
Hedman, C.W., Lear, D.H.V., and Swank, W.T. 1996. In-stream large woody debris loading and riparian forest seral stage associations in the southern Appalachian Mountains. Canadian Journal of Foresty Management 26: 1218-1227. doi:10.1139/x26-136.

Herger, L.G., W.A. Hubert, and M.K. Young. 1996. Comparison of habitat composition and cutthroat trout abundance at two flows in small mountain streams. North American Journal of Fisheries Management 16:294-301

Hilderbrnad, R.H., A.D. Lemly, and C.A.Dolloff. 1999. Habitat sequencing and the importance of discharge in inferences. North American Journal of Fisheries Management 19:198-202.

Hudy, M., Thieling T.M., Gillespie N., Smith E.P. 2008. Distribution, Status, and Land Use characteristics of subwatersheds within the Native Range of brook trout in the Easter United States. North American Journal of Fisheries Management 28: 1069-1085

Huryn, A.D., Wallace JB. 1987. Local geomorphology as a determinant of macrofaunal production in a mountain stream. Ecology 68: 1932-1942.

IPCC. 2007. Climate Change 2007: Working Group 2: Impacts, Adaptation and Vulnerability (Intergovernmental Pan on Climate Change, Geneva).

IPCC. 2014. Climate Change 2014: Summary for Policymakers. Climate change 2014: Impacts, Adaptation, and Vulnerability. Fifth Assessment Report of the Intergovernmental Panel of Climate Change, Cambridge University Press, Cambridge, UK and New York, NY.

Jager, H.I, W, VanWinkle, and B.D. Holcomb. 1999. Would hydrologic climate changes in Sierra Nevada streams influence trout persistence? Transactions of American Fisheries Society 128:222-240.

Jones, T.A., and Daniels, L.D. 2008. Dynamics of large woody debris in small streams disturbed by the 2001 Dogrib fire in the Alberta foothills. Forest Ecology Management 256:1751-1759.

Kanno, Y., Vokoun J.C. and Letcher B.H. .2011. Fine-scale population structure and riverscape genetics of brook trout (Salvelinus fontinalis) distributed continuously along headwater channel networks. Molecular Ecology 20:3711-3729.

Kanno, Y., Vokoun J.C., Holsinger K.E. and Letcher B.H. 2012. Estimating size-specific brook trout abundance in continuously sampled headwater streams using Bayesuan mixed models with zero inflation and overdispersion. Ecology of Freshwater Fishes, 21:404-419.

Kanno, Y., Pregler K.C., Hitt N.P., Letcher B.H., Hocking D.J., Wofford J.B. 2016. Seasonal temperature and precipitation regulate brook trout young-of-the-year abundance and population dynamics. Freshwater Biology 61:88-99

Kirchner, J.W., Finkel R.C., Riebe C.S., Granger D.E., Clayton J.L, King J.G, Megahan W.F. 2001. Mountain erosion over 10yr, 10k.y, and 10 m.y. time scales. Geology 29:7, 591-594.

Koizumi, I., Kanazawa Y. and Tanaka Y. 2013. The Fisherman were right: experimental evidence for tributary refuge hypothesis during floods. Zoological Science. 30: 375-379.

Kundzewicz, Z.W. and Radziekewski M. 2006. Methodologies for trend detection. Climate Variability and Change-Hydrological Impacts. Proceedings of the Fifth World Conference held at Havana, Cuba, November 2006 
Lamberti, G. A., S. V. Gregory, L. R. Ashkenas, R. C. Wildman, and K. M. S. Moore. 1991. Stream eccosystem recovery following a catastrophic debris flow. Canadian Journal of Fisheries and Aquatic Sciences 48: 196-208.

Letcher, B.H., Schueller P., Bassar R.D., Nislow K.H.,Coombs J.A., and Sakrejda K. 2015. Robust estimates of environmental effects on population vital rates: an integrated capturerecapture model of seasonal brook trout growth, survival and movement in a stream network. Journal of Animal Ecology: 84, 337-352.

Lisle, TE. 1986a. Effects of woody debris on anadromous salmonid habitat, Prince of Wales Island, southeast Alaska. North American Journal of Fisheries Management 6: 538-550

Lobon-Cervia, J.2009b. Why, when and how do fish populations decline, collapse and recover? The example of brown trout (Salmo trutta) in Rio Chaballos (northwesternSpain). Freshwater Biology 54:1149-1162.

Lonzarich, D.G., M.R. Lonzarich, and M.L. Warren, Jr. 2000. Effects of riffle length on the short-term movement of fishes among stream pools. Canadian Journal of Fisheries and Aquatic Sciences. 57:1508-1514.

Lytle, D.A, Poff N.L. 2004. Adaptation to Natural Flow Regimes. Trends in Ecology and Evolution 19:94-100

Maathius. B.H.P., and L. Wang. 2006. Digital elevation model-based hydro-processing. Geocarto International 21: 21-26.

Mao L. and Lenzi M.A. 2006. Sediment mobility and bedload transport conditions in an alpine stream. Hydrological Processes 21:1882-1891

Merriam, E.R., Fernandez R., Petty T.J., and Zegre N. 2017. Can brook trout survive climate change in large rivers? If it rain. Science of the Total Environment 1225-1236

Meyers, E.M., Dobrowski B., Tague C. 2013. Climate change impacts on flood frequency, intensity and timing may affect trout species in Sagehen Creek, California. Transactions of American Fisheries Society 139: 1657-1664

Milly, P.C., K.A. Dunne, A.V. Vecchia. 2005. Global pattern of trends in streamflow and water availability in a changing climate, Nature 438:347-350

Montgomery, D.R, Beamer E.M, Pess G.R, Quinn T.P. 1999. Channel type and salmonid spawning distribution and abundance. Canadian Journal of Fisheries and Aquatic Sciences 56: 377-387

Murphy, ML, Koski KV. 1989. Input and depletion of woody debris in Alaska streams and implications for streamside management. North American Journal of Fisheries Management 9: 427-436.

National Marine Fisheries Service (NMFS) 1996. Making ESA determinations of effect for individual or grouped actions at the watershed scale. National Marine Fisheries Service, Environmental Technical Service Division, Habitat Conservation Branch: Portland, OR

Papadaki, C., Soulis K., Munoz-Mas R., Martinez-Capel F., Zogaris S., Ntoadnidis L., and Dimitriou E. 2016. Potential impacts of climate change on flow regime and fish habitat in mountain rivers of the south-western Balkans. Science of Total Environment 540:418-428.

Parmeson, C. Yohe G. 2003. A globally coherent fingerprint of climate change impacts across natural systems. Nature 421: 37-42. 
Pettitt, A.N.1979. A non-parametric approach to the change-point problem. Applied Statistics 28:126135.

Petty, J.T., Hansbarger J.L., Huntsman B.M. and Mazik P.M. 2012. Brook trout movement in response to temperature, flow and thermal refuge within a complex Appalachian riverscape. Transactions of the American Fisheries Society, 141: 1060-1073

Petty, J.T., Lomothe P.J. and Mazik P.M. 2005. Spatial and seasonal dynamics of brook trout populations inhabiting a central Appalachian watershed. Transactions of the American Fisheries Society, 134, 572-587.

Petty, J.T., Thorne D., Huntsman B.M., Mazik P.M. 2014. The temperature-productivity squeeze: constraints on brook trout growth along an Appalachian river continuum. Hydrobiologia 727:15-166.

Pickup, G. and Warner R.F. 1976. Effects of hydrologic regime on magnitude and frequency of dominant discharge. Journal of Hydrology 29:2, 51-75

Poff, N.L., et al. 1997. The natural flow regime. Bioscience 47:769-784.

Propst, D. L., and J. A. Stefferud. 1997. Population dynamics of Gila trout in the Gila River drainage of the southwestern United States. Journal of Fish Biology 51: I 137- I 154.

Radziejewski, M. and Kundzewicz, Z. W. 2004. Detectability of changes in hydrological records. Hydrology Science 49: 39- 51.

Rahel, F.J., C.J. Keleher, and J.L. Anderson. 1996. Potential habitat loss and population regimentation for cold water fish in the North Platte drainage of the Rocky Mountains: response to climate warming. Limnology and Oceanography 41:1116-1123

Rahel, F.J. and Olden J.D. 2008. Assessing the effects of climate change on aquatic invasive species. Conservation Biology, 22:521-533

Ralph, S.C., G.C. Poole, L.L. Conquest, and R.J. Naiman. 2011. Stream channel morphology and woody debris in logged and unlogged basins in western Washington. Canadian Journal Fisheries and Aquatic Science51:37-51

Roberts, J.J., K.D. Fausch, D.P. Peterson, and M.B. Hooten. 2013. Fragmentation and thermal risk from climate change interact to affect persistence of native trout in the Colorado River basin. Global Change Biology 19:1383-1398.

Roghair, C.N., A.C. Dolloff, and M.K. Underwood. 2002. Response of a brook trout population and instream habitat to a catastrophic flood and debris flow. Transactions of the American Fisheries Society 131:718-730.

Rosenzweig, C., KAroly D., Vicarelly M. et al. 2008. Attributing physical and biological impacts to anthropogenic climate change. Nature, 453, 353-U320.

Santiago J.M, Rafeal M., Joaquin S., Diego G., Carlos A., Francisco M., Javier P., Monjo R., Ribalaygua J. 2017. Waning habitats due to climate change: The effects of changes in streamflow and temperature at the rear edge of the distribution of a cold-water fish. Hydrology Earth System Sciences. 21, 4073-4101.

Schrank, A.J. Rahel F.J., Johnstone H.C. 2003. Evaluating laboratory-derived thermal criteria in the field: an example involving Bonneville cutthroat trout. Transactions of the American Fisheries Society, 132:100-109. 
Sullivan K. 1986. Hydraulics and fish habitat in relation to channel morphology. PhD dissertation, Johns Hopkins University, Baltimore, MD.

Swanson, E J., S. L. Johnson, S. V. Gregory, and S. A. Acker. 1998. Flood disturbance in a forested mountain landscape. Bioscience 48:68 1-689.

United States Department of Agriculture (USDA) Forest Service. 1995. Report to Congress: Anadromous fish habitat assessment. USDA Forest Service Report R10-MB-27. Pacific Northwest Research Station, Alaska Region.

United States Department of Agriculture (USDA) Forest Service and United States Department of the Interior (USDI) Bureau of Land Management. 1994. Environmental assessment for the implementation of interim strategies for managing anadromous fish-producing watersheds in eastern Oregon and Washington, Idaho, and portions of California. Washington, DC

Wallace, J.B., Webster J.R., and Meyer J.L. 1995. Influence of log additions on physical and biotic characteristics of a mountain stream. Canadian Journal of Fisheries and Aquatic Sciences 52: 2120-2137.

Warren, D.R., Ernst A.G, and Baldigo B.P. 2009. Influence of spring floods on year-class strength of falland spring-spawning salmonids in Catskill Mountain Streams. Transaction American Fisheries Society 138:200-210

Webb B.W, Nobilis F. 2007. Long-term changes in river temperature and the influence of climatic and hydrological factors. Hydrological Sciences Journal, 52:74-85

Wenger, S.L., Isaak D.J., Luce C.H., Nevile H.M., Fausch K.D., Dunham J.B., Dauwalter D.C., Young M.K., Elsner M.M., Reiman B.E., Hamlet A.F., and Williams J.E. 2011. Flow regime, temperature, and biotic interactions drive differential declines of trout species under climate change. Proceedings of the National Academy of Science, 108: 14175-14180.

Wenger, S.L., Son N.A., Dauwalter D.C., Isaak D.J., Nevile H.M., Luce C.H., Dunham J.B., Young M.K.,Fausch K.D. and Reiman B.E. 2013. Probabilistic accounting of uncertainty in forecasts of species distributions under climate change. Global Change Biology, 19: 3343-3354.

Williams, J.E., Neville H.M., Haak A.L., Coyler W.T., Wenger S.J., Bradshaw S. 2015. Climate change adaptation and restoration of western trout streams: opportunities and strategies. Fisheries, 7:304-317.

Wing, M.G., Keim R.F, Skaugset A.E. 1999. Applying geostatistics to qualify distributions of large woody debris in streams. Computers and Geosciences 25:7, 801-807

Wise, S.M. 2007. Effect of differing DEM creation methods on the results from a hydrological model. Computers and Geosciences 33: 1351-1365.

Wolman, M.G. Miller, J.P. 1960. Magnitude and Frequency of Forces in Geomorphic Processes. The Journal of Geology 68

Vogel, R. M.; Stedinger, J. R.; and Hooper, R. P. 2003. Discharge indices for water quality loads. Water Resour. Res. 39:1273

Vogel, R. M.; Rudolph, B.; and Hooper, R. P. 2005. The probabilistic behavior of water quality loads. J. Environ. Eng. 131:1081-1089. Vogel, R. M.; Stedinger, J. R., and Hooper, R. P. 2003. Discharge indices for water quality loads. Water Resource Research 39:1273 
Young, R.G., Wilkinson J., Hay J., and Hayes J.W. 2010. Movement and mortality of adult brown trout in the Motupiko River, New Zealand: effects of water temperature, flow and flooding. Transactions of American Fisheries Society, 139: 137-146.

Yue, S., Pilon P., and Cavadias G. 2002. Power of the Mann-Kendall and Spearman's rho tests for detecting monotonic trends in hydrological series. Journal of Hydrology 259:1-4, 254-271

Zhang, H, Huang GH, Wang D: Establishment of channel networks in a digital elevation model of the prairie region through hydrological correction and geomorphological assessment. Canadian Water Resource Journal 2013 38:12-23

Zegre, N. 2016. Hydrologic analysis using the dataRetrieval and HydroTSM packages in R. 


\section{Chapter 2}

Andrew, R.G. and K.J. Hartman. 2014. Uneven inputs of woody debris to Appalachian streams from superstorm Sandy. Canadian Journal of Fisheries and Aquatic Science. 72:1-6

Arismendi, I., Safeeq, M., and Johnson, S.L.2013. Increasing synchrony of high temperature and low flow in western North American streams: double trouble for coldwater biota?. Hydrobiologia 712, 61-70

Bassar, R.D., Letcher B.J., Nislow K.H., and Whiteley A.R. 2016. Changes in seasonal climate outpace compensatory density-dependence in eastern brook trout. Global Change Biology 22: 577-593.

Buffington, J.M, Lisle, T.E., Woodsmith, R.D., and Hilton, S. 2002. Controls on the size and occurrence of pool in coarse-grained forest rivers. River Research and Applications 18:6, 507-531

Carline R.F. \& McCullough B.J. 2003. Effects of floods on brook trout populations in the Monongahela National Forest, West Virginia. Transactions of the American Fisheries Society, $132,1014-1020$

Chen F, Du Y, Niu S, Zhao J. 2015. Modeling forest lightning fire occurrence in the Daxinganling mountains of Northeastern China with MAXENT. Forests. 6(12):1422-1438

Clark, M.E., Rose K.A., Levine D.A.,Hargrove W.W. 2001. Predicting climate change effects on Appalachian trout: combining GIS and individual based modeling. Ecological Applications, 11: 161-178.

Clow, D.W. 2010. Changes in the timing of snowmelt and streamflow in Colorado; a response to recent warming. Journal of Climate, 23, 2293-2306.

Comte, L., Buisson L., Daufresne M., Grenouillet G. 2013. Climate-induced changes in distribution of freshwater fish: observed and predicted. Freshwater Biology 58, 625-639.

Convertino, M., Troccoli A., and Catani F. 2012. Detecting fingerprints of landslide drivers:MaxEnt model. Journal of Geophysical Research:Earth Surface 118, 1367-1386

Dilts, T.E. 2015. Stream Gradient and Sinuosity Toolbox for ArcGIS 10.1. University of Nevada Reno. http://www.arcgis.com/home/item.html?id=c8eb4ce1384e45258ccba1b33cd4e3cb

Ehrlen, J. and Morris W.F. 2015. Predicting changes in distribution and abundance of species under environmental change. Ecology Letters 18:3, https://doi.org/10.1111/ele.12410

Elith J, Phillips SJ, Hastie T, Dudík M, Chee YE, Yates CJ. 2011. A statistical explanation of MaxEnt for ecologists. Divers of Distributions. 17:43-57.

Elliott, J.M. 2006. Periodic habitat loss alters the competitive coexistence between brown trout and bullheads in small stream over 34 years. Journal of Animal Ecology, 75: 54-63.

Evans, J.S, Oakleaf J., Cushman S.A., and Theobald D. 2014. An ArcGIS Toolbox for Surface Gradient and Geomorphometric Modeling, version 2.0-0.

Fausch, KD, Hawkes CL, Parsons MG. 1988. Models that predict standing crop of stream fish from habitat variables: 1950-1985. Portland (OR): USDA Forest Service. General Technical Report PNW-213 
Fink, D. B. 2008. Artificial shading and stream temperature modeling for watershed restoration and brook trout (Salvelinus fontinalis) management. Master's thesis. James Madison University, Harrisonburg, Virginia

Flebbe, P.A., L.D. Roghair, J.L. Bruggink. 2006. Spatial modeling to project southern Appalachian trout distributions in a warmer climate. Transactions of the American Fisheries Society 135:1371-1382

Gowan C., and K.D. Fausch. 2002. Why do foraging stream salmonids move during the summer? Environmental Biology of Fishes 64:139-153

Grossman, G.D., Ratajczak R.E., Wagner C.M., Petty J.T. 2010. Dynamics and regulation of the southern brook trout population in an Appalachian stream. Freshwater Biology, 55:1494-1508.

Hakala, J.P., and K.J. Hartman. 2004. Drought effect on stream morphology and Brook trout populations in forested headwater streams. Hydrobiologia 515:203-213

Hankin, D.G., and Reeves, G.H. 1988. Estimating total fish abundance and total habitat area in small streams based on visual estimation methods. Canadian Journal of Fisheries and Aquatic Sciences 45(5): 834-844. doi:10.1139/f88-101.

Hilborn R, Quinn TP, Schindler DE, and Rogers DE. 2003. Biocomplexity and fisheries sustainability. Proc Natl Acad Sci 100:6564-6568

Hitt, N.P., Rogers K.M, Kelly, Z.A., Henesy J., Mullican J.E.2020. Fish life history trends indicate increasing flow stochasticity in an unregulated river. Ecosphere 11:2

Hudy M., Thieling T.M., Gillespie N., Smith E.P. 2008. Distribution, Status, and Land Use characteristics of subwatersheds within the Native Range of brook trout in the Easter United States. North American Journal of Fisheries Management 28: 1069-1085.

IPCC. 2014. Climate Change 2014: Summary for Policymakers. Climate change 2014: Impacts, Adaptation, and Vulnerability. Fifth Assessment Report of the Intergovernmental Panel of Climate Change, Cambridge University Press, Cambridge, UK and New York, NY.

Jager, H.I, W, VanWinkle, and B.D. Holcomb. 1999. Would hydrologic climate changes in Sierra Nevada streams influence trout persistence? Transactions of American Fisheries Society 128:222-240.

Kanno, Y., Vokoun J.C. \& Letcher B.H. 2011. Fine-scale population structure and riverscape genetics of brook trout (Salvelinus fontinalis) distributed continuously along headwater channel networks. Molecular Ecology, 20, 3711-3729.

Kanno, Y., Vokoun J.C., Holsinger K.E. and Letcher B.H. 2012. Estimating size-specific brook trout abundance in continuously sampled headwater streams using Bayesuan mixed models with zero inflation and overdispersion. Ecology of Freshwater Fishes, 21:404-419.

Kanno,Y., Pregler K.C., Hitt N.P., Letcher B.H., Hocking D.J., Wofford J.B. 2016. Seasonal temperature and precipitation regulate brook trout young-of-the-year abundance and population dynamics. Freshwater Biology 61:88-99

Kovach, R.P., Joyce J.E., Echave J.D., Lindberg M.S., and Tallman D.A. 2013. Earlier migration and timing, decreasing phenotypic variation, and bio-complexity in multiple salmonid species. Plos One, 8:1-10. 
Kovach, R.P., Mulhfield C.C., Al-Chokhachy R., Dunham J.B., Letcher B.H., and Kershner J.L. 2016. Impacts of climatic variation on trout: a global synthesis and path forward. Revisions in Fisheries BiologyFisheries, 26: 135-151.

Lawler, J.J. 2009. Climate change adaptation strategies for resource management and conservation planning. Annals New York Academy of Science 1162:79-98.

Letcher, B.H., Nislow K.H., Coombs J.A., O’Donnel M.J., and Dubreuil T.L. 2007. Population response to habitat fragmentation in stream-dwelling brook trout population. Plos One, 2: e1139.

Letcher, B.H., Schueller P., Bassar R.D., Nislow K.H.,Coombs J.A., Sakrejda K.2015. Robust estimates of environmental effects on population vital rates: an integrated capturerecapture model of seasonal brook trout growth, survival and movement in a stream network.Journal of Animal Ecology, 84, 337-352.

Lonzarich, D.G., Warren, M.L., Jr., and Elher-Lonzarich, M.R. 1998. Effects of habitat isolation on the recovery of fish assemblages in experimentally defaunated stream pools in Arkansas. Canadian Journal Fisheries and Aquatic Science 55:2141-2149.

Lonzarich, D.G., Longzarich M.R., Warren Jr. M.L. (2000) Effects of riffle length on the short-term movement of fishes among stream pools. Canadian Journal Fisheries and Aquatic Science 57: 1508-1514.

Luce, C.H., Holden Z.A. 2009. Declining annual streamflow distributions in Pacific Northwest, United States 1994-2006. Geophyscial Research Letters, 36,L16401

Maathius. B.H.P., and L. Wang. 2006. Digital elevation model based hydro-processing. Geo-cartography International 21: 21-26.

McCullough, D.A., Bartholow J.M., Jager H.I., Beschta R.L., Cheslak E.F., Deas M.L., Ebersole J.L., Foott J.S., Johnson S.L., Marine K.R., Mesa M.G., Petersen J.H., Souchon Y., Tiffan K.F., Wurtsbaugh W.A. 2009. Research in thermal biology: Burning questions for coldwater stream fishes. Reviews in Fisheries Science, 17:90-115.

Merow, C., M.J. Smith, and J.A. Silander, Jr. 2013. A practical guide to MaxEnt for modeling species' distributions: what it does, and why inputs and settings matter. Ecography, 36: 1058-1069

Merriam, E.R., Fernandez R., Petty T.J., and Zegre N. 2017. Can brook trout survive climate change in large rivers? If it rains. Science of the Total Environment 1225-1236

Meyers, E.M., Dobrowski B., Tague C. 2013. Climate change impacts on flood frequency, intensity and timing may affect trout species in Sagehen Creek, California. Transactions of American Fisheries Society 139: 1657-1664

Ohlund, G., Nordwall F., Degerman E., Eriksson T. 2008. Life history and large-scale habitat use of brown trout (Salmo trutta) and brook trout (Salvelinus fontinalis)-implications for species replacement patterns. Canadian Journal of Fish and Aquatic Science 65:633-644

Parisien, M-A, Moritz MA. 2009. Environmental controls on the distribution of wildfire at multiple spatial scales. Ecological Monogram. 79(1):127-154.

Papadaki, C., Soulis K., Munoz-Mas R., Martinez-Capel F., Zogaris S., Ntoadnidis L., Dimitriou E. 2016. Potential impacts of climate change on flow regime and fish habitat in mountain rivers of the south-western Balkans. Science of Total Environment 540:418-428. 
Polar-Jeffers, I.O., J.T. Petty, J.T. Anderson, S.J. Kite, M.P. Strager, and R.H. Fortney. 2009. Culvert replacement and stream habitat restoration: Implications from brook trout management in an Appalachian watershed, U.S.A. Restoration Ecology 17:404-413.

Penaluna, B.E, Dunham J.B, Railsback SF.2015. Local Variability Mediates Vulnerability of Trout Populations to Land Use and Climate Change. PLoS One. 2015;10:8.

Petty, J.T., Hansbarger J.L., Huntsman B.M. and Mazik P.M. 2012. Brook trout movement in response to temperature, flow and thermal refuge within a complex Appalachian riverscape. Transactions of the American Fisheries Society, 141: 1060-1073

Petty, J.T., Lomothe P.J. and Mazik P.M. 2005. Spatial and seasonal dynamics of brook trout populations inhabiting a central Appalachian watershed. Transactions of the American Fisheries Society, 134, 572-587.

Petty, J.T., Thorne D., Huntsman B.M., Mazik P.M. 2014. The temperature-productivity squeeze: constraints on brook trout growth along an Appalachian river continuum. Hydrobiologia 727:15-166.

Phillips, S.J, R.P. Anderson, M. Dudík, R.E. Schapire, and M. Blair. 2017. Opening the black box: an open-source release of Maxent. Ecography.

Phillips, S.J, R.P. Anderson, and R.E. Schapire. 2006. Maximum entropy modeling of species geographic distributions. Ecological Modelling, 190:231-259

Rahel, F.J., C.J. Keleher, and J.L. Anderson. 1996. Potential habitat loss and population regimentation for cold water fish in the North Platte drainage of the Rocky Mountains: response to climate warming. Limnology and Oceanography 41:1116-1123

Rahel, F.J. and Olden J.D. 2008. Assessing the effects of climate change on aquatic invasive species. Conservation Biology, 22:521-533

Ralph, S.C., G.C. Poole, L.L. Conquest, and R.J. Naiman. 2011. Stream channel morphology and woody debris in logged and unlogged basins in western Washington. Canadian Journal of Fisheries and Aquatic Science 51:37-51

Rieman, B.E., Isaak D., Adams S., Horan D., Nagel D., Luce C., Meyers D. 2011. Anticipated climate warming effects on Bull trout habitats and populations across the interior Columbia River Basin. Transactions of the American Fisheries Society 13136:1552-1565.

Roghair C.N., Dolloff C.A., Underwood M.K. 2002. Response of a brook trout population and instream habitat to a catastrophic flood and debris flow. Transactions of the American Fisheries Society 131:718-730.

Santiago J.M, Rafeal M., Joaquin S., Diego G., Carlos A., Francisco M., Javier P., Monjo R., and Ribalaygua J. 2017. Waning habitats due to climate change: The effects of changes in streamflow and temperature at the rear edge of the distribution of a cold-water fish. Hydrology Earth System Sciences. 21, 4073-4101.

Studinski, J., A. Hafs, J. Niles, and K. Hartman. 2017. The effects of riparian disturbance on the condition and summer diets of age-0 brook trout (Salvelinus fontinalis) in three central Appalachian streams. Canadian Journal of Fisheries and Aquatic Sciences 74(7):980-986.

Swanson, E J., S. L. Johnson, S. V. Gregory, and S. A. Acker. 1998. Flood disturbance in a forested mountain landscape. Bioscience 48:68 1-689. 
Trumbo, B., Hudy M., Smith E.P., Kim D., Wiggins B.A., Nislow K.H., Dolloff C.A. 2010. Sensitivity and vulnerability of brook trout populations to climate change. Sessions 1: Climate change and Wild trout 62-68

Utz, R.M. and Hartman K.J. 2009.Density-dependent individual growth and size dynamics of central Appalachian brook trout (Salvelinus fontinalis). Canadian Journal of Fisheries and Aquatic Sciences, 66, 1072-1080.

Warren, D.R, Ernst A.G, Baldigo B.P. 2009.Influence of spring floods on year-class strength of falland spring-spawning salmonids in Catskill Mountain Streams. Transaction American Fisheries Society 138:200-210

Warren, D.R., Robinson J.M., Josephson D.C., Sheldon D.R., Kraft C.E. 2012. Elevated summer temperatures delay spawning and reduce red construction for resident brook trout. Global Change Biology, 18:1804-1811

Webb, B.W, Nobilis F. 2007. Long-term changes in river temperature and the influence of climatic and hydrological factors. Hydrological Sciences Journal, 52:74-85

Wenger, S.L., Isaak D.J., Luce C.H., Nevile H.M., Fausch K.D., Dunham J.B., Dauwalter D.C., Young M.K., Elsner M.M., Reiman B.E., Hamlet A.F., and Williams J.E. 2011. Flow regime, temperature, and biotic interactions drive differential declines of trout species under climate change. Proceedings of the National Academy of Science, 108: 14175-14180.

Wenger, S.L., Son N.A., Dauwalter D.C., Isaak D.J., Nevile H.M., Luce C.H., Dunham J.B., Young M.K.,Fausch K.D. and Reiman B.E. 2013. Probabilistic accounting of uncertainty in forecasts of species distributions under climate change. Global Change Biology, 19: 3343-3354.

Williams, J.E., Haak A.L., Neville N.M., Coyler W.T. 2009. Potential consequences of climate change to persistence of cutthroat populations. North American Journal of Fisheries Management, 29: $533-548$

Williams, J.E., Neville H.M., Haak A.L., Coyler W.T., Wenger S.J., Bradshaw S. 2015. Climate change adaptation and restoration of western trout streams: opportunities and strategies. Fisheries Management 7:304-317.

Wise, S.M. 2007. Effect of differing DEM creation methods on the results from a hydrological model. Computers and Geosciences 33: 1351-1365.

Zegre, N. 2016. Hydrologic analysis using the dataRetrieval and HydroTSM packages in R. 


\section{Chapter 3}

Andrew, R.G. and K.J. Hartman. 2014. Uneven inputs of woody debris in Appalchian streams from superstorm Sandy. Canadian Journal of Fisheries Science. 72:1-6.

Bassar, R.D., Letcher B.J., Nislow K.H., Whiteley A.R. 2016. Changes in seasonal climate outpace compensatory density-dependence in eastern brook trout. Global Change Biology 22: 577-593.

Carline, R.F. and McCullough B.J. 2003. Effects of floods on brook trout populations in the Monongahela National Forest, West Virginia. Transactions of the American Fisheries Society, $132,1014-1020$.

Clark, M.E., Rose K.A., Levine D.A.,Hargrove W.W. 2001. Predicting climate change effects on Appalachian trout: combining GIS and individual based modeling. Ecological Applications, 11: $161-178$.

Comte, L., Buisson L., Daufresne M., Grenouillet G. 2013. Climate-induced changes in distribution of freshwater fish: observed and predicted. Freshwater Biology 58, 625-639.

Davis, J.M., C.V. Baxter, E.J. Rosi-Marshal, J.L. Pierce, B.T. Crosby. 2013. Anticipating stream ecosystem responses to climate change: toward predications that incorporate effects via land-water linkages. Ecosystems 16:909-922.

Davis, L.A. and T. Wagner. 2016. Scale-dependent seasonal pool habitat use by sympatric wild brook trout and brown trout populations. Transactions of the American Fisheries Society 145:888-902.

DeVries, D.R. and R.V. Frie. 1996. Determination of age and growth. In Murphy, B.R. and D.W. Willis, Fisheries Techniques, $2^{\text {nd }}$ edition. American Fisheries Society, Betheda, Maryland: 483-512.

DeWeber, J.T. and Wagner T. 2015. Predicting Brook Trout occurrence in stream reaches throughout their native range in the Eastern Unites States. Transactions of the American Fisheries Society. $144: 1,11-24$

Doll, P., Schmied H.M. 2012. How is the impact of climate change on river flow regimes related to the impact on mean annual runoff? A Global-scale analysis. Environmental Resource Letter. 7

Elliott, J.M. 2006. Periodic habitat loss alters the competitive coexistence between brown trout and bullheads in small stream over 34 years. Journal of Animal Ecology, 75: 54-63.

Fajen, O.F. 1962. The influence of stream stability on homing behavior of two smallmouth bass populations. Transactions of American Fisheries Society. 91(4):346-349.

Fausch, KD, Hawkes CL, Parsons MG. 1988. Models that predict standing crop of stream fish from habitat variables: 1950-1985. Portland (OR): USDA Forest Service. General Technical Report PNW-213.

Flebbe, P.A., L.D. Roghair, J.L. Bruggink. 2006. Spatial modeling to project southern Appalachian trout distributions in a warmer climate. Transactions of the American Fisheries Society 135:13711382 
Gowan, C., and K.D. Fausch. 2002. Why do foraging stream salmonids move during the summer? Environmental Biology of Fishes 64:139-153.

Grossman, G.D., Ratajczak R.E., Wagner C.M., Petty J.T. 2010. Dynamics and regulation of the southern brook trout population in an Appalachian stream. Freshwater Biology, 55:1494-1508.

Hakala, J.P., and K.J. Hartman. 2004. Drought effect on stream morphology and Brook trout populations in forested headwater streams. Hydrobiologia 515:203-213.

Hankin, D.G., and Reeves, G.H. 1988. Estimating total fish abundance and total habitat area in small streams based on visual estimation methods. Canadian Journal of Fisheries and Aquatic Sciences 45(5): 834-844. doi:10.1139/f88-101.

Hartman, K.J., Cox K.M. 2008. Refinement and testing of brook trout bioenergetics model. Transactions of the American Fisheries Society. 137: 357-363.

Hartman, K. J., and Logan, M. N. 2010. Movement and habitat use by transplanted adult brook trout in an Appalachian headwater stream. Northeastern Naturalist, 17, 357-373

Hayhoe, K., C. Wake, B. Anderson, X. Liang, E. Maurer, J. Zhu, J. Bradbury, A. DeGaetano, A. Stoner, and D. Wuebbles. 2008. Regional climate change projections for the northeast USA, Mitigation Adapt. Strategies Global Change, 13: 425436.

Heggenes, J., Northcote T.G., and Peter A. 2011. Spatial stability of cutthroat trout (Oncorhynchus clarki) in a small coastal stream. Journal of Fisheries and Aquatic Sciences. 48;5, 757-762.

Hilderbrand, R.H., and J.L. Kershner. 2004. Are there differences in growth and condition between mobile and resident cutthroat trout? Transactions of the American Fisheries Society 133:1042-1046.

Hornbeck, J.W., and J.N. Kochenderfer. 2000. Linkages between forests and streams: a perspective in time. Riparian management in forests of the continental eastern Unites States. Lewis Publishers.89-98.

Hudy. M. and J. Shiflet. 2009. Movement and recolonization of Potomac sculpin in a Virginia stream. North American Journal of Fisheries Management 29:196-204.

IPCC. 2007. Climate Change 2007: Working Group 2: Impacts, Adaptation and Vulnerability (Intergovernmental Pan on Climate Change, Geneva).

IPCC. 2014. Climate Change 2014: Summary for Policymakers. Climate change 2014: Impacts, Adaptation, and Vulnerability. Fifth Assessment Report of the Intergovernmental Panel of Climate Change, Cambridge University Press, Cambridge, UK and New York, NY.

Jones, T.A., and Daniels, L.D. 2008. Dynamics of large woody debris in small streams disturbed by the 2001 Dogrib fire in the Alberta foothills. Forest Ecology Management. 256:10,1751-1759

Kanno Y., Vokoun J.C. and Letcher B.H. 2011. Fine-scale population structure and riverscape genetics of brook trout (Salvelinus fontinalis) distributed continuously along headwater channel networks. Molecular Ecology, 20, 3711-3729.

Kanno Y., Vokoun J.C., Holsinger K.E. and Letcher B.H. 2012. Estimating size-specific brook trout abundance in continuously sampled headwater streams using Bayesuan mixed models with zero inflation and overdispersion. Ecology of Freshwater Fishes, 21:404-419. 
Kanno Y., Pregler K.C., Hitt N.P., Letcher B.H., Hocking D.J., Wofford J.B. 2016. Seasonal temperature and precipitation regulate brook trout young-of-the-year abundance and population dynamics. Freshwater Biology 61:88-99

Koizumi, I., Kanazawa Y. and Tanaka Y. 2013. The Fisherman were right: experimental evidence for tributary refuge hypothesis uding floods. Zoological Science. 30: 375-379.

Kovach, R.P., Joyce J.E., Echave J.D., Lindberg M.S., and Tallman D.A. 2013. Earlier migration and timing, decreasing phenotypic variation, and bio-complexity in multiple salmonid species. Plos One, 8:1-10.

Kovach, R.P., Mulhfield C.C., Al-Chokhachy R., Dunham J.B., Letcher B.H., and Kershner J.L. 2016. Impacts of climatic variation on trout: a global synthesis and path forward. Revisions Fish Biology Fisheries, 26: 135-151.

Kristensen, E.A., and G.P. Closs. 2008. Variation in growth and aggression of juvenile brown trout from upstream and downstream reaches of the same river. Ecology of Freshwater Fishes 17:130-135.

Kushlan, J.A.1976. Environmental Stability and Fish Community Diversity. Ecological Society of America. 57:4,821-825

Lawler, J.J. 2009. Climate change adaptation strategies for resource management and conservation planning. Annals New York Academy of Science 1162:79-98.

Letcher B.H., Nislow K.H., Coombs J.A., O’Donnel M.J., and Dubreuil T.L. 2007. Population response to habitat fragmentation in stream-dwelling brook trout population. Plos One, 2: e1139.

Letcher B.H., Schueller P., Bassar R.D., Nislow K.H.,Coombs J.A., and Sakrejda K. 2015. Robust estimates of environmental effects on population vital rates: an integrated capturerecapture model of seasonal brook trout growth, survival and movement in a stream network.Journal of Animal Ecology, 84, 337-352.

Lobon-Cervia J. 2009b. Why, when and how do fish populations decline, collapse and recover? The example of brown trout (Salmo trutta) in Rio Chaballos (northwesternSpain). Freshwater Biology, 54, 1149-1162.

Lonzarich, D.G., Warren, M.L., Jr., and Elher-Lonzarich, M.R. 1998. Effects of habitat isolation on the recovery of fish assemblages in experimentally defaunated stream pools in Arkansas. Canadian Journal of Fisheries and Aquatic Science.55:2141-2149.

Lonzarich, D.G., M.R. Lonzarich, and Warren M.L.2000. Effects of riffle length on the short-term movement of fishes among stream pools. Canadian Journal of Fisheries and Aquatic Science 57:1508-1514.

Marschall, E.A., and L.B. Crowder. 1996. Assessing population responses to multiple anthropogenic effects: a case study with brook trout. Ecological Applications 6:152-167.

McCullough, D.A., Bartholow J.M., Jager H.I., Beschta R.L., Cheslak E.F., Deas M.L., Ebersole J.L., Foott J.S., Johnson S.L., Marine K.R., Mesa M.G., Petersen J.H., Souchon Y., Tiffan K.F., Wurtsbaugh W.A. 2009. Research in thermal biology: Burning questions for coldwater stream fishes. Reviews in Fisheries Science, 17:90-115.

Merriam, E.R., R. Fernandez, J.T. Petty, and N. Zegre. 2017. Can brook trout survive climate change in large rivers? If it rains. Science of the Total Environment 607-608:1225-1236. 
Meyers, E.M., Dobrowski B., Tague C. 2013. Climate change impacts on flood frequency, intensity and timing may affect trout species in Sagehen Creek, California. Transactions of American Fisheries Society 139: 1657-1664

Munoz-Mas. R., A. Lopez-Nicolas, F.Martinex-Capel, and M. Pulido-Velazquez. 2016. Shifts in the suitable habitat available for brown trout under short-term climate change scenarios. Science of the Total Environment 544:686-700

Olsson, I.C., L.A. Greenberg, E. Bergman, and K. Wysujack. 2006. Environmentally induced migration:the importance of food. Ecology Letters 9:645-651.

Ostergaard, S., Hansen M.M., Loeschcke V., and Nielson E.E. 2008.Long-term temporal changes of genetic composition in brown trout (Salmo trutta L.) populations inhabiting an unstable environment. Moelecular Ecology 12:11,3123-3135

Palmer, M.A., Letenmaeir D.P., Poff N.L., Postel N.L., Richter S.L. Warner B. 2009 Climate change and river ecosystems: protection and adaptation and protection options. Environmental Management, 44:1053-1068.

Papadaki, C., Soulis K., Munoz-Mas R., Martinez-Capel F., Zogaris S., Ntoadnidis L., Dimitriou E. 2016. Potential impacts of climate change on flow regime and fish habitat in mountain rivers of the south-western Balkans. Science of Total Environment 540:418-428.

Petty, J.T., Hansbarger J.L., Huntsman B.M. and Mazik P.M. 2012. Brook trout movement in response to temperature, flow and thermal refuge within a complex Appalachian riverscape. Transactions of the American Fisheries Society, 141: 1060-1073

Petty, J.T., Lomothe P.J. and Mazik P.M. 2005. Spatial and seasonal dynamics of brook trout populations inhabiting a central Appalachian watershed. Transactions of the American Fisheries Society, 134, 572-587.

Petty, J.T., Thorne D., Huntsman B.M., Mazik P.M. 2014. The temperature-productivity squeeze: constraints on brook trout growth along an Appalachian river continuum. Hydrobiologia 727:15-166.

Poplar-Jeffers, I.O., J.T. Petty, J.T. Anderson, S.J. Kite, M.P. Strager, and R.H. Fortney. 2009. Culvert replacement and stream habitat restoration: implications from brook trout management in an Appalachian watershed. U.S.A. Restoration Ecology 17:404-413.

Rahel, F.J., C.J. Keleher, and J.L. Anderson. 1996. Potential habitat loss and population regimentation for cold water fish in the North Platte drainage of the Rocky Mountains: response to climate warming. Limnology and Oceanography 41:1116-1123

Ralph, S.C., G.C. Poole, L.L. Conquest, and R.J. Naiman. 1994. Stream channel morphology and woody debris in logged and unlogged basins in western Washington. Canadian Journal of Fisheries and Aquatic Science 51:37-51

Reice, S.R., R.C. Wissmar, and R. J. Naiman. 1990. Disturbances regimes, resilience, and recovery of animal communities and habitats in lotic ecosystems. Environmental Management 14:647-659.

Roghair, C.N, C.A. Dolloff, M.K. Underwood. 2002. Response of brook trout population and instream habitat to a catastrophic flood and debris flow. Transactions of the American Fisheries Society 131:718-730. 
Santiago, J.M., R. Munoz-Maz, J.Solano-Gutierrez, D. Garcia de Jalon, C. Alonso, F. Martinez-Capel, J.Portoles, R. Monjo,and J. Ribalaygua. 2017. Waning habitats due to climate change: the effects of changes in streamflow and temperature at the rear edge of distribution of a cold-water fish. Hydrology and Earth Systems Science 21:4073-4101.

Schafhauser-Smith, D. and Benfey T.J. 2001. The reproductive physiology of three age classes of adult female diploid and triploid brook trout (Salvelinus fontinalis). Fish Physiology and Biochemistry. 25:319-333

Schlosser, I.J.1987. The role of predation in age-and size related habitat use by stream fishes. Ecology 63:307-313.

Schlosser, I.J. 1995. Critical landscape attributes that influence fish population dynamics in headwater streams. Hydrobiologia, 303:71-81.

Smith, P. P. and Atkinson, J. B. 2001. Flood and debris-flow effects on Virginia brook trout populations. Proceedings of the Annual Conference Southeastern Association of Fish and Wildlife Agencies. 53: 91-99.

Stolarski, J.T., 2007. Age and Growth of Appalachian Brook Trout in Relation to Life-History and Habitat Features. Order No. 1451936 West Virginia Universtiy. PreQuest. Web 3 July 2018

Stolarski, J.T., and K.J. Hartman. 2010. Comparisons of growth and condition of fluvial and resident brook trout within particularly migratory populations. Fisheries Management and Ecology 17:33-39.

Sweka, J.A., and K.J. Hartman. 2006. Effects of large woody debris addition on stream habitat and brook trout population in Appalachian streams. Hydrobiologia 559:363-378

Sweka, J.A., K.J.Hartman, and J.M. Niles. 2010. Long-Term Effects of Large Woody Debris Addition on Stream Habitat and Brook Trout Populations. Journal of Fish and Wildlife Management 1:146151

Theriault, V., Garant D., Bernatchex L., and Dodson J.J. 2007. Heritability of life-history tactics and genetic correlation with body size in natural population of brook charr (Slavelinus fontinalis). Journal of Evolutionary Biology 20: 2266-2277

Utz, R.M. and Hartman K.J. 2009. Density-dependent individual growth and size dynamics of central Appalachian brook trout (Salvelinus fontinalis). Canadian Journal of Fisheries and Aquatic Sciences, 66, 1072-1080.

Warren, D.R., Ernst A.G., and Baldigo B.P.2009. Influence of spring floods on year-class strength of falland spring-spawning salmonids in Catskill Mountain Streams. Transaction of the American Fisheries Society 138:200-210

Warren, D.R., Robinson J.M., Josephson D.C., Sheldon D.R., Kraft C.E. 2012. Elevated summer temperatures delay spawning and reduce red construction for resident brook trout. Global Change Biology, 18:1804-1811

Webb B.W, Nobilis F. 2007. Long-term changes in river temperature and the influence of climatic and hydrological factors. Hydrological Sciences Journal, 52:74-85

Wenger, S.L., Isaak D.J., Luce C.H., Nevile H.M., Fausch K.D., Dunham J.B., Dauwalter D.C., Young M.K., Elsner M.M., Reiman B.E., Hamlet A.F., and Williams J.E. 2011. Flow regime, temperature, and biotic interactions drive differential declines of trout species under climate change. Proceedings of the National Academy of Science, 108: 14175-14180. 
Wenger, S.L., Son N.A., Dauwalter D.C., Isaak D.J., Nevile H.M., Luce C.H., Dunham J.B., Young M.K.,Fausch K.D. and Reiman B.E. 2013. Probabilistic accounting of uncertainty in forecasts of species distributions under climate change. Global Change Biology, 19: 3343-3354.

White, S.L., Gowan C., Fausch K.D., Harris G.H., and Saunders W.C. 2011. Response of trout populations in five Colorado streams two decades after habitat manipulation. Journal of Fisheries and Aquatic Sciences. 68:12,2057-263

Williams, J.E., Haak A.L., Neville N.M., Coyler W.T. 2009. Potential consequences of climate change to persistence of cutthroat populations. North American Journal of Fisheries Management, 29: 533-548

Williams, J.E., Neville H.M., Haak A.L., Coyler W.T., Wenger S.J., and Bradshaw S. 2015. Climate change adaptation and restoration of western trout streams: opportunities and strategies. Fisheries, 7:304-317.

Young, R.G., Wilkinson J., Hay J., Hayes J.W. 2010. Movement and mortality of adult brown trout in the Motupiko River, New Zealand: effects of water temperature, flow and flooding. Transactions of American Fisheries Society, 139: 137-146.

Xu, C, Letcher B.H., and Nislow KH. 2010. Context-specific influence of water temperature on brook trout growth rates in the field. Fresh Biol 55:2253-2264 